\title{
I. Frankreich und die Besatzung in Südwestdeutschland
}

\section{Die Herrschaft der Militärverwaltung}

\section{Die militärischen Aktionen in Südwestdeutschland}

„Karlsruhe und Stuttgart erwarten Sie“", ließ der Chef der Provisorischen Regierung, de Gaulle, den kommandierenden General der Ersten Französischen Armee, Jean de Lattre de Tassigny, am 28. März 1945 wissen, „auch wenn Sie dort nicht erwünscht sind. “ De Lattre hatte tags zuvor von General Devers, seinem militärischen Vorgesetzten, Befehl zum Vorrücken auf beide Städte erhalten ${ }^{2}$. Bei Speyer, Germersheim und Leimersheim begann der Vormarsch der beiden französischen Armeekorps ${ }^{3}$ in den rechtsrheinischen Raum, der nach 38 Tagen beendet sein sollte 4 . Die Überquerung des Rheins mit amerikanischen Pontonbrücken und Booten zeigte anschaulich die Abhängigkeit der Ersten Französischen Armee von der Logistik des westlichen Alliierten. Fast die komplette Ausrüstung ${ }^{5}$ der Franzosen war in den USA produziert worden, finanziert mit Geldern aus dem Lend-Lease-Programm. Die logistische und materielle Bindung an die Amerikaner sollte alle späteren Forderungen hinsichtlich der Ausdehnung der künftigen Französischen Besatzungszone blockieren. Schnell stießen die Verbände der 9. kolonialen Infanteriedivision (9.D.I.C.) nach Karlsruhe vor und besetzten die badische Residenzstadt am 4. April. Die Einheiten der 5. französischen Panzerdivision (5.D.B.), der 3. algerischen (3.D.I.A.) und der 2. marokkanischen Infanteriedivision (2.D.I.M.) gelangten zudem zügig an das Ufer der Enz. Kehl fiel in der folgenden Woche, so daß es der Ersten Französischen Armee möglich wurde, von Straßburg aus über den linksrheinischen Brückenkopf zwei weitere Divisionen - die 1. Panzerdivision (1.D.B.) und die 4. marokkanische Gebirgsdivision (4.D.M.M.) - auf dem südwestdeutschen Kriegsschauplatz einzusetzen. Das zerstörte und geplünderte Freudenstadt wurde für die südwestdeutsche Bevölkerung zum Symbol für den sinnlosen deutschen Widerstand und das rigorose Vorgehen der französischen Angreifer ${ }^{6}$. Die Schwarzwaldstadt bildete die Basis für

\footnotetext{
1 De Gaulle, salut, S. 490.

${ }^{2}$ Krautkrämer, Kriegsende, S. 18.

${ }^{3}$ Das 1. Corps d'Armée (CA) unter dem Kommandierenden General Béthouart, dem späteren Commandant en Chef Français en Autriche, und das 2. CA, befehligt rom Kommandierenden General de Goislard de Monsabert, der ab August 1945 für die gesamten französischen Besatzungstruppen in Deutschland unter General Koenig verantwortlich wurde.

${ }^{4}$ Eine kartographische Darstellung des Vormarsches ist im Historischen Atlas von Baden-Württemberg (VII, 10) zu finden. Zu den Erläuterungen vgl. Cordes, Besetzung; dort auch ein Organigramm zur Gliederung der Ersten Französischen Armee.

${ }^{5}$ Zur Auflistung der amerikanischen Ausrüstung für die Erste Französische Armee vgl. Vigneras, Rearming.

- Zu Unrecht wurde der Sammelband von Hertel, Zerstörung bisher wenig beachtet; obwohl es sich um eine Rekonstruktion der Geschehnisse aus deutscher Sicht handelt, die nicht auf das einschlägige französische Quellenmaterial zurückgreift, sind die Ereignisse bei der Einnahme von Freudenstadt am 16./17. 4. 1945 in extenso dargestellt.
} 
den weiteren Vormarsch. Stuttgart, Tübingen, Rottweil und Freiburg wurden noch bis zum 21. April 1945 erobert. Die Besetzung der württembergischen Landeshauptstadt führte zu schweren Auseinandersetzungen mit den Amerikanern, doch de Lattre hielt sich an die Anweisung de Gaulles vom 23. April, „eine französische Garnison in Stuttgart aufrechtzuerhalten und dort sofort eine Militärregierung einzusetzen "7. Die Pariser Befehle ausführend, gab de Lattre dem Druck des Generals der 6. US-Armeegruppe, Jacob L. Devers, nicht nach ${ }^{8}$. Auf dem Höhepunkt der Krise, am 26. April 1945, drohte Devers angesichts der ihm gemeldeten unzähligen Vergewaltigungen, Plünderungen und der allgemeinen Disziplinlosigkeit der französischen Truppen mit der Übernahme der Stadt durch amerikanische Einheiten. Aber de Lattre wich keinen Schritt zurück und konnte sich durch sein Fait accompli für die nächsten Monate durchsetzen. Am 28. April 1945 entschied Devers zähneknirschend, Stuttgart vorläufig den Franzosen zu überlassen.

Die französischen Verbände hatten mittlerweile am Randen bei Schaffhausen erstmals die Grenze zur neutralen Schweiz erreicht. Grenzverletzungen und damit die Verwicklung der Schweiz in die kriegerischen Geschehnisse konnten dank guter Zusammenarbeit mit den Eidgenossen vermieden werden ${ }^{9}$. Problemlos kam der gesamte südliche Schwarzwald in französische Hand. Die alte Reichsstadt Ulm wurde am 24. April, Konstanz ohne Kampf und Zerstörungen zwei Tage später besetzt. De Lattre hatte nur noch ein militärisches Ziel zu erfüllen: er wollte als erster den Angriff auf die sagenumwobene Alpenfestung beginnen. Die Einheiten der 5.D.B. und der 4.D.M.M. drangen, ohne auf nennenswerten Widerstand zu stoßen, am nördlichen Bodenseeufer nach Osten vor ${ }^{10}$. Die 2.D.I.M. war auf direktem Weg nach der Eroberung von Ulm in Richtung Süden vorgerückt. Am 29. April betraten französische Truppen erstmals österreichischen Boden; einzelne deutsche Rückzugsgefechte fanden statt, von einer systematischen Verteidigung der Alpenfestung konnte aber nicht die Rede sein. Die Spitzen dreier französischer Divisionen trafen am 7. Mai bei St. Anton in Tirol zusammen. Damit war der Krieg auch in den österreichischen Alpen beendet.

\section{Die französischen Besatzungstruppen in Südwestdeutschland 1945/46}

Den Kampftruppen waren sofort neugebildete oder wiederaufgestellte Divisionen, die aus Résistancekämpfern und Teilen der FFI bestanden, nachgerückt. Jahrelanges Leben im Untergrund und Revanchegefühle hatten das Auftreten dieser Soldaten, die jenen oftmals undisziplinierten Sicherungsverbänden unterstellt waren, geprägt. Die 14.I.D., die division d'Alsace, sicherte als Reserve der Ersten Französischen Armee den Hochrhein und die Bodenseeregion, die 1.I.D. löste ab 28. April 1945 die 2.D.I.M. in Stuttgart $a b^{11}$. Die Integration der zusammengewürfelten Verbände in die Erste Französische Armee gehörte mit zu den schwierigsten militärischen Aufgaben de Lattres. Die Ableh-

\footnotetext{
${ }^{7}$ De Gaulle an de Lattre vom 23. 4. 1945; abgedruckt in: De Lattre, Reconquérir, S. 245 f.

8 Die maßgeblichen Dokumente zum Streit um Stuttgart sind abgedruckt bei: De Lattre, Reconquérir, S. 243-263 und de Gaulle, Mémoires, S. 491-496.

${ }^{9} \mathrm{Zu}$ den Ereignissen zwischen Hochrhein und Bodensee vgl. die Veröffentlichung des damaligen Kreuzlinger Bezirksstatthalters Otto Raggenbass (Ders., Stacheldraht).

${ }^{10}$ Einführend: Klöckler, Zivilbevölkerung.

${ }^{11}$ Grohnert, Entnazifizierung, S. 19 Anmerkung 16.
} 
nung des Rassismus in Frankreich sollte durch den Einsatz von Kolonialtruppen demonstriert werden. Diese Zielsetzung schlug gründlich fehl. Die nordafrikanischen Truppen wurden nach Beendigung der Kampfhandlungen rasch aus Deutschland abgezogen.

Für die gesamte Französische Besatzungszone (FBZ) gehen realistische Schätzungen von folgenden Truppenstärken aus: Zum Zeitpunkt der Kapitulation zählten die in Deutschland eingesetzten 12 Divisionen fast eine Million Mann ${ }^{12}$, von denen 9 Divisionen die Erste Französische Armee gebildet hatten. Der Oberbefehlshaber de Lattre verlieh seiner Armee am 24. April 1945, nach dem Überschreiten der Flüsse Rhein und Donau, den Ehrentitel „Rhin et Danube“13. Nach der endgültigen Zoneneinteilung vom Juli 1945 wurde der Südteil der FBZ nur noch von drei französischen Divisionen militärisch kontrolliert, viele - vor allem nordafrikanische - Einheiten waren umgehend aus Deutschland abgezogen worden. Der Landeskommissariatsbezirk Freiburg einschließlich der Landkreise Bühl, Baden-Baden und Rastatt war mit Verbänden der 2.D.I.M. belegt, deren Divisionsstab sich in Waldkirch befand. Der östlich gelegene Landeskommissariatsbezirk Konstanz oblag der Kontrolle der 14.D.I., unter dem Befehl von General Raoul Salan ${ }^{14}$ mit Divisionsstab in der Bodenseemetropole. Der Stab der 5.D.B. residierte in der Hohenzollernstadt Sigmaringen, die Division war verteilt auf die südwürttembergischen und hohenzollerischen Landkreise, einschließlich Lindaus ${ }^{15}$. Im Herbst 1945 hielten sich etwa 300000 französische Soldaten in Südwestdeutschland auf. Bis Januar 1946 reduzierte sich die Truppenstärke auf etwa 200000 Mann und sank bis Mai 1947 auf rund 75000 ; ein Jahr später dürfte die Truppenstärke bei 53000 Soldaten ${ }^{16}$ gelegen haben. Die Reorganisation der französischen Armee zum 1. April 1946 führte ferner zur Auflösung vieler Kriegs- und Résistanceverbände ${ }^{17}$ und zu deren Abzug aus Deutschland. Bezüglich der Überbelegung der Zone mit französischem Militär machte man sich im Herbst 1945 auch in Paris Gedanken. In einem vertraulichen Bericht vom 10. September $1945^{18}$ wurde die damalige Truppenstärke von 300000 Mann als zu hoch

12 Eingesetzt waren die französischen Divisionen (mit den jeweiligen Generalen in chronologischer Reihenfolge): 1.D.B. (Touzet du Vigier/Sudré); 5.D.B. (de Vernejoul/Schlesser); 2.D.I.M. (Carpentier/de Linarès); 3.D.I.A. (Guillaume); 4.D.M.M. (Sevez/de Hesdin); 9.D.I.C. (Valluy/ Magnan/Morlière); 14.D.I. (Salan); außerdem stießen die neugebildete 1.D.I. (Callies) und 10.D.I. hinzu, die 1.D.F.L. (Division Française Libre), 27.D.I.A. und 2.D.B. (Leclerc) zählte de Lattre ebenfalls zur Ersten Französischen Armee; de Lattre, Histoire, S. 619 Anmerkung 1.

Das in den Divisionsstäben produzierte Aktenmaterial befindet sich heute im Archiv des französischen Heeres in Schloß Vincennes. Zur Erforschung der Frühzeit der französischen Besatzung in Deutschland wurde es bisher kaum herangezogen, obwohl die Bestände umfangreich sind. Die einschlägigen Bestände sind: $10 \mathrm{P}$ (Armées et corps d'armée), $11 \mathrm{P}$ (Divisions et brigades) und $12 \mathrm{P}$ (Petits unités); SHAT Findbücher $10 \mathrm{P}, 11 \mathrm{P}$ und $12 \mathrm{P}$. Vgl. Klöckler, Quellen.

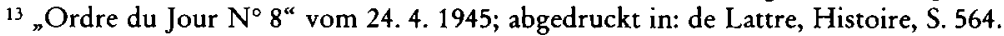

14 Eine knappe Darstellung der persönlichen Erlebnisse des Generals in Südwestdeutschland in: Salan, Mémoires, insbesondere S. 148-162.

${ }^{15}$ Eine Auflistung der Divisionen und deren Untergliederungen enthält eine tabellarische Ausarbeitung vom 27. 7. 1945, die von Oberst Eberle, dem ,provisorischen Militärgouverneur von Baden“, erstellt worden ist; AdO Bade H 1101.

${ }^{16}$ Die Angaben stützen sich auf amtliches französisches Material; vgl. Willis, French, S. 88.

${ }^{17}$ Hudemann, Sozialpolitik, S. 4. Zu den einzelnen Verbänden: Revue d'information des troupes françaises d'occupation en Allemagne Nr. $1 \mathrm{ff}$., Oktober $1945 \mathrm{ff}$.

18 „Note - Sur la situation à Baden-Baden“, SGAAA/Division Politique et Economique vom 10. 9. 1945; MAE PA-AP 338-Laffon 15. 
erachtet, eine Reduzierung auf 30000 Soldaten werde vollkommen genügen, zumal Versorgungsprobleme bestünden. „Unsere Truppen sind schlecht ernährt und sind folglich darauf angewiesen, zu stehlen und zu plündern"19 - angesichts der gravierenden Langeweile war dies nicht verwunderlich; „sie beschäftigen sich, so gut sie können, zumeist, indem sie den Mädchen nachrennen", lautete das Resümee. Die Ereignisse beim Einmarsch der französischen Truppen - Vergewaltigungen, Plünderungen, Diebstähle und Geiselnahmen - trübten das Verhältnis der deutschen Bevölkerung zur Besatzungsmacht.

\section{Jean de Lattre de Tassigny}

General Jean de Lattre de Tassigny ${ }^{20}$ belegte mit dem Stab der Ersten Französischen Armee die im Bodensee gelegene Inselstadt Lindau. Die französischen Einheiten, die elf Wochen lang sämtliche Befehle aus Lindau entgegenzunehmen hatten, verteilten sich im Frühjahr 1945 in der noch nicht definitiv abgegrenzten französischen Zone vom Hochrhein über Karlsruhe bis Stuttgart. Ohne politische Direktiven ausgestattet, konnte de Lattre seinen Vorstellungen über die Behandlung der Deutschen freien Lauf lassen: „In drei Monaten habe ich trotz meiner Anfragen weder über die allgemein in Deutschland zu verfolgende Politik noch über die dort aufzubauenden Strukturen etwas $[d . h$. Instruktionen] erhalten", rechtfertigte de Lattre rückblickend sein Handeln im besetzten Deutschland ${ }^{21}$. Seiner Überzeugung zufolge bedurften die Deutschen der Strenge, eine undisziplinierte Besatzungsmacht würden sie keinesfalls akzeptieren. Nur hartes Auftreten konnte in den Augen de Lattres den angeblich autoritätshörigen Deutschen imponieren. Daher war es „notwendig, nachdrücklich der Bevölkerung, die in absichtlicher Unkenntnis belassen wurde, die Existenz selbst und die vollkommene Unabhängigkeit unserer zu neuem Leben erweckten Nationalarmee zu demonstrieren"22. Die Pflicht deutscher Zivilisten, Automobile französischer Offiziere zu grüßen, selbst wenn diese nur mit dem Fahrer besetzt waren, oder den Hut vor den Vertretern der Besatzungsmacht und vor der Trikolore an Amtsgebäuden zu ziehen, waren die praktischen Umsetzungsversuche des französischen Autoritäts- und Prestigedenkens. Diese symbolischen Zwänge gruben sich tief in das kollektive Gedächtnis der Deutschen ein und prägten das Bild von den dunklen Jahren der „Franzosenzeit“23. Die von de Lattre inszenierten Pa-

\footnotetext{
${ }^{19}$ Ebenda.

20 Jean de Lattre de Tassigny (1890-1952). Absolvent der Militärakademie von Saint-Cyr; als Kavallerieoffizier im Ersten Weltkrieg mehrfach verwundet; 1939 Kommandeur der 14.I.D. und damit jüngster(!) französischer General bei Kriegsausbruch; nach dem Waffenstillstand zeitweise Oberbefehlshaber der französischen Truppen in Tunesien, Verurteilung wegen Aufrufs zum militärischen Widerstand nach Überschreiten der Demarkationslinie durch deutsche Truppen; Überführung in die Festung Riom; 3. 9. 1943 Flucht nach Großbritannien und weiter nach Algier zu de Gaulle; 1944 Ernennung zum Oberbefehlshaber der Ersten Französischen Armee, Landung in der Provence; Mai 1945 Mitunterzeichner der Kapitulationsurkunde; bis Juli 1945 französischer Oberbefehlshaber in Deutschland; Generalinspekteur der Armee; ab November 1945 Chef des EMDN. Veröffentlichte Schriften: de Lattre, Histoire; Ders., subir; Ders., Reconquérir.

21 De Lattre, Histoire, S. 618.

22 Ebenda, S. 617.

${ }^{23}$ Den landläufigen und plastischen Begriff „Franzosenzeit“ wählte Joseph Jurt für seinen mit Zeitzeugnissen und Forschungsberichten ausgestatteten Sammelband; Ders., Franzosenzeit.
} 
raden, die in allen größeren Städten zum Repertoire französischer Selbstdarstellung gehörten, dienten ebenfalls dem Zweck, der Zivilbevölkerung Respekt vor der französischen Armee einzuflößen und gleichzeitig das eigene Selbstwertgefühl zu stärken. Hohe Persönlichkeiten wie der Schweizer General Henri Guisan, der Sultan von Marokko und der Bey von Tunis wurden vom französischen Außenministerium nach Deutschland eingeladen ${ }^{24}$. Die unzerstörten Bodenseestädte Konstanz und Lindau mußten sehr oft als Kulissen für die pompösen Veranstaltungen dienen ${ }^{25}$. Aber selbst im schwer zerstörten Stuttgart ließ es sich de Lattre nicht nehmen, unter den zufriedenen Blicken de Gaulles die militärische Macht Frankreichs zu demonstrieren.

Die ständige Sorge de Lattres hatte seit dem Einmarsch in Deutschland der Disziplin der eigenen Truppe gegolten. Schon vor Abschluß der Kampfhandlungen befahl er mehrmals, Plünderungen hart zu bestrafen. Denn zahlreichen Diebstähle und Zerstörungen entzogen der Truppe wertvolle Mittel und taten dem Prestige Frankreichs Abbruch. Daher machte er die Teileinheitsführer „persönlich für Plünderungen, die von Untergebenen begangen wurden, verantwortlich" ${ }^{26}$. Angesichts der schlechten Versorgungslage zeigten solche Befehle nicht die gewünschte Wirkung. Außerdem sprachen religiöse Speisevorschriften bei den mohammedanischen Kolonialsoldaten gegen das in Büchsen gelieferte, amerikanische Schweinefleisch, ein Umstand, den Hunderttausende Hühner mit dem Leben bezahlten.

War es schon um die Disziplin der französischen Truppen nicht zum besten bestellt, konnte von einer effizienten Besatzungsverwaltung überhaupt nicht die Rede sein. Obgleich die $5^{\circ}$ Bureaux für die Belange der Zivilbevölkerung während der Kampfhandlungen zuständig waren, eigneten sie sich nicht für die Aufgaben einer „zivilen“ Militärregierung, da deren Eingliederung in die Stabsstrukturen das Haupthindernis bildete. Zudem waren die Kreismilitärregierungen bis Anfang Mai 1945 in Südwestdeutschland eingetroffen, ohne daß eine funktionsfähige Hierarchie in Gang gebracht worden wäre. Die Offiziere der $5^{\circ}$ Bureaux, die überall vor Ort saßen, hatten auf Anweisung de Lattres die Befehlsgewalt an sich gezogen und waren nicht gewillt, Kompetenzen an die nun eintreffenden Militärregierungen abzugeben. Noch im September 1945 bemerkte Paris, daß die Zusammenarbeit zwischen Militärregierung und Militärverwaltung insbesondere auf der lokalen Ebene äußerst unbefriedigend war.

Die untragbaren, aber leicht nachvollziehbaren Spannungen zwischen beiden Hierarchien waren von Anfang an zu beobachten; die Offiziere der Militärregierung wurden von den Truppenoffizieren gemeinhin geringgeschätzt: in der zu "hastigen" Ausbildung sah auch de Lattre einen Hauptgrund für die große Zahl wenig qualifizierter, „aus dem Stegreif ernannter Verwalter" [administrateurs improvisés], die Spreu war zu Beginn der Besatzung offensichtlich nicht vom Weizen getrennt ${ }^{27}$. Deshalb betraute de Lattre den Chef seines Stabes und Leiter der $5^{\circ}$ Bureaux, Oberst Carolet, mit der Weisungsbefugnis über die Kreisdelegierten. Die Einbindung der Militärregierung in die Befehlsstrukturen der Ersten Französischen Armee war in den Augen des sonst nicht sonderlich sensiblen

\footnotetext{
${ }^{24}$ De Lattre, Histoire, S. 615.

${ }^{25}$ Mit reichhaltiger Bebilderung: Raggenbass, Stacheldraht, S. 195-200.

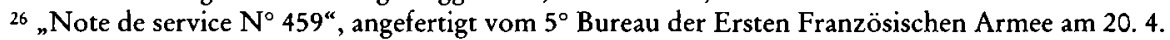
1945; AdO Bade H 1101.

27 De Lattre, Histoire, S. 618.
} 


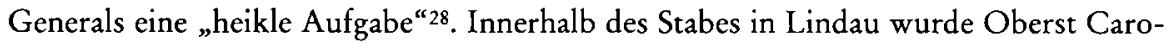
lets Stellvertreter, der mit der schwierigen Aufgabe der Unterstellung der Militärregierungen betraute Major Thomazo, zur zentralen Figur; nicht bei den provisorischen Landesmilitärregierungen von General Schwartz in Stuttgart oder von General Morlière in Karlsruhe liefen die Fäden der Kreismilitärregierungen zusammen, sondern in Lindau.

General de Lattre sah sich erst nach einigen Wochen der Besatzung genötigt, die Kompetenzen mittels Dienstanweisung schriftlich abzuklären. Am 23. Mai 1945 erhielten alle maßgeblichen französischen Stellen einschließlich der Kreismilitärregierungen die vordergründig klar verfaßte Abgrenzung ihres Wirkungsfeldes zugestellt ${ }^{29}$. Die Klärung der Kompetenzen zwischen Militärregierung und Truppenkommandeuren war de Lattre am Ende der militärischen Operationen ein dringliches Anliegen. Da die anfänglich schlechte zahlenmäßige Ausstattung der Militärregierung nicht die Präsenz in allen Städten erlaubte, verfügte der Oberbefehlshaber, daß einige Aufgaben von den Truppenkommandeuren übernommen werden sollten. Die Kompetenzen zwischen Militärregierung und Truppenkommandeuren wurden nun detailliert geregelt ${ }^{30}$. Die Anweisung schloß de Lattre mit der Bemerkung ab, daß „sich die Truppenkommandeure nicht in das öffentliche Verwaltungsleben einmischen sollten, da die Gefahr bestehe, daß dies Verwirrung und Unordnung in die Handlungen der Militärregierung bringen könnte " 31 . Die Dienstanweisung erläuterte die Hierarchie der Militärregierung und unterstellte sie definitiv dem Befehl des Oberkommandierenden der Ersten Französischen Armee. Der Zielkonflikt zwischen Militärverwaltung und Militärregierung war damit jedoch keineswegs gelöst. Die $5^{\circ}$ Bureaux aller Ebenen behielten auch in den folgenden Monaten das Heft fest in der Hand, von einer Verbesserung der Beziehungen war nicht die Spur zu erkennen. Die Militärregierung blieb weiterhin ohne eigene funktionsfähige Struktur. Es war General de Lattre, der vom Bodensee aus seine Zone dirigierte. Ihm schwebte als kulturpolitisches Ziel eine großangelegte französische Renaissance in Südwestdeutschland vor. Dazu lud er das Ensemble der Nationaloper aus Paris ein, um in der Zone für die Verbreitung französischer Kultur zu sorgen. In ähnlicher Funktion hielten sich Mitglieder der Villa Medici, dem französischen Kunstinstitut in Rom, in Lindau auf. Prunksucht und koloniale Allüren trugen de Lattre nicht nur bei den amerikanischen Verbündeten schnell den Spitznamen $d u$ Théâtre ein. Ein humanitäres Anliegen de Lattres war die Versorgung und Unterbringung der aus dem Konzentrationslager Dachau befreiten rund 8000 französischen Häftlinge ${ }^{32}$. Dafür ließ er Mitte Mai 1945 die Inseln Reichenau und Mainau von der deutschen Bevölkerung evakuieren und mit kranken Häftlingen be-

28 "Tâche délicate"; ebenda, S. 618.

29 "Note de service-Objet: Attributions respectives du Gouvernement Militaire et du Commandement des Troupes", Général d'Armée de Lattre de Tassigny vom 23. 5. 1945; SHAT 10 P 223.

${ }^{30}$ Die Militärregierung unterstand de Lattre; sie war für eine indirekte Verwaltung konzipiert. Ihre Aufgaben waren: Entnazifizierung und Einsetzung des deutschen Verwaltungspersonals; Überwachung von Polizei und Justiz; Überwachung und Kontrolle der Vermögen; Kontrolle der industriellen Produktion und der öffentlichen Dienste; Verantwortung für Ernährung, Requisitionen und Truppeneinsatz. Die Kompetenzen der Truppenkommandeure umfaßten: Verantwortung für die öffentliche Sicherheit in enger Zusammenarbeit mit der Militärregierung, Verhängung des Ausnahmezustandes und Requisitionen von Wohnraum.

31 "Note de service...", de Lattre vom 23. 5. 1945; SHAT 10 P 223.

32 Ausführliche Darstellung der Ereignisse bei Moser, Inseln. Bildmaterial zum Abtransport und der Unterbringung der Häftlinge im ECPA 26 T 10460 und 28 T 10524. 
legen. Die leicht zu isolierenden Inseln boten sich wegen der nötigen Quarantäne an, denn in Dachau grassierten nach der Befreiung Typhus und Ruhr.

Trotz aller Maßnahmen kann in den ersten Monaten nicht von einer stringenten französischen Besatzungspolitik gesprochen werden. Der Versuch, die Kompetenzen zwischen Militärverwaltung und Militärregierung abzugrenzen, sind Ausdruck gravierender konzeptioneller Probleme, die nicht mit Dienstanweisungen zu lösen waren. Nur durch Schaffung eines hierarchisch strukturierten Militärregierungsapparates, der allerdings über eine klar abgegrenzte Zone verfügen und mit eindeutigen Vollmachten ausgestattet sein mußte, war eine Klärung zu erreichen. Die Verhandlungen über die endgültige Ausdehnung der künftigen französischen Zone zogen sich aber das ganze Frühjahr 1945 hin. Nach Abschluß der Gespräche und der Übernahme der von den Amerikanern besetzten rheinischen und pfälzischen Gebiete beorderte General de Gaulle den Oberkommandierenden der Ersten Französischen Armee am 24. Juli 1945 aus Deutschland ab. De Lattre empfand diesen Befehl als ungeheuere Demütigung, hatte er sich doch schon als künftigen Oberbefehlshaber der FBZ gesehen. „Meine Hoffnung war, in Deutschland zu bleiben, wenigstens für die Zeit, die zur Grundsteinlegung der Besatzung in einer klar abgegrenzten Zone [...] erforderlich wäre“, umschrieb der General seine Ambitionen im Frühsommer 1945. Mit Tagesbefehl Nr. 10 vom 27. Juli 1945 löste er die Erste Französische Armee auf, empfing am selben Tag in Lindau seinen Nachfolger, General Pierre Koenig, und verließ, nach einem farbenprächtigen Spektakel in Kehl, die Zone in Richtung Frankreich.

\section{Aufbau und Organisation der Militärregierung und der Pariser Dienststellen}

\section{Ausbildung des Personals der Militärregierung}

Frankreich blieb denkbar wenig Zeit für die Ausbildung des Personals der künftigen Militärregierung. Zwischen der Befreiung von Paris am 25. August 1944 und der Besetzung großer Teile Südwestdeutschlands im April 1945 lagen gerade acht Monate. Zudem hatte de Gaulle sich die Anerkennung der Alliierten erst spät gesichert und im Herbst 1944 sein Gouvernement Provisoire durchgesetzt ${ }^{33}$. Behindert durch die Säuberung Frankreichs von den Resten des Vichy-Regimes, konnten nicht vor November 1944 konkrete Planungen für eine eigene Zone in Deutschland getroffen werden. In jenen Tagen war Frankreich auch in die European Advisory Commission (EAC) mit Sitz in London aufgenommen worden, und damit nahm eine französische Besatzungszone in Deutschland langsam konkrete Gestalt an. Die Ausarbeitungen sollten von dem in die Mission Militaire pour les Affaires Allemandes (MMAA) umgewandelten Bureau d'Etudes de l'Armistice unter Leitung von General Louis-Marie Koeltz erstellt werden, eine Entscheidung, die der Etat-Major de la Défense Nationale (EMDN) ${ }^{34}$ am 18 . November 1944 getroffen hatte. Mit der Mission Militaire war ein Instrument geschaffen, das - nach Weisung des

${ }^{33}$ Eine Analyse der drei Phasen des Gouvernement Provisoire und dessen Entstehungsgeschichte bei: Lipgens, Etappen.

${ }^{34}$ Vgl. den Bestand $4 \mathrm{Q}$ (Kabinett des EMDN) im SHAT/Vincennes. 
Chefs der Provisorischen Regierung - mit dem Alliierten Oberkommando in Verbindung stand, um einerseits die französischen Interessen zu vertreten und andererseits die gemeinsame Militärverwaltung in Deutschland zu koordinieren. Außerdem oblag der MMAA auch die Organisation, der Aufbau und der Einsatz des Corps d'Administration Militaire Française en Allemagne $(A M F A)^{35}$, das seit Dezember 1944 in kurzen Ausbildungslehrgängen mit der Schulung des Verwaltungskorps in einem von MMAA und SHAEF eingerichteten Ausbildungszentrum in Paris begann. Bis Juni 1945 wurden etwa 1200 bis 1500 Personen für Militärregierungsaufgaben in Deutschland ausgebildet. Die Lehrgänge dauerten nur wenige Wochen, in Universitäten und in Behörden hingen Werbeplakate für einen Einsatz in Deutschland aus. Selbst die Teilnehmer der Lehrgänge erachteten die Ausbildung als „übereilig"36. Seit dem 2. Dezember 1944 fanden die Kurzschulungen des Personals zuerst in der rue Richelieu in Paris, bald darauf in Montbard statt $^{37}$. Hier tat sich ein willkommenes Schlupfloch für Vichy-Belastete auf, und viele nutzten es. Im übrigen konnte es sich der französische Staat nicht leisten, angesichts der Zerstörungen und der Desorganisation im eigenen Land, allzu viele kompetente Männer nach Deutschland zu schicken. Die Bereitschaft wuchs erst nach und nach, als man in den Ministerien und in der Industrie erkannte, daß qualifiziertes Personal sehr wohl bestimmte Interessen in Deutschland wahrnehmen konnte ${ }^{38}$.

Die Absolventen der Lehrgänge erhielten nach Abschluß der Kurzausbildung einen grade d'assimilation ${ }^{39}$, wobei der verliehene militärische Rang der zivilen Position entsprach. In Uniform und mit militärischen Rangabzeichen traten die künftigen Offiziere der Militärregierung zumeist auf Lkws ihren Weg von Montbard nach Deutschland an. Von einer speziellen Schulung für die jeweiligen Einsatzorte konnte keine Rede sein; nach dem Zufallsprinzip ${ }^{40}$ wurden die Militärregierungen der einzelnen Kreise zusammengestellt. In kleinen Gruppen unter Führung des zukünftigen Kreisdelegierten kamen sie in der Regel wenige Tage nach der Besetzung in den deutschen Städten an, sie folgten den Kampftruppen also auf dem Fuß. Dort fanden die Offiziere der AMFA keine Verwaltungsstrukturen vor, meist waren inzwischen Truppen der nachgerückten FFI vor Ort, welche die Kampftruppen abgelöst hatten. In diesem organisatorischen Chaos begannen die einzelnen Militärregierungen mit ihrer Arbeit. Eine Mittel- oder

${ }^{35}$ Henke, Aspekte, S. 178.

${ }^{36}$ Ferber, Ernstes, S. 24. Georges Ferber selbst war Germanist und hatte sich Ende 1944 für einen Einsatz in Deutschland gemeldet. Anfang Mai 1945 kam er als Informations- und Kulturoffizier nach Konstanz und verrichtete seinen Dienst am Bodensee bis 1952.

${ }^{37}$ Hell, Mitglied, S. 109. Victor Hell (*1920), 1944 Adjoint des Kommandanten der Abteilung Deutschland im Generalstab der Ersten Französischen Armee; 1945 in der Freiburger Oberdelegation als Offizier für Soziale Belange eingesetzt; in dieser Funktion Kontakte mit dem Naziverfolgten Bernhard Dietrich, dessen Alpenlandpläne ihm geläufig waren; 1970-1987 Professor an der Universität Straßburg.

38 Willis, French, S. $19 \mathrm{f}$.

${ }^{39}$ Bostel, Gouvernement, S. 48. Im Frühjahr 1946 wurden die Kategorien Administrateur, Attaché und Auxiliaire für das zivile Verwaltungspersonal der Militärregierung eingeführt; Zauner, Erziehung, S. 59.

${ }^{40}$ André Noël, Kreisdelegierter von Donaueschingen ab 1945, berichtete hierzu, er sei in einem Konvoi in Deutschland angekommen, und auf die Frage von General Schwartz, wo er eingesetzt werden wolle, gab Noël Freiburg zur Antwort. Daraufhin meinte der General trocken, Noël werde nach Donaueschingen fahren. Vgl. Interview mit André Noël vom 18.11. 1993; StadtA KN Cc 775 a. 
Oberinstanz fehlte fast gänzlich. Für französische Verhältnisse völlig atypisch erfolgte der Aufbau der Militärregierung daher zuerst auf der untersten Ebene. Die Bezeichnung und Strukturierung der Organe war komplett auf die amerikanischen Vorgaben ausgerichtet, das englische detachment wurde zum französischen détachement. War die praktische Durchführung des Aufbaus einer Militärregierung schon unzulänglich, war es die theoretische um so mehr. Für die Ausarbeitung eigener Dienstvorschriften und besatzungspolitischen Materials war keine Zeit gewesen. Einen probaten Weg sah man deshalb darin, das der amerikanischen Militärregierung zur Verfügung stehende Handbuch $^{41}$ in Teilen ins Französische zu übersetzen. Den juristischen Teil übersetzte, in einem Zeitraum von knapp drei Wochen, kein geringerer als der spätere französische Außenminister Robert Schuman. Als „vertraulich“ klassifiziert, erschien die Übersetzung ab Dezember 1944 unter dem Titel Manuel à l'usage du Gouvernement Militaire en Allemagne. Avant la défaite ou la reddition ${ }^{42}$. Im März 1945 wurde es unter dem Titel A. M. F. A. Mémento pour les Officiers de Détachements de Gouvernement Militaire erneut veröffentlicht und bildete den einzigen Leitfaden, der den französischen Offizieren der Militärregierung im Frühjahr 1945 zur Verfügung stand. Über die Verhältnisse in den Städten und Landkreisen waren sie nicht informiert, einzig schwarze Listen ${ }^{43}$ mit prominenten Nationalsozialisten und Kriegsverbrechern standen ihnen zur Verfügung. Deshalb ließen sie sogleich von den jeweiligen Bürgermeistern ausführliche Lageberichte anfertigen, damit zur eigenen Orientierung eine erste Beschreibung der Verhältnisse vorhanden war. Die Militärregierungen führten jedoch ein isoliertes Dasein ohne hierarchische Einbindung; sie waren in den ersten Wochen nicht in die Stabsstruktur der Armee eingegliedert ${ }^{44}$. Die AMFA-Zentralstelle in Paris wurde nach der Kapitulation Deutschlands aufgelöst und durch ein Centre d'Organisation du Gouvernement Militaire en Allemagne (COGMA) ersetzt ${ }^{45}$.

\section{Die Kreisdelegierten der französischen Südzone 1945/47}

In den ersten beiden Jahren der Besatzung hatten die Militärregierungen in den Landkreisen, insbesondere der Kreisdelegierte selbst, eine starke Position ${ }^{46}$. Die Einrichtung der Militärregierungen im Frühsommer 1945 vollzog sich im Spannungsfeld mit der bereits vor Ort befindlichen französischen Militärverwaltung. Die Kreismilitärregierungen, die in geschlossenen Konvois von Montbard aus in den jeweiligen deutschen Städten im April und Mai 1945 eintrafen, waren mit der Situation zumeist konzeptionell und organisatorisch überfordert. Um dies zu verdeutlichen, sollen die Ankunft der örtlichen

\footnotetext{
${ }^{41}$ SHAEF Handbook for Military Government in Germany.

${ }^{42}$ Hell, Mitglied, S. 109.

${ }^{43}$ Grohnert, Entnazifizierung, S. 17. Die Orts- und Stadtkommandanten verfügten über schwarze Listen, um durch schnellstmögliche Festnahmen gefährlicher Personen dem allgemein gefürchteten "Werwolf" die personelle Substanz zu entziehen. Die Angst vor „Werwolfaktionen" war in französischen Kreisen zu Unrecht weit verbreitet. Viele Geiselnahmen der ersten Wochen haben darin ihre Ursache.

44 Niethammer, Besatzungsmacht, S. 153.

${ }^{45}$ Zauner, Erziehung, S. 59.

${ }^{46}$ Im Anhang befindet sich eine Liste aller Kreisdelegierten der Jahre 1945 bis 1947 im Südteil der FBZ.
} 
Militärregierungen und die ersten Monate exemplarisch an den Ereignissen in einem badischen und zwei württembergischen Landkreisen in groben Strichen skizziert werden.

Die Militärregierung für den badischen Stadtkreis Konstanz erreichte am 27. April, einen Tag nach der Besetzung der Bodenseemetropole durch Teile der 5.D.B., die unzerstörte Stadt. Anfang Mai traf die Militärregierung für den Bezirk Konstanz am Bodensee $e^{2 i n}{ }^{47}$. Sowohl das détachement $F$ (Bezirk Konstanz) als auch das détachement I (Stadtkreis Konstanz) wurden durch Befehl des Kommandierenden Generals der 14.I.D., Raoul Salan, eingesetzt. Erst mit Wirkung vom 1. Juli 1945 wurden die détachements des Bezirkes Konstanz der sich im Aufbau befindlichen vorgesetzten Oberdelegation in Freiburg angegliedert ${ }^{48}$. Der Bezirksmilitärregierung vom Mai 1945 gehörten drei Berufssoldaten an: Fregattenkapitän Jamet, Korvettenkapitän Cousot und Major Ayzac. Der Rest der Militärregierungsoffiziere waren Zivilisten in Uniform, unter ihnen Leutnant Georges Ferber in der Funktion des Informations- und Kulturoffiziers - neben dem Bezirksdelegierten Jamet und dessen beiden Stellvertretern, die stattliche Zahl von insgesamt 16 Offizieren, die in vier Abteilungen gegliedert waren ${ }^{49}$. Die Kreismilitärregierung für den Stadtkreis Konstanz nahm sich wesentlich bescheidener aus. Hauptmann Hoepffner saß mit einer Handvoll Offizieren im Gebäude der Handelskammer, während die Bezirksmilitärregierung das nicht minder repräsentative See-Hotel bezogen hatte.

Schon zwei Wochen später mußte Fregattenkapitän Jamet Konstanz verlassen. General de Lattre hatte nämlich am 16. Mai 1945 bei einer Inspektionsfahrt durch die Stadt festgestellt, daß Plakate der Militärregierung und eine Telephonleitung beschädigt waren. Sogleich witterte er Sabotage und glaubte an die Wirkung einer exemplarischen Strafmaßnahme bei der Zivilbevölkerung ${ }^{50}$; deshalb ließ er am folgenden Tag für den Wiederholungsfall das Niederbrennen eines ganzen Stadtteiles ankündigen. Noch am selben Abend zitierte de Lattre die Spitzen der Stadtverwaltung ins Inselhotel. In einem Rundumschlag setzte er den erst vor wenigen Wochen ins Amt berufenen Oberbürgermeister Benz ${ }^{51}$ ab und entließ außerdem den Konstanzer Bezirksdelegierten, Fregattenkapitän Jamet, samt dessen Stellvertreter Rohmer von deren Posten. Auch innerhalb des

\footnotetext{
${ }^{47}$ Ferber, Neubeginn, S. 72. Die Militärregierung für den Bezirk Konstanz war das französische Äquivalent zum Landeskommissariatsbezirk Konstanz, der unter Landeskommissär Nordmann die Landkreise Waldshut, Säckingen, Donaueschingen, Villingen, Stockach, Überlingen und Konstanz umfaßte. Die Landeskommissariatsbezirke wurden in einer Verwaltungsreform 1865 im damaligen Großherzogtum Baden geschaffen (mit Sitz in Karlsruhe, Mannheim, Freiburg und Konstanz) und unterstanden als Mittelbehörden dem Innenministerium. Vgl. die Einleitung des Repertoriums des Bestandes A 96/1 (Landeskommissariat Konstanz) im StA FR.

48 "Aide-mémoire destiné à faciliter le dépouillement des archives du Gouvernement Militaire pour le Pays de Bade, du Commissariat pour le Land Bade, de la Délégation Provinciale pour le BadeSud", Freiburg 1955 (masch. 10 S.); PA Bargeton.

${ }^{49}$ Es waren zwei Offiziere der Abteilung „Affaires Administratives“, fünf Offiziere der Abteilung "Affaires Economiques“ und vier Offiziere der Abteilung „Affaires Sociales“ zugeordnet. Die vierte Abteilung, die "Affaires Judiciaire“, war mit weiteren fünf Offizieren besetzt; Cousot an das $5^{\circ}$ Bureau der Ersten Französischen Armee vom 6. 6. 1945; AdO Bade C 1101.

${ }^{50} \mathrm{Zu}$ de Lattres Einschätzung der „affaire de Constance“ vgl. Ders., Reconquérir, S. $324 \mathrm{ff}$.

${ }^{51}$ Die mangelnde Geradlinigkeit der französischen Besatzungspolitik zeigte sich in Konstanz an der Besetzung des Oberbürgermeisterpostens: Zwischen Mai 1945 und Januar 1946 gab es fünf Oberbürgermeister (Mager in Vertretung Hermanns, Benz, Kerle, Schneider, Arnold); Klöckler, Besatzungspolitik, S. 37-42.
} 
Offizierskorps der 14.I.D. gab es Veränderungen: der Stadtkommandant, General Chevillon, wurde umgehend versetzt. Für den bisherigen Bezirksdelegierten Jamet hatte General de Lattre de Tassigny sofort Ersatz bereit. François Hubert Gaetan de Ripert d'Alauzier, selbst Offizier der Kolonialtruppen ${ }^{52}$, wurde zum neuen Bezirksdelegierten ernannt. Er war ein gewissenhafter wie umgänglicher Mensch und guter Soldat, aber mit den ihm gestellten Verwaltungsaufgaben überfordert. Als Angehöriger der Kampfgruppe Lebel war d'Alauzier einige Wochen zuvor in Konstanz und Singen gewesen. In der Hohentwielstadt hatte er Bernhard Dietrich, den Spiritus rector der Alpenlandbewegung, zum Bürgermeister eingesetzt.

Was hatte de Lattre zu diesem Rundumschlag bewogen? Der General fürchtete besonders Vorhaltungen wegen mangelnder Kontrolle unfähiger Offiziere ${ }^{53}$. Die angedrohten Repressalien gelangten schnell in die Schweizer Presse und fanden so umgehend ihren Weg nach Paris. Die affaire de Constance sollte mit zu dem Entschluß de Gaulles beitragen, de Lattre schon im Juli 1945 durch Pierre Koenig zu ersetzen. Die Sommermonate vergingen, und die große Politik warf ihre Schatten auf Konstanz. Der Einfluß der französischen Kommunisten, die in den Wahlen zur Verfassunggebenden Nationalversammlung 26 Prozent der Stimmen auf sich vereinigen konnten, war bedeutend gestiegen. Die Entsendung des als Widerstandskämpfer und Mitglied der KP bekannten Marcel Degliame ${ }^{54}$ war eine unmittelbare Folge der Wahlen. Direkt aus Paris angereist, löste er d'Alauzier Ende November 1945 als Bezirksdelegierten ab. Der Wechsel führte auch zu einer Stärkung der linken Kräfte am Bodensee. Sinnfälligster Ausdruck dafür war die Umstrukturierung der in Konstanz erscheinenden Tageszeitung Südkurier, die auf Veranlassung Degliames mit Rudi Goguel sodann einen Kommunisten im Redaktionsteam erhielt. Es ist wenig verwunderlich, daß der neue Bezirksdelegierte auch der Bewegung „Neues Deutschland" nahestand ${ }^{55}$. Degliame begrüßte eine mögliche Verschmelzung der sozialdemokratischen und der kommunistischen Kräfte. Mit dem raschen Auswechseln der Spitzen der Militärregierung im Bezirk Konstanz hatte sich ab Anfang 1946 die Lage beruhigt, das Personalkarussell drehte sich vorerst nicht weiter. Doch sind drei Bezirksdelegierte in weniger als einem Jahr ein deutliches Zeichen für die unausgegorene Personalpolitik in der FBZ. Sie sind des weiteren Ausdruck eines sich im Aufbau befindlichen Militärregierungsapparates, dessen Funktionsfähigkeit frühestens ab Herbst 1945 konstatiert werden kann. Die Dominanz der Militärverwaltung in den ersten Monaten der Besatzung ist augenscheinlich.

\footnotetext{
52 Ferber, Ernstes, S. 32.

${ }^{53}$ Moser, Konstanz, S. 28.

54 Marcel Degliame(-Fouché) (1912-?), 1928 Strickwarenarbeiter in Troyes; Mitglied der KPF und Engagement im Gewerkschaftsleben; 1933 Militärdienst; 1935-38 Studium an der Université ouvrière; Gewerkschaftsfunktionär; 1940 Reservist, Kriegsgefangenschaft im StaLag IV A; mehrere Ausbruchsversuche; 1941 Flucht über Ungarn, Rumänien und die Türkei in den Nahen Osten (Beirut); dort Sekretär des französischen Konsuls; Rückkehr nach Frankreich und Untergrundtätigkeit im Combat; Mitglied des CNR; 1944-45 als Kontrolloffizier für die Integration der FFI in die Erste Französische Armee verantwortlich; 1946-48 Bezirksdelegierter in Konstanz; 1951-56 Kodirektor des „Théâtre de Babylone“; 1952 Austritt aus der KPF; danach im Filmgeschäft tätig. Vgl. Maitron, Dictionnaire [ohne Seitenzählung].

${ }^{55} \mathrm{Zu}$ den Aktivitäten der Antinaziausschüsse, die besonders im westlichen Bodenseeraum eine beachtliche Initiative entfalteten: Klöckler, Überlingen.
} 
Wesentlich kleinere Dimensionen hatte die Militärregierung des württembergischen Landkreises Tuttlingen. Die Kreisstadt an der jungen Donau war am 21. April 1945 besetzt worden. In jenen Tagen wurde auch das Sonderkommando der AMFA mit der Bezeichnung I17 G3 in Montbard zusammengestellt, das die Militärregierung des Kreises Tuttlingen bilden sollte. Am 28. April setzte sich das Kommando in Bewegung und erreichte nach mehrtägiger Fahrt am 4. Mai 1945 den Bestimmungsort. Der Chef der Gruppe und spätere Kreisdelegierte war Major René Willard, dem je zwei Offiziere und Unteroffiziere sowie vier Soldaten zur Verfügung standen ${ }^{56}$. Als erstes nahm der neue Kreisdelegierte Willard Kontakt mit dem Chef des $5^{\circ}$ Bureau der 9.D.I.C. auf, um sich danach sofort im Gebäude der Stadtwerke einzurichten. Als vorrangig erkannte Major Willard die Notwendigkeit, die Kompetenzen zwischen seiner Dienststelle und dem $5^{\circ}$ Bureau zu klären. Die Militärverwaltung spielte sich aber als Herr im Hause auf; ein unbeschreibliches „Durcheinander ${ }^{457}$ herrschte. Daher begann Willard damit, die Kreismilitärregierung zu organisieren. Doch die Aktivitäten der ersten Tage sollten sich nicht auszahlen. Rasch verlor Major Willard die Kontrolle über den ihm anvertrauten Kreis, nicht zuletzt deshalb, weil die vorgesetzte Dienststelle ${ }^{58}$, die Délégation Supérieure de Wurtemberg, vor September 1945 ihre Tätigkeit nicht aufgenommen hatte. Viel hing deshalb vom persönlichen Einsatz und dem Organisationsgeschick des Kreisdelegierten ab. Sein Nachfolger im Amt, Jean Lucien Estrade, urteilte lakonisch über den wenig autoritären Willard, er habe "in seiner Aufgabe praktisch versagt ${ }^{\text {"59. }}$. Auch Guillaume Widmer in Tübingen bemerkte die Fehlbesetzung, am 31. Januar 1946 entließ er den unglücklich agierenden Willard. Interimistisch wurde der Kreis zwei Monate vom Rottweiler Kreisdelegierten Garnier-Dupré mitverwaltet. Im April 1946 begann der neue Tuttlinger Kreisgouverneur Estrade umsichtig seine Arbeit.

Am Abend der Besetzung von Reutlingen, dem 20. April 1945, wurde Oskar Kalbfell60 als kommissarischer Oberbürgermeister noch von Offizieren der kämpfenden Truppe eingesetzt. Sanktioniert wurde die Maßnahme durch Anweisung des am 1. Mai in Reutlingen eintreffenden Kreisdelegierten Cosleou ${ }^{61}$, der im Rang eines Korvettenkapitäns der Militärregierung vorstand. Da keine übergeordneten Dienststellen bestanden, betrachtete Cosleou das $5^{\circ}$ Bureau der 3.D.I.A. als weisungsbefugt. Dorthin meldete er am 12. Mai, daß er "nach Prüfung der Lage“ Kalbfell auch zum Landrat ernannt habe ${ }^{62}$. Cos-

${ }^{56} \mathrm{Zu}$ den Einzelheiten ist der Bericht des späteren Tuttlinger Kreisdelegierten Jean Lucien Estrade heranzuziehen, den dieser im Jahr 1950 niedergeschrieben hat; Ders., Tuttlingen, besonders S. 11-20.

${ }^{57}$ Ebenda, S. 14.

58 Die württembergische Innenverwaltung kannte keine Mittelinstanzen in Form von Landeskommissariatsbezirken. Die französische Besatzungsmacht schuf daher in Anlehnung an die örtliche deutsche Verwaltung in Württemberg keine Bezirksmilitärregierungen. Demzufolge waren die in den württembergischen Landkreisen eingesetzten Offiziere erheblich länger ohne Kontakt zu einer vorgesetzten Dienststelle.

${ }^{59}$ Estrade, Tuttlingen, S. 16. Man kann Estrade kein tendenzielles Urteil über seinen Amtsvorgänger vorwerfen, die Tuttlinger "Affären" der ersten Monate der Besatzung sprechen für sich.

${ }^{60} \mathrm{Zu}$ Kalbfells Position in der Neugliederungsdiskussion vgl. Kapitel V/1.

${ }^{61}$ Es ist unwahrscheinlich, daß vom 20.4. bis 30.4. 1945 ein Oberleutnant Metzger als Kreisdelegierter in Reutlingen eingesetzt war (Junger, Schicksale, S. 428); es handelte sich bei Metzger vielmehr um ein Mitglied des $5^{\circ}$ Bureau der 3.D.I.A., also um einen aktiven Truppenoffizier.

${ }^{62}$ Junger, Schicksale, S. 462. Die folgenden Ausführungen zu Reutlingen beziehen sich - soweit nicht anders vermerkt - auf die Arbeit von Junger. 
leou nahm seit dem 1. Mai 1945 die Amtsgeschäfte wahr, zuvor hatte der Standortälteste der Truppe die Kontrolle ausgeübt. Wie auch seine Kollegen in den anderen Landkreisen hatte Cosleou mit einem gravierenden Mangel an kompetentem und qualifiziertem Personal innerhalb der Militärregierung zu kämpfen. „Das französische Personal ist ungenügend“, urteilte er lapidar am 12. Juni 1945. Aber wer war für seine Belange zuständig? Die im April in Stuttgart installierte Militärregierung für Württemberg unter General Schwartz war vollkommen überlastet und durch die Verlagerung nach Freudenstadt und wenig später nach Tübingen bis dato außer Gefecht gesetzt. Erst mit der Ankunft von Guillaume Widmer Anfang September festigten sich nach und nach die Strukturen; trotzdem blieb das Gefüge der Militärregierung bis weit ins Jahr 1946 desolat.

Auch die Überwachung der Reutlinger Wirtschaft war wegen Personalmangels nicht lückenlos möglich. Der Kreisdelegierte warf seiner Gendarmerie mangelnde Verve und eine gewisse Gemächlichkeit bei der Ausführung ihrer Aufträge vor. Die knappen Hinweise verdeutlichen die Konzeptlosigkeit, mit der die lokalen Militärregierungen vor ihre Aufgaben gestellt wurden. Dabei waren die Motivation und der Einsatz seiner Offiziere nur eines der Probleme, mit denen Cosleou im Sommer 1945 zu kämpfen hatte: Viel schwerwiegender waren die Kompetenzstreitigkeiten mit der Militärverwaltung. Der für die Belange der Zivilbevölkerung zuständige Cosleou mußte im Sommer 1945 wegen der Erntearbeiten eine Verlängerung der Ausgangssperre bis 21.30 Uhr beim Kommandierenden General der 3.D.I.A. erbitten, obwohl die Militärregierung von de Lattre in diesen Fragen für zuständig erklärt worden war. Anweisungen irgendwelcher Art erhielt Cosleou während seiner Zeit in Reutlingen nicht; selbständig entschied er bis September 1945 nach eigenem Gutdünken die anfallenden Probleme. An seine Stelle trat ab Oktober der neue Kreisdelegierte Chery, der eine mit acht Offizieren besetzte Kreismilitärregierung zu leiten hatte. Offenbar hat sich die Autorität Cosleous beim Aufbau der Militärregierung in Reutlingen verbraucht; von Unfähigkeit zeugen die Quellen jedenfalls nicht.

Die Anfangsschwierigkeiten der Kreismilitärregierungen waren also stets dieselben: schlecht ausgebildetes Personal, Orientierungslosigkeit, Kompetenzstreitigkeiten mit der Militärverwaltung und fehlende Richtlinien für eine stringente Besatzungspolitik. Die personelle Neubesetzung der Kreisdelegiertenstellen war eine logische Folge der Pannen, die sich in den Monaten Mai bis September 1945 zugetragen hatten. Bis zur Jahresmitte 1946 hatten fast alle Kreisdelegierten im Südteil der Französischen Zone ihre Posten verloren. Nur wenigen gelang es, die Jahreswende 1945/46 in ein und demselben Landkreis als Kreisdelegierter zu überstehen; so der zum Bezirksdelegierten aufgestiegene Oberstleutnant Moutenet in Baden-Baden sowie die Kreisdelegierten Luc in Wolfach und Brochu in Hechingen. Versetzt wurden Marc Robert von Donaueschingen nach Offenburg und Jean Lucien Estrade von Ravensburg nach Tuttlingen. Fazit: In 31 der 36 Landkreise wurden die bis Juni 1945 eingesetzten Kreisdelegierten nach weniger als einem Jahr nach Frankreich abberufen, zwei Kreisdelegierte übernahmen aufgrund ihrer Kompetenzen andere Landkreise, und nur drei Kreisdelegierte behielten ihre Positionen auch nach der vom Leiter des Militärregierungsapparates, Generalverwalter Emile Laffon, ab Sommer 1945 begonnenen „Säuberungswelle“. Welche Auswirkungen die Abberufungen und Neubesetzungen auf die Praxis der französischen Besatzungspolitik in den Kreisen hatten, ist offensichtlich: Fehlende Stringenz und mangelnde Kontinuität erschwerten nicht nur politische Aktivitäten im Südwesten. 


\section{Die Oberdelegationen (Délégations Supérieures)}

Drei Ebenen der Militärregierungshierarchie waren auf Freiburg verteilt, zum einen die Militärregierung für den Stadt- und Landkreis, des weiteren die Bezirksmilitärregierung und schließlich die Oberdelegation für das Land Baden (Délégation Supérieure pour le Land Bade). In den Besatzungsdienststellen für den Landeskommissariatsbezirk ${ }^{63}$ waren rund 140 Männer und Frauen beschäftigt ${ }^{64}$. Nach einer Aufstellung vom 15. November 1945 gingen neben Oberstleutnant Marcellin weitere 30 Offiziere Führungsaufgaben nach ${ }^{65}$. Als Informationsoffiziere fungierten die Leutnante Jordy und Toussaint, die bei der Gründung der „Vereinigung Abendland" 66 eine maßgebliche Rolle spielten.

Die Oberdelegation hatte, von Karlsruhe kommend, Anfang Juli 1945 ihren Sitz in Freiburg genommen. Oberst Eberle, der von der alten Residenzstadt aus seit Ende April das Land Baden zu verwalten bemüht war, kam mit seinem Stab nach wenigen Wochen in das südbadische Freiburg. Am 20. Juli 1945 unterzeichnete er als provisorischer Militärkommandant des Bezirks Baden ${ }^{67}$; den Delegierten des Stadtkreises Karlsruhe, Oberstleutnant Marcellin, hatte er mitgebracht und als Bezirksdelegierten des Landeskommissariatsbezirks Freiburg eingesetzt. In Personalunion versah Marcellin auch die Aufgaben des Delegierten für den Stadtkreis Freiburg. Spätestens in der ersten Augustwoche traf dann der neue Oberdelegierte für das Land Baden, General Schwartz, in Freiburg ein ${ }^{68}$. Die Bezeichnung seiner Dienststelle lautete nun Détachement E II. Der "provisorische Gouverneur" Eberle wurde mit der Leitung des Stabes von General Schwartz abgefunden.

General Jacques Fernand Schwartz (1889-1960) wird in der Literatur übereinstimmend als ausgezeichneter Offizier geschildert. Geboren am 15. Juni 1889 in Mülhausen im Elsaß, stand ihm nach Abitur und Lizenziat der Rechte eine militärische Karriere bevor. Zusammen mit André Noël, dem späteren Bezirksdelegierten von Konstanz, befand er sich während des Zweiten Weltkrieges in Marokko als Patron de Région en Maroc ${ }^{69}$. 1942 wurde Schwartz zum Commandeur de la Légion d'Honneur ernannt. In beiden Weltkriegen mit dem Croix de guerre ausgezeichnet, unterstand der dekorierte Offizier mit Wirkung vom 14. April 1945 direkt General Koeltz, dem Leiter der MMAA; nach wenigen Tagen sah er sich als Gouverneur von Württemberg in Stuttgart wieder. Seit dem 23. April - wenige Tage nach der Besetzung der Stadt - oblag ihm die Leitung der Militärregierung, dessen Führungsstab Oberst Niel anvertraut war. Von hier aus plante Schwartz, eine zivile deutsche Landesverwaltung für Württemberg aufzubauen. Dazu bestellte er unter anderem Carlo Schmid in der zweiten Juniwoche 1945 nach Stuttgart

${ }^{63}$ Der Landeskommissariatsbezirk Freiburg umfaßte folgende Landkreise: Emmendingen, Freiburg (Stadt- und Landkreis), Kehl, Lahr, Lörrach, Müllheim, Neustadt, Offenburg und Wolfach. ${ }^{64}$ Haumann, Geschichte, S. 395 f.

65 "Liste du personnel - officiers du G. M. du District“ vom 15. 11. 1945; AdO Bade H 1101.

${ }^{66}$ Leutnant Jordy war am Aufbau der „Vereinigung Abendland“ federführend beteiligt; vgl. Kapitel II/1.

${ }^{67}$ Le Colonel Eberle, Commandant Militaire provisoire du District de Bade, 20. 7. 1945; AdO Bade $\mathrm{H} 1101$.

${ }^{68}$ In einer Ausarbeitung über das Besatzungspersonal, die im Kabinett des Generalverwalters Laffon angefertigt worden war, wurde General Schwartz am 5. 8. 1945 als Gouverneur für Baden bezeichnet; AdO CCFA Cab. Laffon c. 16.

${ }^{69}$ Interview mit André Noël vom 27. 4. 1994; StadtA KN Cc 775 a. 
und bot ihm das Ressort für Unterrichtswesen und kulturelle Angelegenheiten an ${ }^{70}$. Aus dem Stammpersonal der MMAA entlassen und der Befehlsgewalt von General Koenig unterstellt, bekleidete Schwartz ab 29. Juli 1945 den Posten des Délégué Supérieur pour le Gouvernement Militaire du pays de Bade, des Oberdelegierten für das französisch besetzte Baden. Zehn Monate später verließ er Freiburg, um mit Wirkung vom 1. Juni 1946 seinem Nachfolger im Amt, Pierre Pène, den Dienstposten zu übergeben. Seit 1. Februar 1947 unterstand er wieder der Verfügungsgewalt des Kriegsministeriums. Er strebte nach höheren militärischen Weihen, die er im Frühjahr 1947 mit der Plakette zum Grand Officier de la Légion d'Honneur erhalten sollte ${ }^{71}$.

Bei der Übergabe der Amtsgeschäfte an Pierre Pène am 1. Juni 1946 führte der unmittelbare Vorgesetzte, Generalverwalter Emile Laffon, aus: „Ich bin glücklich, daß ich in ein und derselben Würdigung den Soldaten, General Schwartz, und den Résistancekämpfer, Herrn Pène, verbinden kann."72 Tatsächlich verfügte der neue Oberdelegierte über verwaltungstechnische Qualitäten, die dem Soldaten Schwartz abgegangen waren. Sein Werdegang hatte Pierre Pène für eine gewichtige Aufgabe im besetzten Deutschland prädestiniert. Am 10. März 1898 in Paris geboren, war er Soldat im Ersten Weltkrieg gewesen und hatte danach an der Ecole Polytechnique ein Ingenieurstudium aufgenommen. Als ausgebildeter Straßenbauingenieur erhielt er 1922 seine erste Anstellung im Arbeitsministerium und stieg zum Ingénieur en chef des Ponts-et-Chaussées auf. Die Bemerkung de Gaulles, Frankreich habe eine Schlacht, aber nicht den Krieg verloren, hatte sich Pène zu eigen gemacht. Seit 1941 gehörte er der Résistance an, genauer der Führung der Armée Secrète im Departement Aisne. Von der Gestapo in den Ardennen verhaftet, überstand er die Folter, ohne seine Kameraden zu verraten; die Flucht aus dem Gefängnis in Senlis gelang ihm am 9. Juni 1944. Nach der Befreiung übernahm er ab 28. August 1944 als Kommișsar der Republik in Saint-Quentin die Verwaltungsgeschäfte $^{73}$. Seinen engen Mitarbeiter, René Bargeton ${ }^{74}$, nahm er nach seiner Berufung in den Personalbestand des CGAAA mit nach Deutschland und machte ihn zu seinem $D i$ recteur de Cabinet ${ }^{75}$. Als Oberdelegierter, seit 1949 als Kommissar für das Land Baden, blieb er bis zum 16. November 1950 in Freiburg. René Bargeton trat seine Nachfolge an.

Der mit etlichen Fachabteilungen ausgestattete Apparat der Oberdelegation belief sich 1946 auf etwa 250 Personen ${ }^{76}$. Eine Liste der verschiedenen Abteilungen und des

${ }^{70}$ Schmid, Erinnerungen, S. 229.

${ }^{71}$ Das Zeremoniell ist bildlich festgehalten auf S. 26 der Revue de l'information des troupes françaises de l'occupation en Allemagne 19 (1947).

72 "Au Gouvernement militaire - M. Pène Délégué Supérieur pour Bade“, in: Revue de l'information des troupes françaises de l'occupation en Allemagne 10 (1946), S. 36.

${ }^{73}$ Grohnert, Entnazifizierung, S. 223.

${ }^{74}$ René Bargeton, Germanist und Archivar, erhielt keine spezielle Ausbildung für seinen Einsatz im Kabinett von Pierre Pène. Seit 1944 war er in der Verwaltung der Präfektur (Sous-préfet chef de cabinet du commissaire de la République pour la région de Laon-Saint-Quentin) tätig; Interview mit René Bargeton vom 27. 4. 1994; StadtA KN Cc 775 a. Außerdem ist ein kurzer Lebenslauf publiziert in: Jurt, Besatzungszeit, S. $255 \mathrm{f}$.

75 Es sei auf den Unterschied der Aufgabenbereiche eines Directeur de Cabinet und eines Chef de Cabinet hingewiesen: der Directeur de Cabinet stand hierarchisch höher und war engster Mitarbeiter und Stellvertreter des Leiters einer Dienststelle; dem Directeur de Cabinet unterstanden das Cabinet Civil und das Cabinet Militaire. Der Leiter des Cabinet Civil (Chef du Cabinet Civil) nannte sich verkürzt zumeist Chef de Cabinet.

${ }^{76}$ Haumann, Geschichte, S. 396. 
dort tätigen Personals findet sich im Telephonbuch der Freiburger Oberdelegation ${ }^{77}$. Von speziellem Interesse ist das Cabinet Civil, da hier die politischen Belange entschieden wurden. Der Leiter beider Kabinette, René Bargeton, verfügte über eine Unterabteilung, die mit Studien und Zeitungsdokumentationen beschäftigt war. Bargeton selbst beaufsichtigte das zivile und das militärische Kabinett. Das erstere unterstand dem Chef de Cabinet, Lottin, dessen Büro vom Chef $d u$ Bureau du Cabinet, See, geleitet wurde. Dem militärischen Kabinett stand Leutnant Le Masne de Chermont vor. Die Direction des Affaires Administratives, wichtigste Abteilung bezüglich der politischen Fragen innerhalb der Oberdelegation, leitete der Unterpräfekt Daty, dem die Abteilung Inneres und Kirchen unter Leitung von Fourcault de Pavant unterstellt war. Das vielköpfige Personal der Abteilung Wirtschaft und Finanzen führte die Anweisungen von Dominique Magnant aus, der gleichzeitig Vorstand der OFRA ${ }^{78}$ war, einer Organisation von ehemaligen Widerstandskämpfern, die nun im besetzten Deutschland Dienst taten.

Die Einrichtung einer Oberdelegation für Württemberg und Hohenzollern, die sich unter General Schwartz als Commandant Militaire de Wurtemberg seit dem 23. April in Stuttgart in der Aufbauphase befand, zog sich bedingt durch die Neufestsetzung der Zonengrenzen bis Mitte Juli 1945 hin. Die französischen Truppen samt Militärregierung verließen am 8. Juli 1945 die Stadt am Neckar ${ }^{79}$, die Militärregierung für Württemberg mußte in das zerstörte Freudenstadt umziehen. Von dort wurde sie wenig später nach Tübingen verlegt, auch im Hinblick auf die dortige Universität. General Schwartz, nunmehr mit der Leitung der Oberdelegation in Baden beauftragt, fand in Guillaume Widmer seinen Nachfolger.

Der neununddreißigjährige Widmer ${ }^{80}$, der zwischen 1931 und 1939 als Prokurist der Bank von Indochina gearbeitet hatte ${ }^{81}$, verfügte über einen reichen Schatz an Erfahrungen militärischer und ziviler Verwaltungstätigkeit. 1943 verrichtete er in Algier Dienst bei einem interalliierten Generalstab und übernahm 1944 in Frankreich die Region II als militärischer Beauftragter. Seit dem 1. September 1945 war er mit der Délégation Supérieure pour le Gouvernement du Wurtemberg betraut, es unterstanden ihm direkt - neben den 15 württembergischen Landkreisen - die hohenzollerischen Kreise Hechingen und Sigmaringen sowie der bayerische Kreis Lindau. Eine Mittelinstanz nach Art der badischen Landeskommissariatsbezirke existierte nicht. General Widmer machte auch keine Anstalten, auf französischer Seite eine Mittelinstanz einzurichten. Der Zugriff auf die einzelnen Landkreise war deshalb im französisch besetzten Württemberg-Hohenzollern direkter und unmittelbarer als im benachbarten Baden. Demzufolge war die Rolle Widmers bedeutender, seine Befehle wurden nicht durch Mittelinstanzen „ver-

77 Vgl. dazu das Telephonbuch (Annuaire Téléphonique du Gouvernement Militaire de la Délégation Supérieure du Pays de Bade) vom 1. 3. 1948; AdO ohne Signatur.

78 Die Organisation des Fonctionnaires résistants en Allemagne wurde im Januar 1946 als Sektion der Organisation des Fonctionnaires résistants mit Sitz in Paris gegründet. Die Mitgliederzahl belief sich auf circa 350 Personen. Im Ehrenvorstand saßen neben General Koenig die Oberdelegierten Boislambert, Pène und Grandval sowie die Herren Degliame (vgl. Anmerkung 54) und Garnier; „Note - sur l'activité de l'Organisation des Fonctionnaires résistants en Allemagne“ vom 15. 4. 1948; PA Magnant; außerdem: Interview mit Dominique Magnant und Joffre Chétrit vom 21. 11. 1993; StadtA KN Cc 775 a.

79 Nüske, Württemberg (I), S. 228.

${ }^{80}$ Guillaume Widmer (1906-1968). Die biographischen Daten wurden in den Text eingearbeitet.

${ }^{81}$ Grohnert, Entnazifizierung, S. 224. 
wässert". Der bisherige Directeur de Cabinet, Oberst Niel, ein ruhiger und alle persönliche Schärfe vermeidender älterer Offizier ${ }^{82}$, wurde im Herbst 1945 durch Oberst Gonzague Corbin de Mangoux ersetzt ${ }^{83}$. Widmer selbst, mehr Verwaltungsfachmann denn Militär, zählte nicht zu den Gefolgsleuten des Oberkommandierenden Koenig. Aufgeschlossen stand er den deutschen Belangen gegenüber und zeigte insgesamt eine liberale Haltung ${ }^{84}$. Autonomistisch motivierten Neugliederungswünschen erteilte er eine klare Absage.

Sein Stellverteter und Directeur de Cabinet, Corbin de Mangoux, leitete geschickt das zivile und das militärische Kabinett. Er stimmte über weite Strecken mit seinem Vorgesetzten überein, sein Werdegang als Verwaltungsfachmann war mit dem Widmers fast identisch. Der württemberg-badische Ministerpräsident Reinhold Maier erinnerte sich an de Mangoux als einen stets diplomatisch agierenden und gewandten Offizier ${ }^{85}$. Seine zentrale Stellung im Kabinett Widmers ist jedenfalls unbestritten. Der Chef de Cabinet, Yves Burgalat, hatte fünf Abteilungen unter sich, als deren bekannteste wohl die Abteilung für Universitätsangelegenheiten zu bezeichnen ist. Der Kurator der Universität Tübingen, René Cheval ${ }^{86}$, war der zuständige Mann für Säuberung, Reorientierung und Wiedereröffnung der südwürttembergischen Alma mater. Das Pendant zu Burgalat im militärischen Kabinett stellte Hauptmann Millon dar. Die Délégation Supérieure de Wurtemberg dürfte insgesamt an die 200 Frauen und Männer beschäftigt haben ${ }^{87}$.

\section{Die Dienststellen in Baden-Baden}

Das Primat der Militärverwaltung im französisch besetzten Südwesten konnte nur durch einen zentral geleiteten Militärregierungsapparat gebrochen werden. Zwar waren die Kreis-, Bezirks- und Landesmilitärregierungen eingerichtet, aber ein Zusammenspiel war ohne Zentrale undenkbar. Ein funktionierendes französisches Oberkommando in Deutschland, das einerseits die Militärverwaltung in Form des $5^{\circ}$ Bureau der Ersten Französischen Armee abzulösen und andererseits die unterstellten Militärregierungen vor Ort zu kontrollieren hatte, mußte daher im Frühsommer 1945 dringend geschaffen werden. Das Commandement en Chef Français en Allemagne (CCFA) wurde in Paris durch Dekret vom 15. Juni 1945 ins Leben gerufen. Es sah vor, die Posten eines Oberkommandierenden und dessen Adjoint sowie eines politischen und eines wirtschaftlichen Beraters einzurichten. Den geeigneten Mann fand de Gaulle in General Pierre Koenig, Sieger von Bir Hakeim und altvertrauter Gefolgsmann. Am 14. Juli wurden Koenig die Besatzungstruppen unterstellt, am 23. desselben Monats trat er offiziell sein Amt $\mathrm{an}^{88}$. Von einer eindeutigen Übernahme der Macht konnte allerdings nicht die Rede sein. Die Fülle der Aufgaben, mit denen Koenig beauftragt wurde, und „interalliierter

\footnotetext{
82 Schmid, Erinnerungen, S. 237.

${ }^{83}$ Nüske, Württemberg (I), S. 237.

${ }^{84}$ Auerbach, Anfänge, S. 609.

${ }^{85}$ Maier, Grundstein, S. $137 \mathrm{f}$.

${ }^{86}$ René Cheval (1918-1986); Kurzbiographie in: Knipping, Kulturpolitik, S. 413.

87 Rückschlüsse auf die zahlenmäßige Stärke der Militärregierung für Württemberg-Hohenzollern in Tübingen sind aus dem Telephonverzeichnis vom 1. 5. $1947 \mathrm{zu}$ ziehen; Annuaire Téléphonique - G. M. de la Délégation du Wurtemberg; AdO ohne Signatur.

88 Wolfrum, Besatzungspolitik, S. 34.
} 
Druck“ $z$ wangen de Gaulle ${ }^{89}$, einen speziell für die Militärregierung zuständigen Mann nach Baden-Baden zu schicken; es verging ein weiterer Monat, bis der mit dem Aufbau des Militärregierungsapparates beauftragte und Koenig unterstellte Emile Laffon in Baden-Baden eintraf. Ein junger Mitarbeiter aus dem Innenministerium begleitete Laffon, den jener für den Posten des Directeur de Cabinet ausersehen hatte: Maurice Grimaud 90 . Beide waren in jeder Hinsicht unvorbereitet nach Deutschland gekommen ${ }^{91}$. Eine der Hauptaufgaben der ersten Monate bestand in der Ablösung des mittelmäßigen und ungenügend qualifizierten Personals aus der französischen Militärregierung. Dieses Ziel hat Laffon - wenn man die Vorgänge in den Kreisen betrachtet - zweifellos erreicht.

Dabei waren die Zustände auch innerhalb des Gouvernement Militaire in Baden-Baden Anfang September 1945 ausgesprochen „heikel"92. Die Pariser Verbindungsstelle zwischen Außenministerium und Baden-Baden beschwerte sich schriftlich über die Schwerfälligkeit des ganzen Systems der Militärregierung: Ein Brief einer Abteilung zum Beispiel müsse den Directeur Général samt Kabinett, den Generalverwalter einschließlich Kabinett und den Oberkommandierenden inklusive Kabinett passieren, das Antwortschreiben gehe denselben Weg. „Trop de cabinets et trop de monde dans les cabinets "93, lautete das niederschmetternde Pariser Fazit; Geschmeidigkeit im Dienstablauf wurde dringend angemahnt. Man monierte in Paris außerdem den Umstand, daß sich alle Ebenen der Militärregierung beschwerten, einerseits keine Direktiven aus der französischen Hauptstadt zu erhalten, andererseits widersprüchliche Befehle entgegennehmen zu müssen. Hier war die Zentrale gefordert; außerdem seien nur die obersten Positionen mit erstklassigen Fachleuten besetzt, so der Pariser Bericht weiter, die jedoch über Personal „von sehr schlechter Qualität verfügen. Die Auswahl wurde auf gut Glück getroffen, durch Kooptation; man hat die ,guten Kumpel und die ,kleinen Freunde' jener genommen. Es gibt eine sehr große Zahl von Leuten, beiderlei Geschlechts, die wegen Inkompetenz zu entfernen wären. " Einige Dienststellen in BadenBaden wiesen eine zahlenmäßige Unterbesetzung auf, etwa die Direction de l'Intérieur mit 13 oder die Sûreté mit 20 Mitarbeitern, andere hingegen waren unglaublich aufgeblasen, etwa die Direction du Désarmement mit rund 1500 Personen.

Die personellen Verhältnisse stellten den ehrgeizigen und fähigen Juristen, der Emile Laffon zweifellos war, vor keine leichte Aufgabe. Der achtunddreißigjährige Generalverwalter war ausgestattet mit einem unverwechselbaren Organisationstalent und einer phänomenalen Schaffenskraft, Eigenschaften, die ihn in den Augen des Oberkomman-

${ }^{89}$ Interview mit Maurice Grimaud vom 18. 11. 1993; StadtA KN Cc 775 a.

90 Maurice Grimaud ("1913), Gymnasium in Lyon; Studium in Lyon und Paris; 1939-43 Attaché in Marokko; 1943-44 in Algier (Commissariat à l'Intérieur); 1945-47 Directeur de cabinet von Emile Laffon in Baden-Baden; 1948-49 französischer Berater des Flüchtlingshilfswerks in Genf; 1951-54 in Marokko (Directeur de l'Information); 1955-61 Präfekt; 1963 Leiter der Sûreté Nationale; 1967 Polizeipräfekt in Paris; 1981-83 Kabinettsdirektor von Minister Gaston Deferre (Inneres und Dezentralisation).

91 Weder hatten beide eine Kurzschulung nach dem Vorbild der MMFA erhalten, noch waren sie Kenner der deutschen Verhältnisse. Lediglich die Verwaltungserfahrung empfahl sie für die verantwortungsvollen Positionen, die sie im besetzten Deutschland übernehmen sollten; Interview mit Maurice Grimaud vom 18.11. 1993; StadtA KN Cc 775 a.

92 „Note - Sur la situation à Baden-Baden“, SGAAA/Division Politique et Economique vom 10. 9. 1945; MAE PA-AP 338-Laffon 15.

${ }^{93}$ Ebenda. 
dierenden rasch suspekt erscheinen lassen mußten. Aus seiner sozialistischen Überzeugung machte Laffon keinen Hehl, hier taten sich zusätzliche, scharfe Gegensätze zu General Koenig auf. Doch waren die Spannungen ${ }^{94}$ nicht nur in den unterschiedlichen politischen Auffassungen der beiden begründet; sie resultierten bereits aus der Kompetenzverteilung. Formal hatte der Oberkommandierende Koenig die Befehlsgewalt über den Militärregierungsapparat, an dessen Spitze Generalverwalter Laffon stand. Doch hegte Koenig große Bedenken gegenüber der Loyalität des Apparates und befürchtete - wohl nicht zu Unrecht -, daß der ,junge, progressive und größtenteils sozialistisch gesinnte Stab"95 Laffons nach und nach eine besatzungspolitische Personalstruktur schaffen könnte, die seiner Gunst mißfallen mußte. Schon im August 1945 begann Koenig daher mit dem systematischen Aufbau einer Doppelspitze in Baden-Baden. Aus einem kleinen Beraterstab um den Oberkommandierenden entstand innerhalb eines Jahres ein Kabinett ${ }^{96}$ mit mehreren hundert Offizieren.

Im Jahre 1907 in Carcasonne in eine großbürgerliche Familie hineingeboren, besuchte Emile Laffon nach bestandenem Abitur die Ecole des Mines und ließ sich zum Ingenieur ausbilden, parallel dazu studierte er Jura, ein Zeugnis seiner Willensstärke und Energie. Der Beginn einer brillanten Rechtsanwaltskarriere zeichnete sich ab, wäre nicht der deutsche Einmarsch dazwischengekommen. Laffon fungierte in den folgenden Jahren als Verbindungsmann der Résistance zwischen Mutterland und London"7, um schließlich im Untergrund die Befreiung Frankreichs verwaltungstechnisch vorzubereiten ${ }^{98}$. "Ich nahm an der Erhebung in Paris teil, das war das allerschönste Abenteuer meines Lebens" $" 99$, schrieb er an seine Eltern im Oktober 1944. Kurz nach der Befreiung fand er sich als Ministerialdirektor im Innenministerium wieder, und Michel Debré, später Leiter des CGAAA, urteilte über ihn: „Ich habe bereits von seiner Intelligenz gesprochen, seiner Willenskraft sowie seiner Neigung zur Autorität. Es entging ihm nichts, und er strebte danach, über alles zu gebieten." 100 Zusammen mit seinem engen Mitarbeiter Maurice Grimaud trat er im August 1945 die Reise nach Deutschland an, nicht zuletzt wegen der Sympathien de Gaulles ${ }^{101}$ war Laffon dort für eine wichtige Aufgabe ausge-

${ }^{94} \mathrm{Zu}$ den Streitigkeiten und der charakterlichen Inkongruenz von Emile Laffon und Pierre Koenig vgl. Lattard, Zielkonflikte.

${ }_{95}$ Interview mit Maurice Grimaud vom 18. 11. 1993; StadtA KN Cc 775 a.

96 Das Kabinett von Pierre Koenig zählte bereits im September 1945120 Mitarbeiter. Vgl. „Note Sur la situation à Baden-Baden" vom 10. 9. 1945; MAE PA-AP 338-Laffon 15.

${ }^{97}$ Lattard, Zielkonflikte, S. 6.

${ }_{98}$ Die bisher einzige wissenschaftliche Arbeit über Emile Laffon ist an der Universität Paris I am Lehrstuhl von René Girault entstanden. Die Verfasserin, Bénédicte Grange, hat hierzu in groBem Umfang den politischen Teil des Nachlasses Laffon im Archiv des französischen Außenministeriums ausgewertet. Diese Mémoire de Maîtrise ist bisher unveröffentlicht geblieben; Grange, Laffon.

Die Existenz des Nachlasses von Laffon war in der historischen Forschung kaum bekannt. Lattard arbeitete mit Materialien aus dem Privatarchiv von Maurice Grimaud und aus dem Besitz des Sohnes, Olivier Laffon (Lattard, Zielkonflikte). Die im Außenministerium archivierten Dokumente betreffen fast ausschließlich seine beiden Jahre in Baden-Baden (1945-47). Vgl. dazu: MAE PA-AP 338-Laffon.

${ }^{99}$ Emile Laffon an seine Eltern vom 31. 10. 1944; MAE PA-AP 338-Laffon 18.

${ }^{100}$ Debré, Républiques, S. 67.

${ }^{101}$ Laut Maurice Grimaud schätzte auch der Provisorische Regierungschef Laffon sehr; vgl. dazu weiter: Lattard, Zielkonflikte, S. 13. 


\begin{tabular}{|l|l|}
\hline SARRE GR & GRANDVAL \\
\hline BADE & PENE \\
\hline WURTIEMBERG WIDMER & \\
\hline $\begin{array}{c}\text { RHENANIE-PALATINAT } \\
\text { DE BOISLAMBERT }\end{array}$ & \\
\hline
\end{tabular}

\begin{tabular}{|c|}
\hline DIRECTION DE L INTERIEUR ET DES CULTES \\
HOLVECK
\end{tabular}

\begin{tabular}{|c|c|}
\hline $\begin{array}{l}\text { SERVICE DES RENSEIGNEMENTS } \\
\text { GENERAUX } \\
\text { HUMBERT }\end{array}$ & 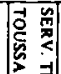 \\
\hline $\begin{array}{l}\text { SERVICE DE LA POLICE } \\
\text { JUDICIAIRE }\end{array}$ & 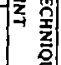 \\
\hline $\begin{array}{l}\text { SERVICE DE LA SURVEILLANCE DU } \\
\text { TERRITOIRE } \\
\text { LAMSFUSS }\end{array}$ & \\
\hline $\begin{array}{l}\text { SERVICE DE LA POLICE GENERALE } \\
\text { IVERSENC }\end{array}$ & 彥 \\
\hline $\begin{array}{l}\text { SERVICE DE L 'ADMINISTRATON } \\
\text { DE LA POLICE } \\
\text { FALRE }\end{array}$ & 可 \\
\hline
\end{tabular}

\begin{tabular}{|c|}
\hline JUSTICE FRANÇAISE \\
GIRAUD \\
\hline $\begin{array}{c}\text { JUSTICE ALLEMANDE } \\
\text { BOURTHOUMIEUX }\end{array}$ \\
\hline $\begin{array}{c}\text { RECHERCHES DES CRIMES DE CUERRE } \\
\text { REBOUL }\end{array}$ \\
\hline ADMINISTRATION PENITENTIAIRE \\
FOUGERON
\end{tabular}




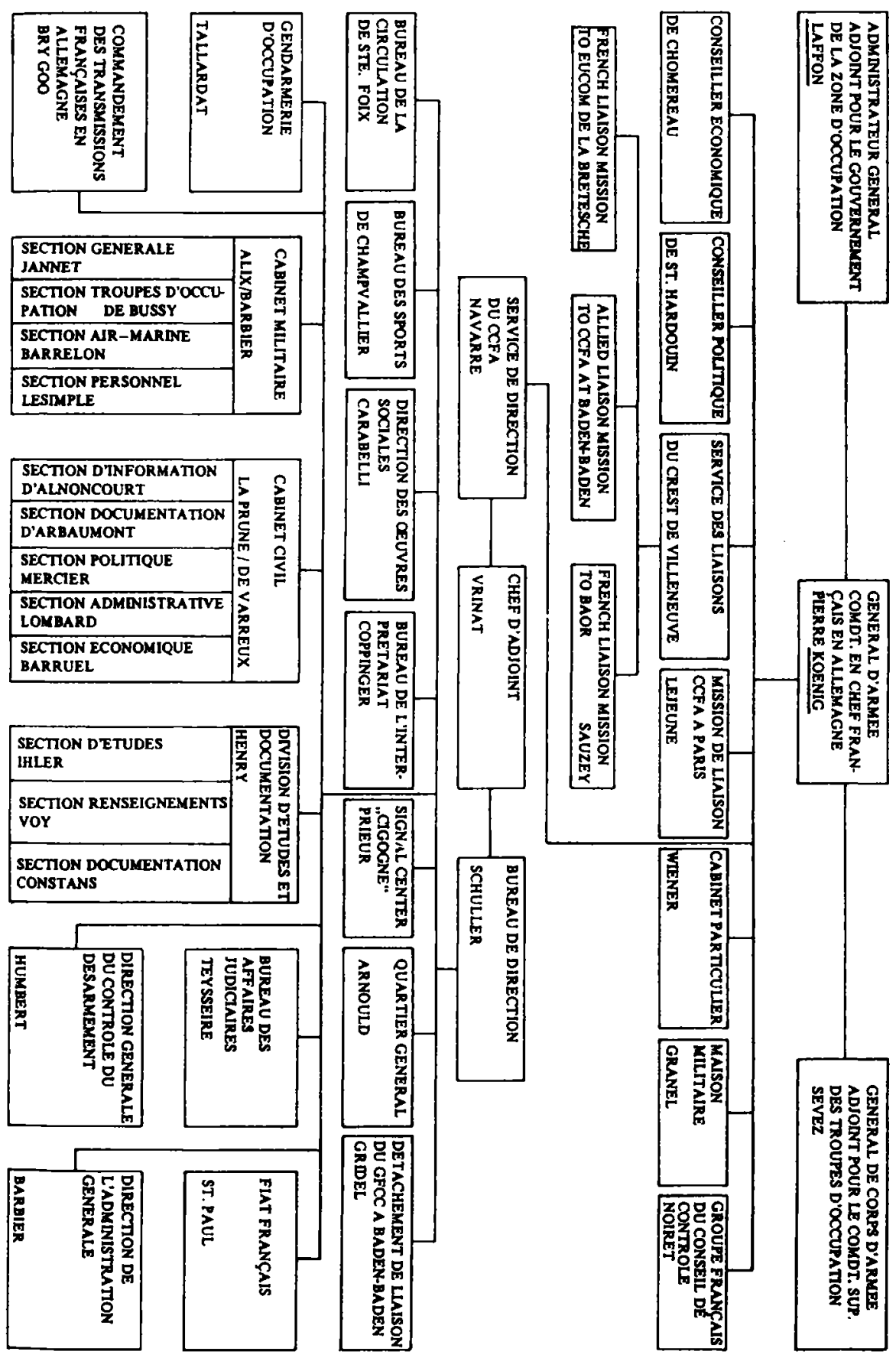

Die Organisation des "Kabinett Koenig“ (Stand 15. Juni 1947) 
wählt worden. Rechts des Rheins bekleidete er das Amt des Generalverwalters, Grimaud wurde sein Directeur de Cabinet. Der Stab seiner Mitarbeiter war durchweg jung, viele Offiziere waren unter dreißig Jahre alt. Seine Amtsführung zeichnete sich durch den Versuch aus, politische Konzeptionen aus der Zeit der Résistance ${ }^{102}$ in Deutschland umzusetzen. Die sozialistischen Gedanken umfaßten immer auch das Ziel, daß nur ein demokratisches Deutschland Garant für ein friedliches Europa sein könne. Fragen der staatlichen Neugliederung in Südwestdeutschland stand Laffon ablehnend gegenüber; eine Reorganisation der deutschen Länder unter einer schwachen Zentralgewalt schien ihm naheliegender. Des weiteren trat er für eine stärkere Zentralisierung der Zone ein, geleitet von dem Interesse nach Maximierung der wirtschaftlichen Nutzung und von dem Wunsch, deutsche und französische Verwaltungsstellen effizienter kontrollieren zu können ${ }^{103}$. Der "Zentralisierer" Laffon hatte aber auch mit einem anderen Problem zu kämpfen: die Durchsetzung seiner Befugnisse gegenüber den Oberdelegierten bereiteten ihm im Sommer 1945 immense Schwierigkeiten. Insbesondere der Oberdelegierte von Rheinland-Hessen-Nassau und später von Rheinland-Pfalz, Claude Hettier de Boislambert, verfügte über ein nicht zu unterschätzendes Prestige als Freund und Weggefährte de Gaulles. Zugleich war er in der Nachkriegszeit stellvertretender Chef von de Gaulles persönlichem Kabinett ${ }^{104}$. Emile Laffon war also gezwungen, auf eine Zentralisierung sämtlicher französischer Dienststellen in Baden-Baden zu drängen, da er sonst Gefahr gelaufen wäre, die ihm zugedachte Aufgabe nicht erfüllen zu können.

In diametral politischem und intellektuellem Gegensatz zu Laffon befand sich General Pierre Koenig. Doch es waren bei weitem nicht nur politische Denkmuster sowie die besatzungspolitischen Vorstellungen, die beide trennten. Auch ihr Temperament war grundverschieden. Als routinierter und an Befehlswege sowie Hierarchien gewöhnter Offizier konnten Koenig die rührigen Aktivitäten seines jungen Generalverwalters nicht gleichgültig lassen. Zu sehr sah er die eigene Autorität geschmälert, seine Politik hintertrieben. In seinem Selbstverständnis als Commandant en Chef dachte er zu keiner Zeit daran, die Zügel aus der Hand zu geben. Über Erfahrung in Besatzungsfragen verfügte er bereits zur Genüge, war er doch nach dem Ersten Weltkrieg als Besatzungsoffizier im Rheinland gewesen. Im Jahr der französischen Niederlage folgte er de Gaulle nach London und wurde zu dessen treuem Anhänger. Mit der Aufgabe eines Militärgouverneurs im August 1944 betraut, bewegte sich Koenig vollends im Umfeld de Gaulles. Seine militärische Reputation stand außer Zweifel, er war in den Augen de Gaulles der richtige Mann für die Leitung des Oberkommandos im französisch besetzten 'Teil Deutschlands. Pierre Koenig zeichnete eine konservative Grundeinstellung aus, die nach dem Rücktritt de Gaulles im Januar 1946 die Zusammenarbeit mit der französischen Regierung erschwerte, und es scheint, als habe er mehr auf die Stimme aus Colombey-les-deux-Eglises gehört als auf die Anweisungen aus Paris.

Das Kabinett Koenigs, ursprünglich nur als Beraterstab geplant, entwickelte sich rasch als zweite Spitze neben dem Kabinett des Generalverwalters. Der Conseiller Politique, Tarbé de Saint Hardouin, verfügte über einen direkten Draht ins Außenministe-

102 Die verschiedenen Gruppierungen und deren Pläne für ein Nachkriegseuropa hat Walter Lipgens herausgearbeitet. Auch die Ideen Laffons sind dort vertreten; Lipgens, Europa-Föderationspläne, S. 177-250.

${ }^{103}$ Hudemann, Zentralismus, S. 207.

104 Ebenda, S. 195. 
rium zu Georges Bidault. Der Außenminister hatte mit dem erfahrenen Diplomaten einen Vertrauten in der Zone, der jederzeit im Sinne gaullistischer Politik handeln konnte. Insgesamt dürfen de Gaulle, Bidault, der Quai d'Orsay, das CGAAA und Koenig samt Saint Hardouin zu den Vertretern einer dezentralistischen Politik gerechnet werden ${ }^{105}$, da sie eine Stärkung der Ländergewalten zuungunsten einer zu schaffenden Zentralgewalt planten. Als Directeur de Cabinet hatte sich Koenig den erfahrenen General Henri Navarre $^{106}$ ausgesucht; Oberst Penette wiederum leitete das Militärkabinett. Der für wirtschaftliche Belange zuständige Mann im Kabinett Koenig war de Chomereau.

Die Koordinierung und Leitung des gesamten Kabinetts des Generalverwalters hatte Maurice Grimaud in seiner Funktion als Directeur de Cabinet inne. Als Chef de Cabinet zeichnete Pierre Bolotte zuständig, der politisch dem MRP nahestand und die Verbindungen Laffons zu dieser Partei des Tripartisme sicherstellte ${ }^{107}$. Das Militärkabinett unterstand Oberst Bonne. Es waren junge Männer, die im direkten Umfeld des Generalverwalters Dienst taten, allesamt aus dem Widerstand kommend und in der Mehrzahl politisch links stehend. Der Directeur de Cabinet charakterisierte nach Jahrzehnten seine Mitarbeiter als ,junge Berater, dreiundzwanzig oder vierundzwanzig Jahre alt, die sich mit dem Feuer ihrer Jugend auf das aufregende Unternehmen, das die Demokratisierung Deutschlands darstellte, einließen"108. Auch Claude de Kémoularia befand sich schon 1944 im Innenministerium im Umfeld von Emile Laffon, von wo aus er direkt nach Baden-Baden versetzt wurde; im Kabinett des Generalverwalters war er für das Pressewesen zuständig. Seine politischen Verbindungen reichten in die Umgebung von Paul Reynaud, dem ehemaligen französischen Ministerpräsidenten und Außenminister. Es bleibt anzumerken, daß kein Mitglied des Kabinetts - einschließlich des Generalverwalters - Germanist war oder wenigstens der deutschen Sprache mächtig gewesen wäre. Auch intime historische Einblicke in die südwestdeutschen Verhältnisse blieben den jungen, meist linksstehenden Offizieren verschlossen. Historische und stammesföderalistische Neugliederungspläne konnten somit in diesem Gremium auf keinen fruchtbaren Boden fallen.

War das Kabinett persönlich von Emile Laffon zusammengestellt worden, hatte der Generaladministrator jedoch keinen Einfluß auf die Auswahl der Abteilungsleiter. Der Directeur de la Délégation Générale pour les Affaires Administratives (DGAA), Maurice Sabatier, der seit 1940 an der Spitze der für die Departements und die Gemeinden zuständigen Verwaltungsstelle im Innenministerium unter Marschall Pétain gestanden und ab 1942 bis zur Befreiung als Präfekt in Bordeaux agiert hatte, war einer der unzähligen Vichy-Belasteten im französischen Militärregierungsapparat. „Unser Kabinett ignorierte im allgemeinen die Dienstebene des Directeur Général des Affaires Administrati-

105 Ebenda, S. 207.

106 Henri Navarre; 1936-40 Leiter der Abteilung Deutschland im Service de Renseignement; 194042 Leiter des $2^{\circ}$ Bureau von General Weygand, dann von General Juin; 1945 Führer einer Panzereinheit in Deutschland; 1945-48 Secrétaire général unter General Koenig in Baden-Baden; 1953 Commandant en Chef in Indochina; Navarre hat seine Memoiren veröffentlicht, seine Erinnerungen an die Jahre im besetzten Deutschland sind allerdings nur rudimentär; Ders., temps, besonders S. 195-213.

107 Grange, Laffon, S. 33.

108 Grimaud, Communication, S. 4. 
ves“, der „weder die Fähigkeit noch die Autorität“ zu diesem Amt besaß109, rechtfertigte Maurice Grimaud das praktizierte Übergehen des Dienstweges. Für die nachstehend aufgeführten Abteilungen der Baden-Badener Zentrale, insbesondere für die Direction de l'Education Publique und die Direction de l'Information, war Maurice Sabatier verantwortlich.

Die nachgeordnete Direction de l'Education Publique (DEP) unter der Leitung von Raymond Schmittlein ${ }^{10}$, der bereits im Juni und Juli 1945 vorbereitende Schritte zur Organisation der Dienststelle unternommen hatte, entwickelte rasch ihre eigene Dynamik. Gänzlich ohne schriftliche Direktiven ausgestattet, konnte Schmittlein „nach eigenem Gutdünken schalten und walten "11. Als seine Hauptaufgabe definierte Schmittlein die Umerziehung des deutschen Volkes ${ }^{112}$, wohl wissend, daß die Ziele der französischen Besatzung in Deutschland niemals deutlich bestimmt und innerhalb des Apparates weitgehend unbekannt waren. In den ersten beiden Jahren arbeiteten rund 65 Mitarbeiter überwiegend Germanisten - in der im Baden-Badener Hotel Stephanie untergebrachten DEP. Nur die engsten Mitarbeiter hatte Schmittlein selbst in Frankreich auswählen können, etwa Irène Giron, seine Stellvertreterin, und seinen Kabinettschef, den Archivar Robert Marquant.

Der Leiter der Direction de l'Information (DI), Jean Arnaud ${ }^{113}$, hatte eine präzise und analytisch begründete Auffassung von den Prinzipien der französischen Besatzung in Deutschland und dem eingesetzten Personal. Über die heterogene Zusammensetzung der Offiziere der Militärregierung in der ganzen Zone urteilte er im Sommer 1946 entschieden: „In der Zone, in Baden-Baden und den Provinzen, gibt es ein ziemlich eigenartiges Gemenge [mélange bétéroclite] an Offizieren, die nach der Eroberung geblieben sind, an Beamten, die ihre Karierre verfolgen, wie sie es auch in der Metropole oder in Nordafrika tun könnten, an Technikern, an Geschäftsleuten und an einer kleinen Zahl von Deutschlehrern." 114 Für die Umsetzung einer auf indirekter Verwaltung beruhenden französischen Politik sah Arnaud es als unerläßlich an, die Offiziere der Militärregierung verstärkt durch „Deutschlandkenner“ [connaisseurs de l'Allemagne] zu ersetzen, die mit Kultur und Geschichte der besetzten Gebiete vertraut waren. Denn das Ziel der französischen Besatzung war für Arnaud knapp und prägnant definiert: „Umerzie-

${ }^{109}$ Ebenda, S. 9.

110 Raymond Schmittlein (1904-1974), Mutter elsässischer Abstammung; Militärdienst u. a. in Marokko; Studium an der Sorbonne (Germanistik); Studienaufenthalt in Berlin, dort Heirat mit Gerda Eichholz; 1932 agrégé d'allemand; 1934 Professor in Kaunas (Litauen); 1938 Direktor des Institut Français in Riga (Lettland); 1940 Flucht nach Stockholm; in Kairo Anschluß an die FFI; 1942 im Auftrag de Gaulles in Moskau; 1943 im Kabinett de Gaulles in Algier als Attaché; 194445 Angehöriger der 2.D.I.M.; 1945-49 Directeur de l'Education Publique in Baden-Baden. Vgl. Heinemann, Hochschuloffiziere, 1991, passim; ausführlich: Zauner, Erziehung, 1994, passim.

111 Über die Gründungsphase der DEP vgl. Zauner, Erziehung, 1994, S. 66-70, hier S. 68.

112 Vgl. Schmittlein, Umerziehung, 1984. Als einleitende Bemerkung traf Schmittlein 1948 die Feststellung, daß die Ziele der französischen Besatzung in Deutschland niemals bestimmt worden seien; ebenda, S. 161 .

113 Jean Arnaud ("1910), Studium der Literaturwissenschaften in Lyon und Paris; 1935-38 Lektor an der Universität Köln; 1939 Stellvertretender Direktor des Maison Académique Française in Berlin; 1940-45 Stellvertretender Leiter des Französischen Instituts in Barcelona; 1945-47 Leiter der DI in Baden-Baden.

${ }^{114}$ Jean Arnaud: „Réflexions sur l'Occupation - Annexe au Rapport Mensuel du Mois de Juin 1946“ (masch. 3 S.); AdO HCFA Con. Pol. 196-III-0. 
hen im Sinne eines demokratischen und humanistischen Ideals“115. Dazu zählte für den Leiter der DI auch die ideelle Unterstützung von Intellektuellen und Vertretern föderalistischer Positionen. Am 16. Januar 1946 erteilte die DI daher der deutschen Presse die Anweisung, die Begriffe „Separatismus“ und „Separatist“ durch die Begriffe „Föderalismus" und „Föderalist" zu ersetzen ${ }^{116}$.

Der Wirtschafts- und Finanzdirektor in Baden-Baden, Jean Filippi, war neben Sabatier ebenfalls kein Wunschkandidat Laffons. Bis 1942 war Filippi Kabinettsdirektor des französischen Finanzministers Yves Bouthillier gewesen, um dann anläßlich eines von Ministerpräsident Pierre Laval angekündigten verschärften Kollaborationskurses zurückzutreten. Als Generalsekretär der französischen Eisenbahnen war er bei Kriegsende in seiner Heimat eine Persona non grata und wurde nach Baden-Baden beordert. In den Augen der französischen Kommunisten war Filippi ein Protagonist der Kollaboration $^{117}$, er selbst rechtfertigte seine Rolle im Vichy-Frankreich mit der Verteidigung französischer Interessen. Im besetzten Deutschland galt es ihm als recht und billig, das dortige Wirtschaftspotential für den Wiederaufbau Frankreichs einzusetzen.

\section{Die Verbindungsstellen in Paris}

Das Comité Interministériel des Affaires Allemandes et Autrichiennes (CIAAA) war per Dekret am 7. Juli $1945^{118}$ ins Leben gerufen worden und befand sich organisatorisch in den Händen von Marcel Berthelot ${ }^{119}$, dem Secrétaire Général, der auch als Verfasser der "Directives pour notre action en Allemagne" vom 19. Juli 1945 gilt $^{120}$. Seine Aufgabe bestand in der Aufnahme und Pflege der Verbindung zwischen den französischen Oberkommandierenden in Deutschland und Österreich und den Ministerien in Paris. Das Generalsekretariat - Secrétariat Général aux Affaires Allemandes et Autrichiennes (SGAAA) - regelte nicht selbständig anfallende Probleme, sondern es hatte zu koordinieren ${ }^{121}$. Vor allem war es als die einzige Anlaufstelle für die beiden Oberkommandierenden gedacht, da alle Korrespondenz in beide Richtungen über das SGAAA abgewikkelt werden mußte. Das CIAAA setzte sich aus sechs Ministern (Außen-, Wirtschafts-, Wiederaufbau-, Kriegs-, Transport- und Industrieproduktionsminister) unter dem Vorsitz des Chefs des Gouvernement Provisoire, de Gaulle, zusammen. Mit beratender Stimme waren bei den Sitzungen des CIAAA die beiden Oberkommandierenden, der Chef der EMDN und der Generalsekretär der Regierung anwesend. Das CIAAA verlor aber bis März 1946 zunehmend an Gewicht ${ }^{122}$. Eine Stelle, die ebenfalls koordinierend zwischen Provisorischer Regierung und Baden-Baden bzw. Wien fungieren sollte, wurde in Form des Generalkommissariats für die deutschen und österreichischen Ange-

\footnotetext{
115 Ebenda.

116 Direction, Directives, S. 19.

117 Zu Filippi vgl. ferner: Hudemann, Sozialpolitik, S. 7.

118 "Décret $N^{\circ}$ 45-1654 du 7 Juillet 1945 portant création d'un comité interministériel pour les affaires allemandes et autrichiennes“; MAE Y-Int. 1944-1949650.

119 Lattard, Gewerkschaften, S. 18.

${ }^{120}$ Deutschlandpolitik, 1987, S. 147. Zu den Direktiven vgl. Anmerkung 169.

121 "Règlement intérieur du Secrétariat Général des Affaires Allemandes et Autrichiennes“, de Gaulle vom 13. 8. 1945; MAE Y-Int. 1944-1949650.

122 Hudemann, De Gaulle, S. 154.
} 
legenheiten - Commissariat Général aux Affaires Allemandes et Autrichiennes (CGAAA) - dem CIAAA im Dezember 1945 zur Seite gestellt. Diese Dienststelle hatte die Aufgabe, insbesondere den Kommunikationsfluß zwischen Paris und Baden-Baden aufrechtzuhalten. Das CGAAA ist also nicht Nachfolgeorganisation des CIAAA ${ }^{123}$, sondern beide Gremien bestanden nebeneinander. Der Commissaire Général hatte weitgehende Vollmachten: Laut Ausführungsbestimmungen des Gründungsdekrets sollte er die französische Verwaltung in Deutschland und Österreich lenken und kontrollieren. Zum ersten Commissaire Général wurde am 26. Dezember 1945 René Mayer ernannt ${ }^{124}$; der ehemalige Minister unternahm sogleich eine Reise ins besetzte Deutschland, die ihn nach Saarbrücken, Baden-Baden und Berlin führte ${ }^{125}$. Er bekleidete das Amt bis zum 13. Juli 1946 ${ }^{126}$. Nach Mayers Ausscheiden wurde die Stelle im August 1946 in SGAAA umbenannt, eine Bezeichnung, die zuvor nur für das direkte Umfeld des Generalsekretärs in Gebrauch war, und wurde mit dem Unterstaatssekretär Pierre Schneiter besetzt $^{127}$. Nacheinander leiteten Alain Savary, Michel Debré und Alain Poher das Generalsekretariat (SGAAA) ${ }^{128}$. Das SGAAA wurde im November 1947 in Secrétariat d'Etat aux Affaires Allemandes et Autrichiennes (SEAAA) umgetauft. Diese Benennung verschwand schon im Laufe des Jahres 1948 wieder ${ }^{129}$. Der andauernde Wechsel der Bezeichnungen, gepaart mit Abgrenzungen und Abänderungen der Kompetenzen, kennzeichnet die Konzeptlosigkeit und mangelnde Koordination auch auf der Pariser Ebene und ist ein deutlicher Beleg für den ineffizienten Kommunikationsfluß zwischen der französischen Hauptstadt und Baden-Baden.

\section{Das Außenministerium}

Als Vorsitzender des Conseil National de la Résistance (CNR) hatte Georges Bidault ${ }^{130}$ am 9. September 1944 das französische Außenministerium übernommen. Mit dessen Nominierung beabsichtigte de Gaulle, den wichtigsten Repräsentanten des Widerstands

${ }^{123}$ Das CGAAA ist nicht Nachfolgegremium des CIAAA; vgl. Hüser, Frankreich, S. 54. Laut Dekret $\mathrm{N}^{\circ}$ 45-0141 vom 26. 12. 1945, durch welches das CGAAA gegründet wurde, bestand das CIAAA - etwas vergrößert - weiter. Vgl. hierzu Artikel 3: „Le Comité interministériel des affaires allemandes et autrichiennes est présidé par le Président du Gouvernement Provisoire de la République française. Il comprends neuf membres: [...].“ Neu hinzugekommen waren der Finanzminister, der Landwirtschaftsminister und der Commissaire Général (CGAAA); MAE YInt. 1944-1949653.

124 „Décret $N^{\circ} 45-0141$ du 26 Décembre 1945, portant création du Commissariat Général aux affaires allemandes et autrichiennes et réorganisation du comité interministériel des affaires allemandes et autrichiennes"; MAE Y-Int. 1944-1949 653.

${ }_{125}$ Poidevin, politique, S. 233.

${ }^{126}$ Zur Person des ersten Generalkommissars vgl. Poidevin, Mayer, besonders S. 74.

127 Ebenda, S. 78.

${ }^{128}$ Mombert, église, S. 21.

${ }^{129}$ Lattard, Zielkonflikte, S. 3.

${ }^{130}$ Georges Bidault (1899-1983), Jesuiten-Kolleg in Turin; Studium der Geschichte und Geographie; Geschichtslehrer; 1936-39 Journalist der christlich-demokratischen Zeitung L'Aube; 1940 deutsche Kriegsgefangenschaft; 1943 Präsident des CNR; 1944 Mitbegründer und Vorsitzender (1949-51) des MRP; französischer Außenminister (1944-46, 1947-48 und 1953-54) und Ministerpräsident (1946 und 1949-50); 1962 Mitglied des Exekutivkomitees der OAS; 1962-68 Exil in Brasilien und Belgien; 1968 Rückkehr nach Paris. 
auf die Außenpolitik zu fixieren, um innenpolitisch freie Hand zu haben. Bidault löste René Massigli im Außenministerium ab, der als Botschafter nach London ging und der ihm nach eigenen Angaben ${ }^{131}$ nur einen Kabinettsdirektor und einen Chiffrierbeamten hinterließ. Die Archive befanden sich noch in Algier, sie kehrten erst nach und nach in den Quai d'Orsay zurück, Teile waren auch unwiederbringlich verloren. Das Außenministerium in seiner vollen Funktionsfähigkeit wiederaufzubauen, beanspruchte mindestens mehrere Monate, wenn nicht Jahre. Die Außenpolitik Frankreichs lag bis Juli 1948 - von einem kurzen Zwischenspiel Léon Blums ${ }^{132}$ Ende 1946 abgesehen - in den Händen Bidaults, der weitgehend mit der Deutschlandpolitik de Gaulles übereinstimmte.

Georges Bidault, Geschichtsprofessor und geprägt von der Ideologie der deutsch-französischen Erbfeindschaft ${ }^{133}$, war derjenige Politiker des MRP, der die Deutschlandpolitik de Gaulles nach außen umsetzte ${ }^{134}$. Trotzdem darf Bidault nicht ausschließlich als Handlanger de Gaulles gelten. Vertrat der Provisorische Regierungschef eine Politik der Wiederherstellung der französischen grandeur, kümmerte sich Bidault um die wirtschaftliche Reorganisation Frankreichs durch Nutzung des deutschen Potentials ${ }^{135}$. Die Zukunft Deutschlands war für den französischen Außenminister in Form eines Staatenbundes möglich, wobei er keinen Zweifel an der Wiederherstellung der süddeutschen Länder ließ. Seine Bemühungen, auf diplomatischem Weg den Amerikanern den Tausch von Südwürttemberg gegen Nordbaden schmackhaft zu machen, belegen den Stellenwert, den Bidault den Ländern Württemberg und Baden im deutschen Südwesten beimaß. Die Deutschlandpolitik Bidaults insgesamt, wie er sie auch auf den Nachkriegskonferenzen vertreten hat, wurde 1945/46 durch die öffentliche Meinung in Frankreich weitgehend gestützt ${ }^{136}$.

Vor allem die Spitzenpositionen des Quai d'Orsay waren mit langjährigen Parteigängern de Gaulles besetzt worden ${ }^{137}$, die auf die französische Außen- und Deutschlandpolitik geschickt Einfluß nahmen. Mehrere Abteilungen des französischen Außenministeriums beschäftigten sich mit der Deutschlandpolitik. Der Secrétaire Général, Jean Chauvel ${ }^{138}$, bekleidete die wichtigste Position im Verwaltungsapparat des Quai d'Orsay. Als Berater von Bidault liefen bei ihm die Fäden der Hauptabteilungen zusammen ${ }^{139}$. Gemeinsam mit Hervé Alphand, dem Leiter der Hauptabteilung Wirtschaft, war Chauvel federführend für die Deutschlandpolitik zuständig. Seine Hoffnungen galten der Rückbesinnung der Deutschen auf deren vorwilhelminische, staatenbündische Traditionen ${ }^{140}$. Selbst eine Zweiteilung in einen norddeutschen, protestantischen und einen süddeutschen, katholischen Staatenblock, sowie die Abtrennung des Saarlandes und des Rheinlandes und die Internationalisierung der Ruhr schienen als Lösung der deutschen Frage akzeptabel ${ }^{141}$. Die Pläne Chauvels können als Reaktionen auf das kurzzeitig ins Leben

\footnotetext{
131 Bidault, Rebell, S. 85.

$132 \mathrm{Zu}$ Léon Blums Leben und Wirken nach 1945: Lacouture, Blum, S. 511-591.

133 Ziebura, Beziehungen, S. 45.

134 Pfetsch, Verfassungspolitik, S. 129.

135 Auf die bisher unterschätzte Eigenständigkeit Bidaults hat Schreiner, Bidault, S. 41 hingewiesen.

136 Cuttoli-Uhel, politique, S. 97.

137 Auerbach, Wende, S. 587.

138 Vgl. die Memoiren: Chauvel, Commentaire.

139 Gerbet, relèvement, S. 243.

140 „La renaissance des traditions régionales, étatiques et centrifuges, antérieures à l'empire Wilhelminien“; Chauvel, Commentaire, S. 108.

141 „Nous voulions le retour à une Allemagne divisée autant qu'elle pourrait l'être, avec un groupe-
} 
gerufene „Komitee zur Zerstückelung Deutschlands“142 im März 1945 gewertet werden. Informiert durch den amerikanischen Botschafter in Paris, Jefferson Caffery, hoffte man in der Stadt an der Seine einige Wochen lang, an der bereits wieder aufgelösten Einrichtung in London teilnehmen zu können ${ }^{143}$.

Das Außenministerium gliederte sich neben der Wirtschaftsabteilung in weitere drei Hauptabteilungen: Politik, Kultur und Verwaltung. Der Hauptabteilung für politische Angelegenheiten kam dabei ein besonderer Stellenwert $\mathrm{zu}^{144}$. In deren Zentrale fungierte Maurice Dejean ${ }^{145}$ als Directeur Général chargé des Affaires politiques. Bis Ende 1945 war Dejean auf jeder der wichtigen Nachkriegskonferenzen anwesend. Nach dessen Wechsel auf den Botschafterstuhl in Prag übernahm Maurice Couve de Murville die Leitung der politischen Abteilung im MAE; die Hauptabteilung für politische Angelegenheiten untergliederte sich in wiederum vier Unterabteilungen: Europa, Asien-Ozeanien, Afrika-Naher Osten und Amerika. Für Deutschland im speziellen war die Abteilung Mitteleuropa - als Teil der Unterabteilung Europa - am Quai d'Orsay zuständig, die seit spätestens 1948 von Pierre de Leusse geleitet wurde.

Ein weiterer Diplomat des französischen Außenministeriums machte sich unmittelbar nach 1945 Gedanken über den staatlichen Aufbau Deutschlands: André FrançoisPoncet ${ }^{146}$. Er postulierte 1946 im Vorwort eines Neugliederungsvorschlages von Paul Olagnier ${ }^{147}$ die vollkommene Dezentralisierung und die Schaffung dauerhafter und lebensfähiger deutscher Staaten. Eine Zollunion und ein schwacher Bundesrat mit streng begrenzten Befugnissen sollten die Klammer eines deutschen Staatenbundes sein. Im

ment d'Etats catholiques au sud faisant équilibre à un autre groupement, protestant, au nord"; ebenda, S. 109.

142 "Comité pour le démembrement de l'Allemagne“. Das „Zerstückelungskomitee“ hielt Anfang März 1945 tatsächlich zwei Sitzungen ab; Mosely, Dismemberment, S. 492 ff. Mosely hielt zwei Versionen der Kapitulationsurkunde im EAC in London bereit: eine mit und eine ohne das Wort „dismemberment"; ebenda, S. 495.

${ }^{143}$ Das Dossier MAE Y-Int. 1944-1949 Dejean 691 gibt den hektischen Telegrammwechsel zwischen Moskau, Washington, Paris und London wieder. Der französische Botschafter in London, René Massigli, recherchierte ausgiebig, trug letztlich aber bereits zu den Akten gelegte Fakten zusammen; Massigli an Bidault vom 14. 4. 1945; ebenda.

144 Gerbet, relèvement, S. 245.

145 Maurice Dejean (1899-?), 1918-20 Studium in Paris; 1921-22 Militärdienst als Übersetzer in Saarbrücken und im Rheinland, 1923-30 Berater für deutsche Angelegenheiten im Kriegsministerium; Diplomatische Laufbahn; Conseiller Diplomatique beim CFLN; Directeur Général chargé des Affaires politiques im MAE bis November 1945, 1945-49 Botschafter in Prag, im Fernen Osten (1950-54) und in Moskau (1955-64).

${ }^{146}$ André François-Poncet (1887-1978), Germanist; 1924-31 Abgeordneter in der Nationalversammlung; 1928-31 Unterstaatssekretär; 1931-38 Botschafter in Berlin; 1938-40 Botschafter in Rom; 1940-43 Mitglied des Nationalrats; Deportation und Internierung; 1948 diplomatischer Berater und Beauftragter bei Pierre Koenig in Baden-Baden; 1949-53 Hochkommissar in Deutschland; 1953-55 Botschafter in Bonn.

${ }_{147}$ Olagnier unternahm den Versuch, eine Dreiteilung Deutschlands nach sogenannten Kultureinflußgebieten vorzunehmen: Das "romanische Deutschland“ sollte Bewohner der Pfalz, des Rheinlandes, Rheinhessens, Badens, Württembergs, Bayerns und „Donau-Österreichs" umfassen, da diese geistig romanisiert seien; das "germanische Deutschland“ - niemals Teil des Römischen Reiches - sollte aus Hannover, Mecklenburg, Braunschweig, Brandenburg, SchleswigHolstein und Sachsen zusammengesetzt sein. Schließlich das "slawische Deutschland“, bestehend aus Pommern und den Ostgebieten. Aus den Teilen sollten drei autonome Staaten geformt werden; Olagnier, Allemagnes. 
Zuge der Südweststaatsauseinandersetzung machte sich François-Poncet für den Erhalt des Landes Baden stark, womit er in der Tradition der französischen Föderalismusvorstellungen verharrte.

\section{Die Provisorische Regierung}

Mit Wirkung vom 3. Juni 1944 gab sich das Comité Français de Libération Nationale (CFLN) den Titel „Gouvernement provisoire de la République française“ (GPRF); nach einem Besuch de Gaulles bei Präsident Roosevelt vom 6. bis 11. Juli 1944 nahm die amerikanische Regierung am 13. Juli Abschied von dem Plan, eine Militärregierung für Frankreich zu installieren, und erkannte das CFLN - und damit das GPRF - als befähigt an, die Verwaltung Frankreichs zu versehen ${ }^{148}$. Die endgültige und offizielle Bestätigung durch die „Großen Drei“ erfolgte am 23. Oktober 1944, knapp zwei Monate nach dem triumphalen Einzug de Gaulles in Paris. 468 Tage sollte die Amtsdauer der Provisorischen Regierung, die von de Gaulle dominiert war, andauern. Der frühzeitigen Anerkennung der Regierung des Generals bei den Alliierten folgte eine in drei Etappen zu gliedernde Periode ${ }^{149}$ : im Herbst 1944 die zweimonatige Auftaktphase mit Durchsetzung des Gouvernement Provisoire, eine einjährige, fast unumschränkte Herrschaft der Provisorischen Regierung und schließlich die Auseinandersetzung de Gaulles mit der ersten gewählten Constituante, die im Winter 1945/46 zu seinem Rücktritt führte. Die Periode unter dem Provisorischen Regierungschef de Gaulle wurde als die Phase der Illusionen zutreffend interpretiert ${ }^{150}$. Nach den Wahlen zur Verfassunggebenden Nationalversammlung im November 1945 blieb der General nur noch 57 Tage an der Macht.

Die chaotischen Zustände, die innerhalb der FBZ während des ganzen Jahres 1945 herrschten, blieben in Frankreich nicht unbekannt. Am 31. Januar 1946 machte sich ein sechsunddreißigköpfiger Parlamentarischer Untersuchungsausschuß der Nationalversammlung auf den Weg nach Deutschland. Präsidiert vom Deutschlandexperten und Vorstandsmitglied der französischen Sozialisten, Salomon Grumbach, deckten die Parlamentarier etliche gravierende Mißstände auf. In Form eines Rapports lag der Bericht im Frühjahr 1946 der Nationalversammlung vor ${ }^{151}$. Die Zielrichtung der Kritik ging gegen die verantwortlichen Pariser Politiker, den Verwaltungsapparat in der FBZ und die Vergangenheit vieler Besatzungsoffiziere ${ }^{152}$. Einstimmig beklagte die Untersuchungskommission die Kalamitäten. Sie monierte die schwierige Dualität, die zwischen Besatzungstruppen und Militärverwaltung bestünde, die Überfülle an zivilem und militärischem Personal bei gleichzeitiger Vernachlässigung der personellen Ausstattung der Kreisdelegationen und die Anwesenheit einer großen Zahl von ehemaligen Vichy-Anhängern sowohl innerhalb der Militärregierung als auch in den Einheiten der Armee.

148 Gerbet, relèvement, S. 20.

${ }^{149}$ Lipgens, Bedingungen, S. 70 f.

150 In einem längerfristigen Zusammenhang unterscheidet Raymond Poidevin drei Phasen der französischen Deutschlandpolitik: 1. Phase der Ungewißheit (Herbst 1943-Sommer 1944), 2. Phase der Illusionen (Sommer 1944 - Januar 1946), 3. Zeit der Enttäuschungen (Anfang 1946 - Herbst 1949); Ders., Deutschlandpolitik, S. 15-25.

151 Der Rapport der Parlamentarischen Untersuchungskommission liegt gedruckt vor: Assemblée Nationale Constituante Année 1946, Documents, Annexe N 959; AdO SGAAA c. 2704.

$152 \mathrm{Zu}$ dem Untersuchungsbericht und dessen Forderungen vgl. Henke, Aspekte, S. 184 f. 
Des weiteren vertrat die Untersuchungskommission die Ansicht, daß die Vorherrschaft der zivilen Verwaltung derart lange nach Abschluß der Kampfhandlungen endlich hergestellt werden müsse. Die Militärregierung solle von nun an die indirekte Kontrolle der Verwaltung übernehmen und die Deutschen mit Aufgaben betrauen.

Doch die Kritik ging noch tiefer, sie richtete sich unmittelbar an Paris. Das gänzliche Fehlen zusammenhängender Direktiven aus der Hauptstadt seit Mai 1945 wurde ebenso bitter beklagt wie die nichtexistenten wirtschaftlichen Planungen für die Zone. Das eigenmächtige Agieren der Oberdelegierten, die ohne Koordination und Verbindung handelten und keine übergeordnete Autorität wahrnähmen, gekoppelt mit einer unglaublichen Langsamkeit der Nachrichtenübermittlung, bildete den Schlußpunkt der Kritik der Parlamentarier. Wie sollten nach Ansicht der Untersuchungskommission die vorgetragenen Mißstände behoben werden? Das Konzept, das die Lösung der Probleme zu versprechen schien, hieß indirekte Verwaltung. Die Provisorische Regierung wurde deshalb in einer Resolution aufgerufen, ein Ministerium für die besetzten Gebiete in Deutschland und Österreich zu errichten, materiell besser ausgestattete Truppen einzusetzen, die Kompetenzstreitigkeiten zugunsten der Militärregierung zu entscheiden, die Koordination zwischen den einzelnen Hierarchien sicherzustellen und die Verwaltung samt Armee in den besetzten Gebieten von Vichy-Belasteten zu säubern. Der Forderungskatalog ging aber noch weiter und umfaßte die Übergabe der direkten Verwaltung in deutsche Hand, die Beschleunigung der Entnazifizierung insbesondere auf wirtschaftlicher Ebene, die Ausarbeitung eines Produktionsplanes für Industrie und Landwirtschaft, die Erleichterung des Einsatzes von Mitarbeitern des Unterrichtsministeriums für Kontrollaufgaben sowie die Übersendung klarer Anweisungen nach Baden-Baden mit dem Ziel, den Wiederaufbau und das Wirken von Gewerkschaften und politischen Parteien zu genehmigen.

Die Kritik an den Zuständen war niederschmetternd, die aktuellen Mißstände wurden schonungslos ausgebreitet. Doch Kritik und Resolution blieben ohne nennenswerte Konsequenzen. Resigniert mußte Grumbach Mitte 1947 vor der Nationalversammlung feststellen, daß sich die Hoffnungen, die man in die Resolution gesteckt habe, als nichtig erwiesen hätten. Auf die Funktionsfähigkeit des französischen Militärregierungsapparates für die unmittelbaren Jahre nach 1945 wirft diese Feststellung kein gutes Licht.

\section{De Gaulle und die französische Deutschlandpolitik}

Die französische Besatzungspolitik ist strikt von der Deutschlandpolitik Frankreichs zu trennen. Letztere ist gekennzeichnet durch das Spannungsverhältnis von Zentralismus und Dezentralisierung, von einem ständigen Zurückstecken und von einer Reihe von Enttäuschungen; sie ist bis 1946 eng an die Vorstellungen von General de Gaulle geknüpft. Die Pariser Deutschlandpolitik gab eine weitgehende Dezentralisierung als politische Zielsetzung aus, die Besatzungspolitik mußte jedoch eine straffe Kontrolle der Zone anstreben, um wirtschaftlichen Vorgaben gerecht zu werden ${ }^{153}$. Dies war der Aus-

${ }^{153}$ Zum Spannungsverhältnis von Zentralismus und Dezentralisation vgl. Hudemann, Zentralismus, S. 192. 
gangspunkt für eine zentrale französische Verwaltung im besetzten Deutschland und war mitverantwortlich für das Scheitern von Dezentralisationsplänen für die Zonenverwaltung.

Zwei Standpunkte waren in den Jahren der deutschen Besatzung herangereift, die unterschiedlichen Wurzeln entsprangen. Sollte Frankreich auf die Schaffung einer Vormachtstellung in Europa unter Ausnutzung des deutschen Potentials abzielen, also Deutschland dominieren, oder sollte es vielmehr alles daransetzen, die deutsche Gesellschaft zu demokratisieren und Deutschland in eine supranationale Organisation zu integrieren? Über den Rücktritt des Generals hinaus bildete das Dominanzkonzept Grundlage der offiziellen französischen Deutschlandpolitik. Prinzipiell stellten sich jedoch beide Positionen, das Dominanz- wie das Integrationsmodell, in der französischen Bevölkerung als mehrheitsfähig dar ${ }^{154}$. Meinungsumfragen vom Sommer 1945 ermittelten eine überwältigende Mehrheit von 78 Prozent der Franzosen, die sich für die Zerstückelung und damit für das Dominanzmodell aussprachen. Gleichzeitig erachteten 73 Prozent der Befragten eine Europäische Föderation für wünschenswert. Entscheidend war deshalb, inwieweit das Gouvernement Provisoire die widersprüchlichen Empfindungen in die eine oder in die andere Richtung lenken konnte.

Indes bestanden über die deutschlandpolitischen Vorstellungen de Gaulles keine Zweifel. Der General verstand es, seine Ideen in offizielle französische Politik umzusetzen. Das Dominanzkonzept, das die Separierung von Rheinland, Ruhr und Saar bei gleichzeitiger Dezentralisierung der übrigen Reichsteile vorsah, beinhaltete auch die Nutzbarmachung des deutschen Wirtschaftspotentials zur Errichtung und Durchsetzung der französischen Vormachtstellung. Die Umsetzung seiner Positionen gestaltete sich nicht leicht. Geschickt war es de Gaulle freilich gelungen, die Kräfte der Résistance mit ihren Integrationsmodellen in die zweite Reihe zu drängen und mittels cäsaristischer Herrschaftstechniken sich zum Sprecher des „befreiten Frankreichs“ aufzuschwingen. Als Kontrollinstanz fungierte nur die öffentliche Meinung, die sich zudem durch die Beschwörung der grandeur des ewigen Frankreichs geschmeichelt fühlte und von der scheinbar wiedererlangten Größe angetan war. Die französische Bevölkerung übersah die Diskrepanz zwischen dem von de Gaulle aufgebauten Großmachtanspruch und der aktuellen Schwäche des eigenen Landes. Das Dominanzkonzept fand dadurch ab Sommer 1944 eine immer größer werdende Verbreitung und avancierte zum nach außen sichtbaren Mehrheitskonzept. Die verfolgte Deutschlandpolitik genoß allgemeine Akzeptanz und änderte sich auch im Januar 1946 mit dem Rücktritt de Gaulles nicht, sondern wurde noch geraume Zeit weiterbetrieben. Der langjährige Außenminister Bidault hatte längst die wesentlichen Positionen seines Regierungschefs übernommen, auch wenn er sich später daran nicht mehr erinnern wollte ${ }^{155}$. In Bidault fand de Gaulles Politik die geradlinige Fortsetzung ${ }^{156}$. Erst im Frühjahr 1947, als Frankreich immer mehr in den Sog der amerikanischen Hegemonialpolitik geraten war und der Ost-West-Konflikt

\footnotetext{
${ }^{154} \mathrm{Zu}$ den beiden von Wilfried Loth eingeführten Begriffen vgl. Ders., Franzosen, S. 32.

155 Die Memoiren Georges Bidaults (Ders., Rebell) sind ein anschauliches Beispiel für die Übertragung späterer politischer Anschauungen auf frühere Jahre. Bidault suggeriert dem Leser, er hätte schon nach 1945 die anachronistischen Züge der Politik de Gaulles erkannt. Die Quellen sprechen allerdings eine andere Sprache.

${ }_{156}$ Vgl. auch das Unterkapitel zum französischen Außenministerium und der Rolle Bidaults.
} 
mit dem Scheitern der Moskauer Außenministerkonferenz deutlich hervortrat, brach die am Dominanzmodell orientierte französische Deutschlandpolitik zusammen ${ }^{157}$.

Das Deutschlandbild de Gaulles war tief beeinflußt von der nationalen Rechten, insbesondere von den Vorstellungen Jacques Bainvilles ${ }^{158}$, der mit seinem Buch „Histoire de deux peuples. La France et l'empire allemand", das zu Beginn des Ersten Weltkrieges erschienen war, die Sichtweise mehr als einer Generation entscheidend geprägt hatte. 1933 um das Kapitel „continuée jusqu'à Hitler" erweitert, erlebte die Schrift eine Unzahl von Auflagen. Auch im nationalsozialistischen Deutschland wurde das Buch mit hoher Auflage verbreitet, da die Absichten Frankreichs prägnant formuliert schienen und es sich somit zur Rechtfertigung der deutschen Kriegsziele als tauglich erwies ${ }^{159}$. Bainville propagierte den Westfälischen Frieden als Orientierungspunkt aller weiteren Überlegungen bezüglich der Gestaltung des deutsch-französischen Verhältnisses. Nur der Zustand der Anarchie in Form der staatlichen Zersplitterung dünkte ihm als Garant für die Sicherheit Frankreichs ${ }^{160}$. Preußen müsse zerstört werden, es sei die Klammer, die Deutschland zusammenhalte. Deshalb hatte Bainville schon im Ersten Weltkrieg die Forderung nach Zersplitterung Deutschlands zum signifikanten Kriegsziel erhoben ${ }^{161}$.

Aber auch eine andere Figur der politischen Rechten hatte auf de Gaulle abgefärbt. Der Mitbegründer der Action Française (AF), Charles Maurras ${ }^{162}$, kämpfte publizistisch gegen Deutschland und stand mit der Forderung nach Zerschlagung Preußens ganz auf der Linie Bainvilles. Eine Lösung des deutschen Problems sah er in einer Rückkehr zu den „Deutschländern“, die der Westfälische Friede konstituiert hatte. Damals - so argumentierte er - konnte das Elsaß von Deutschland problemlos getrennt werden, 1918 wäre dies mit dem Rheinland möglich gewesen. Nach der Niederlage von 1940 behielt Maurras sein Feindbild bei. Dies hinderte ihn aber nicht daran, in standhafter Loyalität gegenüber Marschall Pétain den Weg der Kollaboration zu beschreiten. 1945 büßte Maurras sein Verhalten mit lebenslanger $\mathrm{Haft}^{163}$, aus der er jedoch schon 1948 entlassen wurde.

General de Gaulle hat die nationalistischen Gedanken schon in früher Jugend in sich aufgesogen, seine Deutschland betreffenden Konzepte speisten sich aus diesen Quellen, auch wenn er den monarchistischen und antirepublikanischen Ideen Maurras' und der AF später den Rücken kehrte ${ }^{164}$. Trotz des langen Weges von London nach Algier verlor

157 Ziebura, Beziehungen, S. 43.

158 Marcowitz, Grundzüge, S. 122.

159 Die Auflage des als Sonderdruck für die Abteilung Inland des Oberkommandos der Wehrmacht erschienenen Buches wird auf 120000 Exemplaren veranschlagt; Köhler, Preußen, S. 60.

${ }^{160}$ Das zweite Kapitel ist betitelt: „Les traités de Westphalie: l'anarchie allemande et la sécurité de la France garantie"; Bainville, histoire, S. 49-82.

161 Als Organ stand ihm die Action Française zur Verfügung. Zwischen Februar 1911 und November 1918 veröffentlichte er 82 Artikel zum Thema "Deutschland“, die 1939 posthum unter dem Titel: Bainville, Allemagne im Band I eines zweibändigen Sammelwerkes erschienen sind.

162 Charles Maurras (1868-1952), Antisemit; Mitbegründer der Action Française; 1935 Morddrohung an einen Abgeordneten der Deputiertenkammer; 1936-37 daher Inhaftierung Maurras'; 1940 enge Anlehnung an den „Etat Français“; 1945 Verurteilung zu lebenslanger Haft; $1948 \mathrm{Be}$ gnadigung.

${ }^{163} \mathrm{Zu}$ Maurras vgl. auch das Kapitel "Les grands procès“, insbesondere S. 470-480, in: Amouroux, page, S. 469-502.

${ }^{164}$ Lacouture, De Gaulle - Le rebelle, S. 173. 
de Gaulle seine deutschlandpolitischen Ziele nicht aus den Augen. Nach der Ausschaltung von General Henri-Honoré Giraud und Admiral François Darlan stand de Gaulle an der Spitze des CFLN in Algier. Von nun an war es nur noch ein kleiner Sprung, bis er sich ab Juni 1943 an der Spitze der französischen Exilregierung wiederfand, die sich knapp ein Jahr später zur Provisorischen Regierung Frankreichs formierte. Im Sommer 1944 stellte de Gaulle seine ersten Forderungen nach einer französischen Besatzungszone im besiegten Deutschland. Ausgangspunkt aller Überlegungen war das Axiom: plus de Reich centralisé165. Das deutschlandpolitische Konzept de Gaulles nährte sich aus der von der nationalistischen Rechten übernommenen Geschichtsphilosophie, die in den deutschen Aggressionen gegen Frankreich einen „germanischen Herrschaftswillen“ zu erkennen glaubte. Für de Gaulle bestand ein direkter Zusammenhang zwischen deutschem Zentralismus und Expansion, den zu vermeiden nur eine vage definierte Konföderation deutscher Einzelstaaten in der Lage sei ${ }^{166}$. Mit der Atomisierung Deutschlands postulierte de Gaulle die Schaffung eines Glacis an der französischen Ostgrenze: Die Ruhr sollte internationalisiert und die linksrheinischen Gebiete auf unbestimmte Zeit besetzt werden. Deshalb verlangte der Chef der Provisorischen Regierung eine territoriale Ausdehnung der französischen Zone, die das Saargebiet und den größten Teil der Rheinprovinz bis nördlich von Köln, zuzüglich ganz Baden, Hessen-Darmstadt und die ehemals nassauischen Gebiete nördlich von Frankfurt umfassen sollte ${ }^{167}$. Daran anschließend hätte sich eine militärische Sicherheitszone unter deutscher Souveränität bis in den Raum Kassel zu erstrecken, die allen Siegermächten zugänglich gewesen wäre. Der Umfang der territorialen Forderungen zur Umsetzung der Zielvorgaben wurde leicht modifiziert bis ins Frühjahr 1945 beibehalten. Das wichtigste Element der de Gaulleschen Deutschlandpolitik war damit schon vorweggenommen: Das Ruhrgebiet, das industrielle Herz Deutschlands, sollte einer internationalen Kontrolle unterstellt werden.

Der nächste, wesentliche Schritt zur Umsetzung dieser Politik war die Aufnahme Frankreichs in die Europäische Beratende Kommission (EAC) im November 1944. Obwohl durch das zweite Zonenprotokoll die Aufteilung Deutschlands in drei Besatzungszonen beschlossene Sache war, tröpfelten die Planungen der Provisorischen Regierung vor sich hin, das allgemeine Planungsdefizit war augenscheinlich ${ }^{168}$. Bis zur Konferenz von Jalta blieb eine Teilnahme Frankreichs an der Besatzung mit ernsten Zweifeln behaftet. Die Unterstützung der französischen Wünsche durch Churchill war gesichert, die Haltung von Roosevelt und Stalin aber enigmatisch. Die Reise de Gaulles in die Sowjetunion im Dezember 1944 diente nicht zuletzt dazu, Stalin für die Forderungen nach einer Besatzungszone zu gewinnen. Die Krimkonferenz hat dann auch ohne die Teil-

165 General Pierre Lassalle erinnerte sich daran: „Refus avant tout d'un Reich centralisé“; Lassalle, Note, S. 227. Für das Zitat vgl. de Gaulle, Salut, S. 46.

166 Ziebura, Beziehungen, S. 35.

${ }^{167}$ Krautkrämer, Rhénanieprojekt, S. 71. Dort auch eine Skizze der von de Gaulle vorgeschlagenen Besatzungszone; ebenda, S. 70. Es sticht ins Auge, daß de Gaulle sich im Südwesten mit dem Land Baden begnügte und keine Ansprüche auf Württemberg und Hohenzollern anmeldete. Hier ist eine Grundforderung der französischen Politik im Südwesten zu erkennen: Baden als Staat bildete einen Eckpfeiler der französischen, auf Dezentralisierung ausgerichteten Deutschlandpolitik und sollte daher im Ganzen besetzt werden.

${ }^{168}$ Hudemann, Besatzungsmächte, S. 22. 
nahme Frankreichs den gewünschten Erfolg gezeitigt; zögernd gaben Roosevelt und Stalin dem Drängen Churchills nach, und es wurde vereinbart, eine französische Zone aus den beiden Westzonen herauszuschneiden. Die Umsetzung der Vorgabe wurde an die EAC in London delegiert.

Die Planungen für die französische Besatzungspolitik wurden erst nach endgültiger Festlegung der Zonengrenzen Anfang Juli 1945 abgeschlossen. Bis dahin verblieben selbst die höchsten französischen Offiziere in Deutschland ohne offizielle Leitlinien oder Direktiven. Im Pariser Comité interministériel entstanden unter dem Vorsitz de Gaulles um den 19. Juli 1945 drei Geheimdirektiven. Die Dokumente $N^{\circ} 1$ „Directives pour notre action en Allemagne“, $\mathrm{N}^{\circ} 2$ "Directives pour notre action en Autriche" und $\mathrm{N}^{\circ} 3$ „Note sur le probleme allemand" ${ }^{169}$ bildeten die theoretische Grundlage der von Paris vorgegebenen französischen Besatzungspolitik. Sie sind Ausdruck der Zersplitterungspolitik General de Gaulles, die von einer absoluten Priorität der Sicherheitsfrage beherrscht war.

„Das Problem des Separatismus muß aufmerksam beobachtet werden, aber wir sollten zu keinen fruchtlosen Versuchen auffordern ${ }^{\alpha 170}$, das war die Zielvorgabe des ersten Dokuments im Hinblick auf den Fehlschlag des rheinischen Separatismus der zwanziger Jahre. Die Stützung von Autonomismus und Partikularismus in Südwestdeutschland konnte für de Gaulle nur auf der Grundlage der historisch gewachsenen Länder Baden und Württemberg erfolgen, eine andere Möglichkeit nahm er nicht wahr. Eine Gliederung Deutschlands nach den Stämmen bewegte sich jenseits der Vorstellungskraft des Generals. In der ersten Direktive kam de Gaulle zu dem Schluß, daß die Französische Besatzungszone in fünf Verwaltungseinheiten ${ }^{171}$ aufzuteilen sei, darunter die Länder (Süd-)Baden und (Süd-)Württemberg-Hohenzollern. Insgesamt war von einer einheitlichen Verwaltung der FBZ keine Rede, für die einzelnen Regionen kam nur eine unterschiedliche Behandlung in Frage. „Tatsächlich bildet diese Zone weder vom politischen noch vom ethnischen Gesichtspunkt her eine Einheit [...]. Gleichzeitig kann man schwerlich eine Politik für den Süden Deutschlands entwerfen, der aus drei verschiedenen Stummeln [tronçons] - ohne die alten Hauptstädte - besteht und in denen keine konfessionelle Einheit anzutreffen ist." 172 Einhergehend mit dieser Einsicht verlieh der General der Hoffnung Ausdruck, eines Tages „eine kompaktere und zusammenhängendere Zone" zu erhalten. Damit war im Südwesten der Tausch des ungeliebten (Süd-)Württemberg-Hohenzollern gegen (Nord-)Baden gemeint. Vorerst mußte aber für jede der fünf Verwaltungseinheiten eine eigene Politik entwickelt werden, um geschmeidig genug auf eine erhoffte Revision der Zonengrenzen antworten zu können. An dieser Haltung sollten letztlich die süddeutschen Konföderationspläne im Umfeld von Pierre Koenig scheitern.

${ }^{169}$ Die Dokumente $\mathrm{N}^{\circ} 1$ und $\mathrm{N}^{\circ} 3$ sind publiziert in: Ménudier, Allemagne, S. 169-182. Sie sind in verschiedenen Beständen im MAE archiviert; MAE Y-Int. 1944-1949650 sowie Y-Int. 19441949 433. Das Dokument N' 2 ist publiziert in: Klöckler, Quellen, S. 9-12.

170 „Directives pour notre action en Allemagne“; MAE Y-Int. 1944-1949650.

${ }_{171}$ Die Regionen sind a) der bayerische Landkreis Lindau, der Süden von Württemberg und „das Land Hohenzollern“ b) das Land Baden c) „die Saarregion“ d) die Pfalz und e) „der Teil des Rheinlandes, der Zugang hat zur Mosel mit den Städten Koblenz und Trier"; ebenda.

172 "Note sur le problème allemand“; MAE Y-Int. 1944-1949 650. 
Wenige Tage später, Ende Juli 1945, wurde unter Leitung de Gaulles ein weiteres Papier zur Deutschlandpolitik erarbeitet ${ }^{173}$. Die Singularität der Situation im besetzten Deutschland erkennend, legte Paris darin zwei französische Optionen dar: Annexionen oder die Gründung von deutschen Satellitenstaaten; "wir werden das zweite Rezept [d. h. die Gründung von Satelliten] ins Auge fassen, das für den gegenwärtigen Zustand der internationalen Beziehungen geeignet scheint. Es ist [deshalb] absolut zwingend und dringend notwendig, eine französische Deutschlandpolitik zu bestimmen und eine Respektierung der vereinbarten Richtlinien durch das Besatzungspersonal zu fordern. " 174 Das konnte für den Südwesten nur die französischen Ambitionen auf die Besetzung ganz Badens bedeuten; Mutmaßungen in der historischen Forschung über ein von de Gaulle geplantes "katholisches Reich à la Charlemagne“ dürfen dagegen in den Bereich der Legenden verwiesen werden ${ }^{175}$.

Im Westen glaubte de Gaulle, ein unabhängiges Rheinland und Ruhrgebiet schaffen zu können, für die rechtsrheinischen Gebiete sah er eine enge Anlehnung an Frankreich vor. Das Bild des Rheins als „Arterie“ - als liens occidental - war eine Grundmetapher der Deutschlandpolitik, auf die de Gaulle nicht nur in seiner Rede vom 5. Oktober 1945 in Straßburg hinwies. Überhaupt hatte die Deutschlandreise de Gaulles im Oktober 1945 große Resonanz gefunden. In Baden-Baden führte er seine Politik näher aus: es sei Ziel der französischen Politik, „d'installer la France ici ${ }^{{ }^{176}}$. De Gaulle beanspruchte die Verfügungsgewalt über die Territorien, die er als „natürliche Erweiterung“ Frankreichs ansah, konkret die linksrheinischen Gebiete. Baden sollte eng an Frankreich gebunden werden, da die intellektuellen und wirtschaftlichen Bande in der Vergangenheit ausgeprägt gewesen seien. In bezug auf Württemberg sei eine ähnliche Entwicklung möglich. Er sprach des weiteren von Karlsruhe, das Frankreich eines Tages wieder unter seine „Fuchtel“ ${ }^{177}$ nehmen werde. Auch hier zeigte sich die Hoffnung de Gaulles, durch eine Umgestaltung der französischen Zone ganz Baden unter die eigene Besatzung zu bekommen.

\section{Der Einfluß französischer Germanisten}

Die beiden französischen Germanisten Edmond Vermeil und Robert d'Harcourt bestimmten die deutschlandpolitische Nachkriegsdiskussion in Frankreich maßgeblich ${ }^{178}$.

173 „Note - Politique allemande“, Présidence du Gouvernement provisoire de la République française vom 31. 7. 1945; AdO CCFA Con. Pol. 196-III-0.

174 Ebenda.

${ }^{175}$ De Gaulle solle, so die Mutmaßungen Gerhard Hirschers, nach seinem Rücktritt im Januar 1946 als Privatmann an einem Plan gearbeitet haben, der das Elsaß, Lothringen, Bayern, das Saarland, Baden und Württemberg zu einer katholischen Konföderation zusammengefaßt hätte. Von diesen Plänen habe Carlo Schmid zur Zeit der Münchener Ministerpräsidentenkonferenz im Juni 1947 erfahren. Hirscher beruft sich bei den Angaben auf den amerikanischen Historiker Angus Munro. De Gaulle hätte allerdings niemals das Ausscheiden von Elsaß und Lothringen aus dem französischen Staatsverband gutgeheißen, geschweige denn Planungen in diese Richtung betrieben. Vgl. Hirscher, Schmid, S. 20 und Munro, Occupation, Bd. I, S. 97.

${ }^{176}$ Für den Wortlaut der Rede vom 5. Oktober 1945 in Baden-Baden vgl. de Gaulle, Lettres, S. 95-98.

177 „Et Karlsruhe que, un jour ou l'autre, nous reprendrons sous notre coupe “; ebenda, S. 97.

${ }^{178}$ Die folgenden Ausführungen zu Vermeil und d'Harcourt beziehen sich im wesentlichen auf die Forschungen von Hellmuth Auerbach; Ders., Que faire, S. 289-299. 
Robert d'Harcourt stammte aus einer der ältesten normannischen Adelsfamilien, seine katholische Prägung war unverkennbar. Als Professor am Institut Catbolique besaß er nach 1940 nur einen relativ beschränkten Wirkungskreis, dennoch fiel er der Verfolgung durch die Gestapo anheim. Seine Publikation Catholique d'Allemagne wurde konfisziert und eingestampft. Nach der Befreiung meldete er sich im Frühjahr 1945 mit dem Aufsatz "Comment traiter l'Allemagne" in der Zeitschrift Cabiers du Monde Nouveau zu Wort. Entgegen dem gewählten Titel erteilte d'Harcourt allerdings kaum Ratschläge über die Behandlung Deutschlands. Vielmehr beschäftigte er sich - wie auch in den folgenden Jahren - mit der deutschen Psyche, vor allem der Frage der Verdrängung der Schuld. Seine Publikationen sind zugleich Plattform für Stimmen des katholischen Nachkriegsdeutschlands gewesen: Theodor Haecker ${ }^{179}$, Romano Guardini, Reinhold Schneider und Walter Dirks zitierte er mit Freude und Zustimmung. Fragen der territorialen Neugestaltung beschäftigten Robert d'Harcourt eher am Rande.

Darüber machte sich jedoch Edmond Vermeil ${ }^{180}$ häufig Gedanken. Seit er sich 1943 nach London begeben hatte, um sich de Gaulle anzuschließen, avancierte er bald zum Deutschlandexperten, der in keinem einflußreichen Gremium fehlen durfte. Auf den reichen Schatz an Wissen, den sich Edmond Vermeil im Laufe eines Jahrzehnts auf seinem Straßburger Lehrstuhl erworben hatte, konnte die französische Exilregierung keinesfalls verzichten. Kurz vor der Aufnahme in die EAC hat Vermeil im Centre d'Etudes de Politique Etrangères in Paris ein umfangreiches Exposé181 erarbeitet, das seine Deutschland betreffenden Vorstellungen darlegte. Von einer Zerstückelung Deutschlands war darin keine Rede mehr, ein weitgehender Föderalismus sollte aber das Prinzip der staatlichen Reorganisation Deutschlands sein. In Preußen als Staat konstatierte Vermeil die Ursache des unheilvollen Weges, den Deutschland beschritten habe, weshalb es von der Landkarte verschwinden müsse ${ }^{182}$. Die déprussification stellte neben der Umerziehung die Leitidee der Überlegungen dar.

$\mathrm{Zu}$ Propagandazwecken und zur praktischen Umsetzung seiner Ziele hatte Vermeil den Vorsitz des „Comité d'Etudes pour les frontières de l'Est et le problème de l'Allemagne occidentale " übernommen. Der Generalsekretär des Komitees, Fernand l'Huillier, verbreitete die deutschlandpolitischen Ansichten mittels einer Informationsschrift, die den Titel Les Cabiers du Rhin trug. Er zeichnete gleichzeitig als Chefredakteur der Zeitschrift und war damit von höchstem politischen Interesse. Außenminister Bidault hatte den Wert der Publikation und insbesondere von l'Huillier erkannt und förderte beide

${ }_{179} \mathrm{Zu}$ Haecker und der Rolle seines Sohnes in der Alpenlandfrage vgl. Kapitel III/1.

${ }^{180}$ Edmond Vermeil (1878-1964) stammte aus einer kleinbürgerlichen, hugenottischen Familie der Languedoc; 1913 Promotion in Paris und Beginn einer akademischen Laufbahn; 1919-34 Ordinarius an der Universität Straßburg; nach 1940 von der Gestapo verfolgt; 1943 im Umfeld de Gaulles in London; galt als Deutschlandexperte und wirkte in den folgenden Jahren entscheidend an allen Fragen über die Behandlung des besetzten Deutschlands mit; zeitlebens galt Vermeil als bester französischer Deutschlandkenner.

181 Vermeil, Le problème allemand, 1945, S. 17-96. Zitiert nach Auerbach, Que faire, S. 299.

182 Vermeil galt zurecht als einer der schärfsten Kritiker des protestantischen Preußens; Merlio, germanistes, passim. Sein Antiborussianismus verband ihn mit den katholischen, süddeutschen Föderalisten. 
entsprechend ${ }^{183}$. Für eine bessere Ausstattung und Verbreitung der Cabiers $d u$ Rhin erhielt l'Huillier 1945 vom französischen Außenministerium einen Betrag von 200000 Francs; für das Jahr 1947 wurde noch einmal derselbe Betrag in Aussicht gestellt ${ }^{184}$.

Die ersten beiden Nummern erschienen unter dem Titel Le Rhin im Januar und Februar 1945. Neben Edmond Vermeil und Fernand l'Huillier zeichnete unter anderem Wladimir d'Ormesson als Mitglied des Komitees. Die Aufmachung und der Titel der Zeitschrift änderten sich bereits im März 1945. Les Cabiers $d u$ Rhin war der Nachfolgetitel, der auch nach neuer Zählung (nouvelle série) im Dezember 1945 beibehalten wurde. Im siebten Heft des dritten Jahrganges (Juli/August 1947) war die Ankündigung zu lesen, daß die Zeitschrift eingestellt, aber konzeptionell erneuert gegen Ende des Jahres wiedererscheinen würde. Tatsächlich wurde die Zeitschrift nicht fortgesetzt. Aber immerhin verfügte das französische Außenministerium rund zweieinhalb Jahre über ein Sprachrohr von großer Publikumswirksamkeit. In der Märzausgabe 1946 der Cabiers $d u$ Rhin machte sich Charles Harnist eigene Gedanken, wie das deutsche Problem zu lösen sei ${ }^{185}$. Deutschland unterteile sich in drei wirtschaftliche und ethnographische Regionen: die baltische Zone östlich der Elbe, den Donauraum und den atlantischen Teil, der von der Elbe bis zum Rhein reiche. Der „Rheinstaat“ solle die preußische Rheinprovinz, die Pfalz, Rheinhessen, Franken, Baden und Teile von Württemberg umfassen, die linksrheinischen Gebiete hätten eine Sicherheitszone zu bilden. Die Ruhr und die Braunkohlereviere Sachsens seien zu internationalisieren. Die weiteren deutschen Staaten sollten „Ostelbien“, „Sachsen“ und „Bayern-Österreich“ sein. Jede der vier Besatzungsmächte, so Harnist, werde das Protektorat über einen dieser Staaten zugesprochen bekommen, die Sowjetunion über „Ostelbien“, Großbritannien über „Sachsen“, die USA über „Bayern-Österreich“ und Frankreich über den „Rheinstaat“. In Frankfurt oder Köln sei eine alliierte Kontrollkommission für wirtschaftliche Fragen für den „Rheinstaat“ einzurichten, das gleiche in Hannover oder Bremen für den Staat „Sachsen“.

Die Stoßrichtung des Vorschlages war abzusehen, Frankreichs Einfluß im Westen und Süden sollte erheblich wachsen. Mit der Abtrennung der linksrheinischen Gebiete und der Internationalisierung der Ruhr waren zwei Axiome der französischen Nachkriegspolitik erfüllt. Der „Rheinstaat“, der von Franken, Schwaben und Alemannen bewohnt würde, hätte Frankreichs Großmachtansprüche garantiert. Neben solchen Vorschlägen zur Aufteilung Deutschlands wurde in der Zeitschrift kräftig die Trommel für den Föderalismus als Lösungsansatz der deutschen Frage geschlagen. Unter dem Pseudonym Clodion erschien im April 1946 ein Artikel zu Constantin Frantz ${ }^{186}$, einem Föderalisten des 19. Jahrhunderts, dem in Deutschland nach 1945 eine Renaissance zuteil wurde.

${ }^{183}$ Georges Bidault schätze an l'Huillier „la valeur de sa collaboration à notre politique“; Directeur Général (MAE) an Directeur de l'Enseignement supérieur de l'Education Nationale vom 16. 8. 1945; MAE Y-Int. 1944-1949 402. Grund des Schreibens war die Bitte, l'Huillier an der Universität Straßburg zu beschäftigen, damit er sich verstärkt um „le monde rhénan “ bemühen könne.

${ }^{184}$ „Note pour le Cabinet du Ministre“, Direction Politique (MAE) vom 6. 1. 1947; MAE YInt. 1944-1949 402.

${ }^{185}$ Charles Harnist: Une solution du problème allemand, in: Cahiers du Rhin 4 (1946), S. 9-11.

${ }^{186}$ Clodion: Konstantin Franz [sic !] et la Prusse, in: Cahiers du Rhin 5 (1946), S. 6 ff. Zu Frantz vgl. Kapitel II/1. 


\section{Frankreichs Wunsch nach Änderung der Zonengrenzen}

Der latente Wunsch der Pariser Stellen nach einer Modifizierung der Zonengrenzen im Südwesten konterkarierte die Politik Pierre Koenigs in Baden-Baden; damit mußte jede projektierte Reform der Zonenverwaltung im Ansatz steckenbleiben. Seit Sommer 1945 trugen die Franzosen über verschiedenste Kanäle immer wieder den Vorschlag an die Amerikaner heran, die Zonengrenzen zu revidieren. Tatsächlich hatte der amerikanische Außenminister Byrnes der Provisorischen Regierung in Paris zugesagt, die Besatzungsverhältnisse in Südwestdeutschland gegebenenfalls zu korrigieren ${ }^{187}$. Aber das Gebaren Frankreichs im Aostatal und im Vorderen Orient hatte den Amerikanern, allen voran General Lucius D. Clay ${ }^{188}$, gezeigt, daß ein Entgegenkommen nicht ratsam war. Im Kontrollrat mußte Clay die französische Obstruktionspolitik hautnah erleben, und daher reifte in ihm der Entschluß, jeden zukünftigen französischen Wunsch kategorisch abzulehnen. Zusammen mit Robert Murphy ${ }^{189}$ bekleidete Clay die Schlüsselposition beim amerikanischen Widerstand gegen eine Änderung der Zonengrenzen. Darüber hinaus hatte Clay im Juli 1945 einen kompletten Abzug der Franzosen aus den südlichen Teilen Württembergs und Badens begrüßt ${ }^{190}$. Die amerikanischen Militärs lehnten danach geschlossen jede Veränderung der Besatzungsgrenzen in Südwestdeutschland ab ${ }^{191}$. So bewegte sich während des ganzen Jahres 1945 in dieser Frage nichts. Am 18. Januar 1946 entschied de Gaulle in Paris, mit der amerikanischen Regierung über eine Abänderung der Zonengrenzen in Südwestdeutschland offiziell in Verhandlungen zu treten ${ }^{192}$. Der Wunsch, innerhalb der besetzten Zonen historisch gewachsene Länder in die Hände einer Besatzungsmacht zu legen, war der Vater des Gedankens ${ }^{193}$. Die französische Botschaft in Washington unterbreitete am 31. Januar den Rektifizierungsvorschlag; in Washington stießen die Pläne auf Ablehnung, und folgerichtig erhielt der französische Botschafter Henri Bonnet am 22. April 1946 eine negative Antwortnote ${ }^{194}$.

Hatte die französische Politik bisher auf den von amerikanischer Seite ignorierten Tausch von Südwürttemberg gegen Nordbaden hingearbeitet, änderte Paris nun die

187 Nüske, Württemberg (II), S. 107.

${ }^{188}$ Lucius D. Clay (1897-1978), 1945-46 Stellvertreter General Eisenhowers; 1947-49 Militärgouverneur in der ABZ; Mitinitiator und Organisator der Luftbrücke während der Berliner Blokkade; 1961-62 persönlicher Beauftragter Kennedys für die Berlin-Frage. Vgl. Backer, Jahre.

${ }^{189}$ Robert Murphy (1894-1978), seit 1944 politischer Berater von General Eisenhower und der amerikanischen Militärregierung in Deutschland; 1949-52 Botschafter in Brüssel; 1954-59 Stellvertretender Unterstaatssekretär im amerikanischen Außenministerium. Vgl. insbesondere Murphy, Diplomat, S. 342-363.

190 "Moreover it would seem more logical for the French to be asked to return both south Württemberg and south Baden to the United States", Clay am 15. 7. 1945; zitiert nach Smith, Papers, S. 234.

191 Nüske, Württemberg (II), S. 108.

192 CGAAA an das Außenministerium vom 6. 2. 1946; MAE Y-Int. 1944-1949 651.

Auf der Sitzung des CIAAA vom 18. 1. 1946 formulierte de Gaulle diesen Punkt folgendermaßen: „C'est pourquoi, le Gouvernement Français, en vue de compléter dans ses propres zones la constitution des Länder entreprend dès maintenant avec le Gouvernement américain, des négotiations tendant à rectifier la limite des zones d'occupation des armées françaises et américaines, dans les Etats de Bade et de Wurtemberg“; ebenda.

${ }^{193}$ Sitzungsbericht des CIAAA unter Vorsitz von de Gaulle vom 18. 1. 1946; MAE Y-Int. 19441949651.

${ }_{194}$ Nüske, Württemberg (II), S. 109. 
Taktik. Am 25. April 1946 wies Außenminister Bidault seinen Botschafter in Washington an, der amerikanischen Regierung neue Vorschläge zu unterbreiten. Seine Pläne sahen eine Wiederherstellung der Länder Baden und Württemberg vor, nun jedoch unter gemischter Kontrolle [contrôle mixte] ${ }^{195}$, wobei Bidault als ersten Schritt die Einbeziehung der badischen Hauptstadt Karlsruhe in die Französische Besatzungszone vorschlug. Das industrialisierte Mannheim wäre in der ersten Phase unter amerikanischer Besatzung verblieben, gleichzeitig sollte (Süd-)Württemberg-Hohenzollern auf Kreisebene vorerst unter französischer Kontrolle bleiben. Für Bidault war nämlich der Südstaat - im Gegensatz zu Koenig - aus wirtschaftlichen Erwägungen heraus kein The$\mathrm{ma}^{196}$. Mit Sitz in Karlsruhe hätte die zukünftige badische Regierung unter der Kontrolle Frankreichs gestanden. Lediglich ein amerikanisches Verbindungsbüro hätte in der ehemaligen Residenzstadt bestanden. Für Württemberg, so Bidault, könne unter umgekehrten Vorzeichen identisch verfahren werden. Früher oder später wäre somit Baden vollständig unter französische Besatzung gekommen.

Als die amerikanische Seite Wochen später auf diese Vorschläge noch immer nicht geantwortet hatte, schob der Quai d'Orsay am 11. Juni 1946 eine revidierte Fassung nach, mit der ausdrücklichen Bitte um rasche Beantwortung. Die französisch kontrollierten Kreise in (Süd-)Württemberg-Hohenzollern sollten zwar der Kontrolle Stuttgarts unterstellt werden, aber in der französischen Zone verbleiben. Die Amerikaner sahen sich nun vollends auf der Geberseite und antworteten vorerst nicht auf den neuerlichen Vorschlag. Das Ergebnis langer, interner Abwägungen in Washington war die Übermittlung einer Note vom 23. September 1946 an den französischen Botschafter Bonnet. Das State Department wies ohne jede diplomatische Umschweife sämtliche französischen Vorschläge zurück ${ }^{197}$; von einer Revision der Zonengrenze oder einer gemeinsamen Besatzungsverwaltung wollte Washington nichts wissen. Trotz der Eindeutigkeit in der amerikanischen Haltung ließ die französische Diplomatie nicht locker: Immer wieder wurde darauf hingearbeitet, durch den Tausch von Südwürttemberg gegen Nordbaden das ganze Land Baden unter französische Besatzung zu bekommen ${ }^{198}$. Doch der Status quo konnte auch in den folgenden Jahren nicht abgeändert werden.

\section{Die Neugliederungspläne der Militärregierung für Südwestdeutschland}

Die endgültige Zoneneinteilung Anfang Juli 1945 hatte der französischen Besatzungsmacht ein Gebiet beschert, das aus zwei etwa gleich großen Dreiecken bestand. Im Norden (zone nord) ein Territorium, das von Montabaur über Landau nach Trier reichte, im Süden (zone sud) das Dreieck zwischen Baden-Baden, Lindau und Lörrach. Der nördliche Teil der Zone bildete ab 30 . August 1946 das spätere Bundesland Rheinland-Pfalz. Dem Saargebiet fiel schon ab 31. Juli 1945 eine besondere Rolle innerhalb der französi-

\footnotetext{
195 Bidault an Koenig vom 28. 6. 1946; MAE PA-AP 338-Laffon 8 C.

196 "Il nous est cependant impossible de constituer une entité viable avec les fractions de Bade et de Wurtemberg que nous administrons"; ebenda.

197 Nüske, Württemberg (II), S. 111.

${ }^{198}$ Hudemann, Wirkungen, S. 177.
} 
schen Besatzungspolitik zu. Die Südzone (zone sud), bestehend aus den südlichen Landesteilen von Baden und Württemberg sowie dem ehemals preußischen Regierungsbezirk Hohenzollern und dem bayerischen Landkreis Lindau, bot ein stark zersplittertes Bild. Von höchsten Stellen der französischen Militärregierung wurden daher Planspiele betrieben, wie die Zersplitterung für die Durchsetzung der französischen Föderalismusvorstellungen genutzt werden könnte.

Föderalismus hatte in den französischen Konzeptionen einen für deutsche Ohren differenten theoretischen Hintergrund ${ }^{199}$ : Deutschland sollte nämlich nicht als Bundesstaat, sondern als Staatenbund reorganisiert werden. Emile Laffon hat die französischen Föderalismusvorstellungen im Mai 1946 auf eine kompakte Formel gebracht: „Die föderalistische Politik [Frankreichs...] hat zum Ziel, die schon historisch bestehenden Länder daran zu gewöhnen, so initiativ wie nur möglich zu werden, dergestalt, daß der Einfluß einer später ins Leben gerufenen deutschen Zentralgewalt, der auf sie ausstrahlt, verringert wird." 200 An den durch Napoleon zu Beginn des 19. Jahrhunderts gebildeten süddeutschen Ländern sollten keine territorialen Veränderungen vorgenommen werden. Es ging also letztlich bei der französischen Föderalismusdiskussion für den Süden nur um zwei Varianten: Sollten die Länder Baden, Württemberg und Bayern direkt in einen deutschen Staatenbund aufgenommen werden, oder sollte man zuerst eine Konföderation der süddeutschen Länder betreiben? Dies waren - cum grano salis - die beiden konkurrierenden Konzepte, für die einerseits Emile Laffon samt seinem Kabinett und andererseits Pierre Koenig und Tarbé de Saint Hardouin standen. Auch Koenig wagte sich Ende 1946 an eine Definition des französischen Föderalismusbegriffs, der die staatenbündischen Elemente hervorhob: „Föderalismus - für uns - muß die Schaffung fest gezimmerter [fortement charpentés] Staaten bedeuten, die ihre Stimme laut und unzweideutig erheben und die sich eines ausreichenden wirtschaftlichen Gleichgewichtes, unabhängiger Finanzen und der Freiheit in der Außenpolitik erfreuen. “" ${ }^{201}$ An einem staatenbündischen Aufbau des zukünftigen Deutschlands herrschte in den Jahren 1945/46 in den Baden-Badener Kreisen kein Zweifel. Auch im Außenministerium unterstrich René Roux im Dezember 1946 mit drei Kartenskizzen eine Gliederung des zukünftigen Bundes deutscher Staaten. Im Süden wäre einzig Hohenzollern an Württemberg angegliedert, ansonsten sollten Baden, Bayern und Württemberg drei historisch gewachsene Einheiten bilden ${ }^{202}$.

199 Das Alpenlandprojekt (vgl. Kapitel III/1) - in Deutschland mit dem Begriff "Separatismus" belegt - findet sich in den Unterlagen des SGAAA als föderalistischer Plan; Dossier „fédéralisme“; AdO SGAAA c. 2665 p. 1.

200 Emile Laffon: „Organisation Politique de la Zone Française“ [Mai 1946] (masch. 4 S.); MAE PA-AP 338-Laffon 8 A.

201 „Note sur la politique de la France en Allemagne“ (masch. 2 S.); Ausarbeitung vom 4. 12. 1946, entstanden im Kabinett von General Koenig; AdO HCFA Cab. Civil c. 50 POL V A1).

202 Die drei Kartenskizzen vom 15.12. 1946 („Organisation territoriale de l'Allemagne, projet $\mathrm{N}^{\circ} 1 / \mathrm{N}^{\circ} 2 \mathrm{a} / \mathrm{N}^{\circ} 2 \mathrm{~b}$ ) sahen eine Gliederung Deutschlands in folgende Teile vor: Schleswig-Holstein, Mecklenburg-Pommern, Hamburg, Bremen, Niedersachsen, Brandenburg-Magdeburg, Ober-Sachsen, Hessen, Ruhr, Rheinland, Saarland, Baden, Württemberg und Bayern (projet $\mathrm{N}^{\circ} 1$ ). Die beiden Varianten (projet $\mathrm{N}^{\circ} 2 \mathrm{a}$ und $\mathrm{N}^{\circ} 2 \mathrm{~b}$ ) projektierten lediglich im Westen andere Zusammenschlüsse: Rhein-Westfalen, Rheinland-Pfalz und Saarland $\left(\mathrm{N}^{\circ} 2 \mathrm{a}\right)$ bzw. einen einzigen Staat „Rhein-Westfalen" ( ${ }^{\circ}$ 2b); MAE PA-AP 210-Roux 1. 


\section{Die Reform der Strukturen der Südzone}

Es ist keineswegs verwunderlich, daß die Strukturreformpläne allesamt aus dem Umkreis von General Pierre Koenig stammten. Die politische Dezentralisierung war durchgängiges Leitmotiv, die Schwächung und Abschaffung der Position des Generalverwalters dadurch unausweichlich. Pläne, die einer extremen Dezentralisierung in der Zone das Wort redeten, können unter dem Begriff „Heterogenitätsmodell“ subsumiert werden. Im Gegensatz dazu steht das „Homogenitätsmodell“203, das von einer Wiederherstellung der alten Länder Baden und Württemberg ausgeht; beide Begriffe sind auf die territorialen Verhältnisse gemünzt, sie betreffen nicht die französischen Föderalismusvorstellungen.

Der unausgegorene Zustand der Besatzungsverwaltung, der im Sommer 1945 in der FBZ herrschte, brachte eine erste Ausarbeitung zutage, die noch keine Spitze gegen den erst wenige Wochen zuvor eingetroffenen Laffon trieb; die Verhältnisse stellten sich nämlich nach wie vor unübersichtlich dar. Der Dreijahresplan vom Spätsommer 1945204, der im Kabinett des Oberkommandierenden entstanden war, sah die Stärkung der historisch gewachsenen Einheiten vor. Der Partikularismus in Baden, in Württemberg und im Rheinland sollte gefördert werden, eine enge Anbindung der Gebiete an Frankreich konnte nicht in Abrede gestellt sein. Die Einsetzung von Verwaltungsspitzen nach Frankreichs Gnaden - im Sinne von Vichy-Regierungen - komplettierte die Vorstellungen. Die Krönung französischer Dezentralisierungswünsche lag damit schriftlich vor Koenig. Die politischen Ereignisse im Spätjahr 1945 gaben dem Verfasser in bezug auf die Pariser Wünsche recht. Auf seiner Deutschlandreise im Oktober unterließ es General de Gaulle in seinen Reden ${ }^{205}$ nicht, auf die deutschen Länder und deren Bindungen an Frankreich hinzuweisen. „Mir kam das vor, als wolle man uns in die Postkutschenzeit zurückversetzen "206, urteilte Carlo Schmid, nachdem er die Ausführungen de Gaulles in Freiburg vernommen hatte. Es bestand kein Zweifel, daß die politische Dezentralisierung von der Provisorischen Regierung gewünscht wurde, die Umsetzung der Pläne oblag aber Baden-Baden. Konnte eine politische Dezentralisierung in Deutschland gelingen, wenn sich gleichzeitig die Strukturen der Besatzungsmacht zentralistisch gaben?

Nur eine Umstrukturierung der Militärregierung hätte die Grundlage für eine Dezentralisierung der deutschen Verhältnisse bilden können. In diese Richtung stießen alle Neustrukturierungspläne, die im Kabinett General Koenigs ins Werk gesetzt wurden. Parallel dazu mußte die Position Laffons und dessen Apparat in Abrede gestellt werden. Mit Mißtrauen verfolgte Koenig, wie sein Generalverwalter die Zügel in die Hand zu nehmen trachtete, indem er von Baden-Baden aus die FBZ zu kontrollieren und die Schaltstellen mit politisch Gleichgesinnten zu besetzen suchte. Der Kronprinz drohte, eine unumschränkte Stellung einzunehmen. Die Reaktionen Koenigs gingen in zwei Richtungen: Erstens betrieb er einen rasanten personellen Ausbau seines Kabinetts, um

${ }^{203} \mathrm{Zu}$ den beiden Begriffen vgl. Wolfrum, Neugliederungspläne, S. 435.

204 "Projet de plan triennal par l'administration de la Zone Française en Allemagne“ vom 10. 9. 1945; AdO Cab. Civ. Pol. I B2.

${ }^{205}$ De Gaulle hielt Anfang Oktober 1945 fünf Reden, am 3. Oktober in Trier und Koblenz, am 4. Oktober in Freiburg, am 5. Oktober in Sasbach und in Baden-Baden. Für den Wortlaut vgl. de Gaulle, Lettres, S. 91-98.

${ }^{206}$ Schmid, Erinnerungen, S. 227. 
binnen weniger Monate ein wirkliches Spiegelbild in Form einer Doppelspitze zu schaffen; zweitens hoffte er mittels Umstrukturierungsplänen, Paris von der Notwendigkeit einer Verwaltungsreform in der FBZ zu überzeugen. Vorweg gesagt: Die Doppelspitze schuf er, die Umstrukturierung scheiterte vorerst.

Den nächsten Versuch einer möglichen Neugliederung der Südzone lancierte ein Mitarbeiter des Conseiller Politique, François Puaux, zu Beginn des folgenden Jahres. Die Mitarbeiter um Saint Hardouin waren die entschiedensten Gegner Laffons, nicht nur wegen der unterschiedlichen Auffassung bezüglich der Dezentralisierung. Der bezeichnende Titel Über die französische Dezentralisierungspolitik ${ }^{207}$, den die Schrift von Puaux trug, stellte in aller Klarheit den Standpunkt des Kabinetts Koenig dar. Die amtliche Dezentralisierungspolitik müsse am Wasserkopf Baden-Baden scheitern, deshalb war - laut Puaux - ein Abbau unumgänglich. Dem Nordteil der FBZ mit zukünftiger Hauptstadt Mainz wurde eine langfristige Anbindung an Frankreich vorausgesagt, dem Südteil, von Freiburg aus vom Gouvernement militaire des Souabes du Sud verwaltet, mußte eine differenzierte Besatzungspolitik angedeihen. Die „Rheinlande“ und „Südschwaben“ waren das Ziel der Strukturreform, der Personal- und Kompetenzabbau in Baden-Baden die andere Seite der Medaille. Die vier Länder der Konföderation „Südschwaben“ fungierten in dieser Skizze als „Zünder" für einen süddeutschen Staatenbund, der Föderalismus galt als weitverbreitete Geisteshaltung südlich des Mains. Puaux schlug vor, in BadenBaden nur noch eine Koordinationsstelle für wirtschaftliche Belange zu gestatten, alle anderen Abteilungen auf Mainz und Freiburg zu verteilen. Dies kam praktisch der Auflösung des Apparates des Generalverwalters gleich.

Ein gänzlich unbeachteter Plan war das im Zivilkabinett entstandene Exposé vom 16. Januar 1946. Das darin propagierte „Frankenreich“ 208 blieb ohne weiteren Reflex und wurde sofort zu den Akten gelegt. Es ist als Resonanz auf Meldungen zu werten, die von der Gründung des „Aktionskomitees des Alpenländischen demokratischen Bundes" 209 in der Baden-Badener Zentrale im November 1945 eintrafen. Der Bürgermeister von Singen am Hohentwiel, Bernhard Dietrich, wurde als Urheber der Alpenlandpläne ausdrücklich genannt ${ }^{210}$ und als frankophil beschrieben. Schon an diesem Umstand ist zu erkennen, daß die Alpenlandpläne nicht originär französischen Ursprungs waren. Der Autor des Exposés schlug die Bildung eines Staates „Rheinland“ vor, der aus den beiden Provinzen Hessen-Pfalz und Rheinland-Nassau bestehen sollte. „Die Errichtung eines badisch [en] oder badisch-württembergischen Staates bildete die zweite Stufe unserer föderativen Handlung. " Gleichzeitig oder mit zeitlicher Verschiebung müsse dann eine größere Föderation ins Auge gefaßt werden. „Es handelte sich darum, in einer Rhein-Donau-Föderation einige Gebiete Österreichs und Bayerns mit den beiden zuvor skizzierten rheinischen und badischen Staaten zu verschmelzen. "211 Der Verfasser der Studie schlußfolgerte daraus, daß erstens der rheinische Staat zu schaffen sei und daß

207 "Note - A. S. de la politique française de décentralisation" vom 10. 1. 1946; AdO HCFA Con. Pol. 196-III-O.

208 „Note: Préparer une Union Fédérative des régions rhénane, badoise, bavaroise et autrichienne (Frankenreich)“, Aufzeichnung vom 16. 1. 1946; AdO HCFA Cab. Civil c. 50 Pol V A 1).

${ }^{209} \mathrm{Zu}$ Gründung und Programm des „Aktionskomitees“ vgl. Kapitel III/1.

${ }^{210}$ Zur Urheberschaft der „Alpenlandpläne“ vgl. Klöckler, Ursprünge (im Druck) und Klöckler, Neugliederungskonzepte.

211 „Note: Préparer une Union Fédérative...", AdO, ebenda. 
man zweitens mit Dietrich in Kontakt treten solle, um „seine Handlungen zu unterstützen und die notwendigen Verbindungen mit den französischen Dienststellen in Österreich aufzunehmen“. Zu einer Unterstützung der Alpenlandpläne kam es auf Intervention aus Paris aber nie ${ }^{212}$, de Gaulle mißfiel jede Politik, die einen Angriff auf die österreichische Eigenstaatlichkeit darstellte.

Die politischen Berater Koenigs aus dem Quai d'Orsay ließen weitere Ausarbeitungen $^{213}$ folgen. Es trat immer deutlicher zum Vorschein, daß das Hauptanliegen der Umstrukturierung die unterschiedliche Behandlung darstellte, die dem Nord-und dem Südteil der Besatzungszone angedeihen sollte. Die politischen Konzeptionen für beide Zonen waren höchst unterschiedlich. Die „Rheinlande“ sollten sich eng an Frankreich anlehnen und später entweder gänzlich unabhängig oder in einen losen Staatenbund eingereiht sein. Das Rhénanieprojekt ${ }^{214}$ kann in diesem Zusammenhang nicht weiter untersucht werden. Dem Südteil der Zone war eine andere Funktion zugedacht: Vereint unter dem Dach einer Konföderation mit Sitz in Freiburg, waren die Berater des Conseiller Politique gewillt, den Rumpfteilen von Baden und Württemberg die größtmögliche Eigenständigkeit zu belassen. Selbst der ehemals preußische Regierungsbezirk Hohenzollern durfte auf Autonomie hoffen, der Landkreis Lindau versprach Frankreichs Eintrittskarte in die Politik Bayerns zu werden. Ein süddeutscher Staatenbund, der aus vier autonomen Gebilden bestehen sollte, dessen kleinstes von kaum mehr als 50000 Staatsbürgern bewohnt gewesen wäre, wurde an Kühnheit von keiner anderen französischen Planung erreicht. Andererseits wies man die Möglichkeit, die vier Teile zu einer Verwaltungseinheit nach dem Vorbild von Württemberg-Baden zu vereinigen, zurück. Zwar fand ein schwäbisch-alemannischer Staat als stammesföderalistischer Plan keine Resonanz im Kabinett von General Koenig. Dennoch wäre es „uninteressant oder sogar gegen unsere Interessen, den westlichen [sic!] Teil von Württemberg von den Amerikanern gegen den Norden des Landes Baden einzutauschen, dadurch würde unser Handlungsspielraum eingeschränkt ${ }^{\text {“215 }}$, urteilte das Zivilkabinett im Gegensatz zu de Gaulle. Die von Frankreich besetzten südwestdeutschen Länderteile sollten nämlich auf die Amerikanische Besatzungszone ausstrahlen und den künftigen staatlichen Aufbau Deutschlands maßgeblich beeinflussen. Der Föderalismus sollte von hier aus seinen Siegeszug in Süddeutschland antreten; eine Konföderation von Baden, Württemberg, Hohenzollern und Bayern sollte aus Sicht des Zivilkabinetts das föderalistische Gegengewicht zum unitaristischen Norden Deutschlands darstellen.

Für diesen Staatenbund „Südschwaben“ war ein Bundesrat vorgesehen, analog zur Institution des Länderrates in Stuttgart. Der Bundesrat hätte unter dem Vorsitz jeweils eines der Mitgliedstaaten getagt. An Kompetenzen - so die Planung - müßten ihm AuBen-, Kultur- und Wirtschaftspolitik zustehen. Parallel zu den bundesstaatlichen Struk-

$212 \mathrm{Zu}$ den Motiven hinsichtlich der ablehnenden Haltung, die Paris gegenüber der „union alpine“ einnahm, vgl. Kapitel III/1.

213 „Déconcentration de l'administration de la Zone“ vom 12. 1. 1946; AdO HCFA Cab. Civil Pol. III A 2 p. 30; "Organisation de l'occupation française en Allemagne“ vom 9. 2. 1946; ebenda; „Note sur la réorganisation de la Zone française“ vom 25. 2. 1946; AdO HCFA Con. Pol. c. 196 III-O.

${ }^{214} \mathrm{Zu}$ den französischen Rheinlandplänen: Krautkrämer, Rhénanieprojekt, S. 61-85.

215 „Note sur la réorganisation de la Zone française“ vom 25. 2. 1946; AdO HCFA Con. Pol. c. 196III-O. 
turen sollte die neue Gliederung der Militärregierung erfolgen: Am Sitz der Konföderation in Konstanz war das Amt eines Gouverneur Général geplant, der als intimer Kenner Südwestdeutschlands mehr als nur ein einfacher Verwalter sein sollte. Die Oberdelegationen in Freiburg und Tübingen hätten entschlackt weiterbestanden, Sigmaringen und Lindau sollten mit untergeordneten Délégations autonomes ${ }^{216}$ ausgestattet werden. Die Sonderrolle des Lindauer Delegierten war augenfällig, er hätte Kontakt zu den bayerischen Ministerien und zu den amerikanischen Behörden in München halten sollen.

Anfang März 1946 kehrte im Kabinett Ruhe ein. Die Vorschläge waren vorgelegt, zum Teil bis ins Detail ausgearbeitet. Nun war es an der Zeit, daß sich Emile Laffon zu Wort meldete, seine Position wäre schließlich zuerst der Neustrukturierung zum Opfer gefallen $^{217}$. Am 2. März 1946 machte er mit einem Schreiben ${ }^{218}$ an Koenig seinen Standpunkt deutlich. Beigefügt hatte er eine Ausarbeitung über die wirtschaftlichen Nachteile einer Änderung der Zonengrenzen. Laffon selbst führte politische Gründe an: Abgesehen vom Prestigeverlust für Frankreich in bestimmten Kreisen der Bevölkerung sei eine Lösung nur im Großen zu erwarten. Der Föderalismus könne sich seiner Ansicht nach nur auf großräumige Gebilde stützen. Für Frankreich reklamierte er deshalb die vollständige Besetzung von Baden, Württemberg und dem Rheinland. Hannover und Westfalen sollten unter britische, ganz Bayern unter amerikanische Kontrolle gestellt werden $^{219}$. Die Stoßrichtung der Stellungnahme war für Koenig leicht zu durchschauen: keine Zwergstaaten innerhalb der Südzone, da diese den Föderalismus in Deutschland nicht stärken konnten, und damit eine klare Abfuhr an die Neugliederungspläne des Conseiller Politique.

Der erste Schuß vor den Bug war abgegeben. General Koenig sah sich gezwungen, nun mit offenen Karten zu spielen. Mit Bitte um Stellungnahme übersandte er seinem Administrateur Général eine Neugliederungsstudie. Mit Schreiben vom 15. April 1946 antwortete Emile Laffon und führte aus, daß, gerade weil eine föderalistische Politik betrieben würde, er die Konföderationspläne für die Südzone energisch zurückweisen müsse ${ }^{220}$. Die Existenz von Baden und Württemberg in einem föderalistisch aufgebauten Deutschland konnte er sich gut vorstellen, aber ein Staatsgebilde mit Namen Hohenzollern war in seinen Augen ein Anachronismus, der Gedanke des Föderalismus werde dadurch diskreditiert. Überhaupt könne das Problem nur auf nationaler Ebene gelöst werden. Laffon wurde deutlicher: „Die wichtigste Grundbedingung, um zum Föderalismus zurückzugelangen, ist die Besetzung jedes Landes durch eine einzige Macht; das übrige

216 Ebenda.

217 Wolfrum interpretiert die Planungen zur Neustrukturierung der FBZ als direkte Spitze gegen Laffon. Die Auflösung der Dienststelle Laffons wäre allerdings Folge, nicht Ursache der Umstrukturierung gewesen. Laffon hat keineswegs „neben den Dienststellen des französischen Oberbefehlshabers Pierre Koenig“ seinen „eigenen, zentralen und sehr umfangreichen Verwaltungsapparat aufgebaut“, vielmehr verhielt sich der Sachverhalt umgekehrt; Wolfrum, Neugliederungspläne, S. $433 \mathrm{f}$.

218 „Conséquences politiques et économiques entraînées par une modification éventuelle des limites de la Zone Française (Bade-Wurtemberg)“ vom 2. 3. 1946; AdO CCFA Cab. Laffon c. 13.

219 Ebenda.

220 „Etude de la réorganisation du Gouvernement Militaire“ vom 15. 4. 1946; AdO CCFA Cab. Laffon c. 13. 
ist zweitrangig." ${ }^{221}$ Eine Neustrukturierung nach Art des Heterogenitätsmodells aus dem Kabinett Koenig lehnte er ab. Der Generalverwalter gab sich überzeugt von der Prämisse, den Föderalismus auf historisch gewachsenen Einheiten fußen lassen zu müssen.

Aus Paris waren ähnliche Töne zu hören, ein Tausch von Südwürttemberg-Hohenzollern gegen Nordbaden stand weiter auf der Tagesordnung. Dagegen mußte Koenig das Heterogenitätsmodell verteidigen. Am 18. März 1946 schrieb er an René Mayer ${ }^{222}$ und wandte sich ausdrücklich gegen einen solchen Tausch. Eindringlich wies der Oberkommandierende auf den Umstand hin, von vier süddeutschen Ländern - Baden, Württemberg, Hohenzollern und Bayern - einen mehr oder weniger großen Teil besetzt zu halten. „Über kurz oder lang ist die Gründung einer Föderation oder Konföderation in Südwestdeutschland, die sich instinktiv dem preußischen Geist entgegenstellt und die sich zwangsläufig an Frankreich anlehnt, keineswegs eine Utopie.“223 Eine Besetzung ganz Badens werde diese Politik begrenzen, wobei mit dem Verlust der Universität Tübingen einer der intellektuellen Mittelpunkte des Protestantismus in Deutschland verlorengehen würde. Auch wirtschaftliche Erwägungen führte Koenig ins Feld, die mit der Feststellung, daß Südwürttemberg geeigneter als Nordbaden sei, selbständig zu leben, auf den Punkt gebracht sind.

In diese Kerbe hieb Laffon im Mai 1946 ebenfalls - allerdings für seine Zwecke - in Form einer erneuten Ausarbeitung über die politische Organisation der FBZ 224 . Er plädierte dafür, erst abzuwarten, ob die Gespräche mit den Alliierten bezüglich einer Neuregelung der Zonengrenzen fruchteten. Erst dann, so Laffon, könne an eine Umstrukturierung der Militärregierung gedacht werden. Für den Südteil der Zone vermutete er, daß die Bevölkerung die Wiederherstellung der alten Länder Baden und Württemberg wünsche. Eine Art Länderrat mit Sitz in Freiburg oder Konstanz lehnte Laffon weiterhin kategorisch ab. Das Austarieren des Gleichgewichts zwischen Baden und Württemberg in einer derartigen Organisation schien ihm angesichts der Probleme bei der Ernennung der Provisorischen Landesverwaltungen unmöglich; mit Freiburg als Sitz der Konföderation würden sich die Württemberger niemals abfinden. Zu Koenigs Plan, Hohenzollern Mitglied einer Süddeutschen Konföderation werden zu lassen, fand der Generalverwalter abermals klare Worte: „Die geographische Situation dieses Landes im Innern von Württemberg, seine wirtschaftliche und demographische Schwäche läßt meiner Ansicht nach jede Idee, daraus eine Einheit innerhalb des Verbandes einer Föderation zu machen, illusorisch erscheinen. " Genauso dezidiert fiel sein Urteil zu Koenigs Vorstellungen bezüglich Lindaus aus, das schließlich „nur einen winzig kleinen Teil von Bayern repräsentiert und dem schon eine besondere Behandlung widerfährt, um seine politische und wirtschaftliche Orientierung zu berücksichtigen".

Emile Laffon gab sich mit den bereits eingereichten Stellungnahmen nicht zufrieden. Mitte Juli 1946 ließ er Koenig eine couragierte Ausarbeitung über die „Wiedererrichtung

221 „La condition première et urgente d'un retour au fédéralisme est l'occupation de chaque Etat allemand par une seule et même puissance; le reste est secondaire"; ebenda.

222 Koenig an Mayer vom 18. 3. 1946; MAE Y-Int. 1944-1949 448.

${ }^{223}$ Ebenda.

${ }^{224}$ „Organisation Politique de la Zone Française“, Emile Laffon [Mai 1946]; MAE PA-AP 338-Laffon 8. Dort auch die folgenden Zitate. 
der Länder Baden und Württemberg" ${ }^{\text {"225 }}$ übermitteln, deren vornehmlicher Zweck es war, den Oberbefehlshaber auf dem aktuellen Stand der Verhandlungen mit den Amerikanern zu halten. Der Quai d'Orsay hoffte nämlich weiterhin, einen Tausch herbeiführen zu können. Erneut gab Laffon seiner Auffassung von der Nichtlebensfähigkeit eines Südstaates Ausdruck und führte weiter aus, daß das Außenministerium in Verhandlungen mit Washington eine Unterstellung ganz Badens unter französische Besatzung zu erreichen suche. Wieder machte sich Laffon zum überzeugten Fürsprecher der klaren Trennung von Württemberg und Baden aufgrund von Mentalitäts- und Religionsunterschieden. Außerdem mißfiel ihm jede Art von gemeinsamer Kontrolle über Baden und Württemberg, da sich die Amerikaner zu stark in die französische Besatzungspolitik einmischen könnten.

Der entscheidende Punkt blieb aber weiterhin die Wirtschaft. Konnten die französischen Wünsche bei gleichzeitiger Dezentralisierung der Verwaltung ausreichend erfüllt werden? Die Beurteilung dieser Problematik war Aufgabe des Directeur Général de l'Economie et des Finances, Jean Filippi, der direkt Generalverwalter Laffon unterstand. Er legte im Juli 1946 innerhalb zweier Tage je eine Ausarbeitung über die Dezentralisierung der Wirtschafts- und Finanzabteilungen und der Verwaltung der französischen Zone vor ${ }^{226}$. Die Frage der Dezentralisierung sei schon oft gestellt worden - so Filippi in seiner ersten Ausarbeitung - und es sei Gemeingut, daß sie die Voraussetzung einer indirekten Verwaltung darstelle. Aber sie treffe auf „unüberwindliche Hindernisse im Bereich der gelenkten Wirtschaft". Filippi führte dafür Gründe technischer, verwaltungsmäßiger und wirtschaftlicher Art an. Technisch sei man nicht in der Lage, die Geldpolitik und damit die Festlegung der Preise zu dezentralisieren. Das Fehlen einer deutschen Zentralverwaltung auf Zonenebene zwinge die Militärregierung darüber hinaus, verwaltungstechnisch direkt einzugreifen. Im wirtschaftlichen Bereich könne eine ausgeglichene Handelsbilanz der Zone nur durch eine systematische Auswertung der Ressourcen, die zentral zu steuern seien, und durch Einsparungen bei den Importen gewährleistet werden. „Die vorstehenden Bemerkungen bleiben gleichermaßen gültig, egal, ob man nun von der Dezentralisierung nicht mehr zugunsten von vier oder fünf Provinzen, sondern von einem Nord- und einem Südteil ausgeht." ${ }^{227}$ Das Anliegen Filippis, der eine harte Wirtschaftspolitik verfolgte, war augenfällig, eine Dezentralisierung gefährdete die wirtschaftliche Ausnutzung der Zone. Bei seinem Vorgesetzten Laffon rannte er damit offene Türen ein, galt jener doch als Verfechter einer harten Wirtschaftspolitik.

Einen Tag später, am 24. Juli 1946, reichte Filippi eine zweite Ausarbeitung nach, die sich mit der Verwaltung der Zone befaßte ${ }^{228}$. Er machte sich zum Fürsprecher einer deutschen Regierung für die gesamte FBZ. „Der Zeitpunkt scheint gekommen zu sein, ein deutsches Organ zu schaffen, das entweder den Charakter einer bundesstaatlichen Verwaltung oder einer Föderation der verschiedenen Länder hat.“ Dem Rheinland komme eine gewisse Bevorzugung zugute, es solle die Föderation der FBZ politisch an-

225 „Reconstitution des Etats du Bade et du Würtemberg [sic!]“, Laffon an Koenig vom 16. 7. 1946; AdO HCFA AP c. 3304 p. 104 d. 1520.

226 „Note sur la décentralisation des services économiques et financièrs du Gouvernement Militaire de la Zone Française d'Occupation“, Jean Filippi vom 23.7.1946 und "Note sur l'administration de la Zone Française“, Jean Filippi vom 24. 7. 1946; MAE PA-AP 338-Laffon 14.

227 „Note sur la décentralisation...“; ebenda.

228 "Note sur l'administration..."; ebenda. 
führen. Die wirtschaftlichen und politischen Vorteile einer diesbezüglichen Gliederung wurden von Filippi dahingehend umrissen, daß die Militärregierung zur indirekten Kontrolle übergehen könnte und im gleichen Zug Deutsche auf die Probe gestellt würden, die beim zukünftigen föderalistischen Aufbau Deutschlands von Nutzen wären.

Das Kabinett um Koenig suchte derweilen unverdrossen nach Möglichkeiten, das Heterogenitätsmodell zu untermauern. „Auf der Suche nach einer französischen Lösung für das deutsche Problem" hieß das nächste, vom Leiter der Section Politique des Zivilkabinetts, Major Marcel Mercier, im August 1946 lancierte Exposé229. Ausgehend von einem wiederherzustellenden Gleichgewicht in Europa, das Mercier durch den sowjetischen Wunsch nach Schaffung eines einheitlichen deutschen Staates mit anschließender Niederdrückung zum Satelliten verletzt sah, entwickelte er einen politischen Lösungsvorschlag für das deutsche Problem, den er in der Schaffung der Vereinigten Staaten von Europa sah. Die Aufgabe erfolgreicher Demokratisierung sei die Ausgestaltung eines Deutschlands, das in diese Gemeinschaft aufgenommen werden könnte. Frankreich stehe hierzu eine Einflußsphäre zur Verfügung, die durch Latinität und Katholizismus geprägt sei: die rheinischen Provinzen und die Länder Süddeutschlands, also Baden, Württemberg und Bayern. Die Teilung der FBZ in Nord- und Südzone habe dasselbe Ziel, jedoch unterschiedliche Methoden notwendig gemacht. Die Südzone verfüge über einen mehr oder weniger großen Teil aller deutschen Länder südlich des Mains. Den Partikularismus dieser Länder müsse man frei sich entwickeln lassen, dann werde er auf die anderen süddeutschen Länder, einschließlich Österreich, wirken. „Deshalb muß man den Teilen der Länder, die wir kontrollieren, die vollkommene Eigenart belassen, indem man sie in eine Konföderation integriert. "230 Auf Hohenzollern als eigenständigen Staat verzichtete Mercier, eine Einverleibung nach Württemberg schien ihm sinnvoll, während der Kreis Lindau direkt in einen „konföderalen Organismus“ angebunden gewesen wäre. Als Sitz der Konföderation komme zu Beginn Freiburg in Frage, aber nach Verschmelzung mit dem Länderrat könne der Einfluß ausgedehnt und eine neue Hauptstadt gesucht werden. Deshalb sei die Gründung „mehr als dringlich, wenn wir den amerikanischen Anziehungspol neutralisieren und eine bedeutende Rolle in Süddeutschland spielen wollen“. Folge dieser Politik wäre eine Dezentralisierung der französischen Verwaltung und damit einhergehend die Kompetenzbeschneidung der BadenBadener Dienststellen gewesen. Die indirekte Verwaltung hätte aber auf diesem Weg erreicht werden können.

Doch die Neugliederungsdiskussion auf französischer Seite war damit nicht beendet. Anfang September 1946 meldete sich ein weiterer Verfechter des Heterogenitätsmodells zu Wort. Nach Unterhaltungen mit Pierre de Leusse, Leiter der Mitteleuropaabteilung im französischen Außenministerium, schmiedete man erneut Pläne, um nach der Gründung von Rheinland-Pfalz nun das Problem der Südzone zu lösen ${ }^{231}$. Die Vorteile lagen auf der Hand: Dem nördlichen Württemberg-Baden wäre eine Südkonföderation gegenübergestellt worden, die den Ausgangspunkt für die Verbreitung der Ideen und der Kultur Frankreichs in ganz Süddeutschland gebildet hätte. In Paris teilte man erwar-

${ }^{229}$ „A la recherche d'une solution française du problème allemand“, Major Mercier im August 1946; AdO CCFA Cab. Civil c. 11 POL I B d. 2.

230 Ebenda.

231 „Fiche pour le Général - Réorganisation de la zone sud“ vom 6. 9. 1946; AdO HCFA Cab. Civil c. 31 POL III A 8. 
tungsgemäß diese Einschätzung nicht. Das Homogenitätsmodell hatte das weitaus größere Gewicht, die Länder Baden und Württemberg standen im Vordergrund. Außenminister Bidault war kein Mann der Experimente, so daß der erneute Vorstoß aus BadenBaden rasch versandete. Die Vorgänge blieben allerdings im restlichen Europa keineswegs unbeobachtet. Das Eidgenössische Politische Departement in Bern war durch den neuen Baden-Badener Oberbürgermeister und Präsidenten der Handelskammer, Dr. Ernst Schlapper, genauestens informiert. Die Bildung „eines alemannischen Landes“ an der Nordgrenze berührte die Schweizer Beamten, allen voran Legationsrat Zehnder, sichtlich ${ }^{232}$. Welche Auswirkungen würde ein Südstaat auf die Schweiz haben?

In der französischen Verwaltung war die Auseinandersetzung noch nicht beendet. Im November 1946 gab General Koenig vor den höchsten Chargen der Militärregierung seinen unabänderlichen Willen zur Schaffung einer zentralen Verwaltung für die Südzone, die ihren Sitz in einer rechtsrheinisch gelegenen Stadt haben sollte, erneut bekannt $^{233}$. Anfang Dezember 1946 betrat das Zivilkabinett Koenig ein weiteres Mal die Baden-Badener Bühne. Eine Ausarbeitung zur französischen Politik in Deutschland ${ }^{234}$, die für die Section Politique bestimmt war, umriß vor allem die französischen Föderalismusvorstellungen. Deutschland werde eines Tages einen wichtigen Faktor in der Welt und insbesondere in Europa darstellen, doch die Einheit Deutschlands wiederherzustellen bedeute gleichfalls, das stark zentralisierte Vorkriegsdeutschland zu erneuern. „Alle Anstrengungen Frankreichs müssen deshalb darauf abzielen, die deutsche Einheit dauerhaft zu erschüttern und die Länder, die am nächsten an unseren Grenzen gelegen sind, an unsere Politik anzunähern. " ${ }^{235}$ Föderalismus sei nur ein Wort, das in den westlichen Zonen unterschiedliche Bedeutung habe. Obwohl die FBZ nur acht Prozent der deutschen Bevölkerung umfasse, glaubte man im Zivilkabinett, daß Frankreich die Reform der deutschen Strukturen beeinflussen könne. Mit Zustimmung der Briten bestünde die Möglichkeit, eine rheinische Provinz zu bilden, mit Hilfe der Pfalz könnte diese verstärkt oder in die bayerischen Angelegenheiten interveniert werden. „Im Süden kann sie [die Zone] im Einverständnis mit den Amerikanern Baden und Württemberg wiederherstellen. Aber sie kann vor allem die Schaffung einer Konföderation süddeutscher Staaten hervorrufen, indem sie sich des bayerischen Landkreises Lindau bedient. Eine Konföderation süddeutscher Staaten unter Einschluß von Bayern, eine rheinische Provinz mit der Pfalz, das ist ein Drittel Deutschlands, auf das wir unseren Einfluß ausüben. "236 Der hier geäußerte Föderalismusgedanke ließ für eine bundesstaatliche Lösung der deutschen Frage keinen Platz. Föderalismus hatte im Umkreis von General Koenig einem Ziel zu dienen: die Bildung selbständiger deutscher Staaten im Rahmen eines Staaten-

232 "Was die politische Organisation des deutschen Gebietes anbelangt, besteht ein französischer Plan, ein alemannisches Land aus dem Süden Württembergs und Badens zu errichten. Hauptstadt wäre wahrscheinlich Rottweil oder Tübingen, weil sich die Württemberger dagegen wehren, dass diese Rolle Freiburg zufällt [...]. Es wird gegenwärtig in deutschen Kreisen [...] unter der Oberfläche ein ziemlich leidenschaftlicher Kampf ausgetragen"; Schweizer Konsul in Baden-Baden an Zehnder vom 21. 10. 1946; BA Bern E 2300 Baden-Baden 1.

233 „Procès-verbal de la séance du Conseil du Gouvernement“ (masch. 7 S.) vom 26. 10. 1946, hier S. 4; AdO HCFA Con. Pol. 196-III-0.

234 „Note sur la politique de la France en Allemagne“, Cabinet Civil vom 4. 12. 1946; AdO HCFA Cab. Civil c. 50 Pol V A 1).

235 Ebenda.

${ }^{236}$ Ebenda. 
bundes zu garantieren. Im Frühjahr 1947 unternahm Koenig einen erneuten Versuch. In Baden-Baden ließ er eine von ihm einberufene Dezentralisierungskommission tagen, deren Ergebnis ein Reformvorschlag zur Zonenverwaltung war ${ }^{237}$. Möglichkeiten zur Reduzierung des umfangreichen Besatzungsapparates wurden ebenso ausgearbeitet wie strukturelle Überlegungen beim Übergang von einer direkten zu einer indirekten Besatzungsverwaltung.

Im Hinblick auf die Moskauer Außenministerkonferenz übermittelte Koenig seinem Generalverwalter am 30. Januar 1947 Anweisungen mit dem Ziel, „sofort in der französischen Zone die Prinzipien des Föderalismus [...] zu verwirklichen "238. Dazu müßten die Länder der Zone umgehend die Rechte erhalten, die sie in einem zukünftigen Staatenbund besitzen würden. General Koenig gab außerdem seinem Dafürhalten Ausdruck, daß nach Errichtung von Rheinland-Pfalz nun der Ausgestaltung von Baden und Württemberg das Augenmerk geschenkt werden müsse. Dazu sei es notwendig, Sorge zu tragen, daß sich die Verfassungen der südlichen Landeshälften, die gerade erarbeitet wurden, nicht zu weit von der schon in den nördlichen Landeshälften bestehenden entfernten, um eine spätere Wiedervereinigung zu erleichtern. Die Dezentralisierung der Militärregierung war unabdingbare Voraussetzung für die Stärkung der Länderebene.

Aber letztlich verliefen alle Reformvorschläge für den Südteil der FBZ im Sand. Weder das Heterogenitätsmodell aus dem Umfeld Pierre Koenigs konnte sich durchsetzen, noch war der Pariser Zonengrenzpolitik Erfolg beschieden. Es bleibt zu konstatieren, daß um die Jahreswende 1945/46 auf der Grundlage theoretischer Vorbereitungen und von Reformwünschen innerhalb der Militärregierung der Südstaat in den Bereich des politisch Möglichen und Realisierbaren gerückt war. Der Oberkommandierende konnte sich aber gegen die Widerstände Laffons und des Außenministeriums nicht durchsetzen. Da jedoch auch die Tauschwünsche nicht in Erfüllung gingen, muß der französischen Besatzungsmacht in bezug auf die Neugliederung des Südwestens das Verspielen vorhandener Möglichkeiten vorgehalten werden. Frankreich war damit in die Rolle des Verzögerers jeder Neugliederung Südwestdeutschlands und in das Fahrwasser der anglo-amerikanischen Bundesstaatspläne geraten.

\section{Eingeforderte und freizillige deutsche Stellungnabmen}

Zeitgleich mit der französischen Neugliederungsdiskussion gingen in den Jahren nach 1945 teils beorderte, teils freiwillige deutsche Stellungnahmen zur Gründung eines aus dem Südteil der FBZ bestehenden Staates bei der Militärregierung ein. Gemeinsam war diesen Exposés, Reflexe auf die nach außen gedrungenen französischen Pläne zu sein. Sie entsprangen nicht einer kohärenten oder langgehegten politischen Überzeugung, sondern sie waren Ausfluß einer momentanen Stimmungslage und somit losgelöst von stringenten politischen Konzeptionen ${ }^{239}$.

${ }^{237}$ Hudemann, Zentralismus, S. 203.

238 „Instruction - Objet: Application à la Zone française des projets remis aux Alliés concernant l'organisation future de l'Allemagne“, Koenig an Laffon vom 20. 1. 1947; AdO HCFA Con. Pol. c. 196-III-0.

${ }^{239} \mathrm{Zu}$ den konzeptionell durchdachten und plannmäßig unter der Bevölkerung verbreiteten Neugliederungsplänen vgl. die Kapitel II bis IV. 
Das chronologisch erste, in den Akten überlieferte Exposé mit dem Titel „Gedanken zwecks Gründung eines ,Zonenlandes““240 datiert auf den 23. November 1945 und wurde in Konstanz von Hans Constantin Paulssen in großindustriellem Umfeld niedergeschrieben ${ }^{241}$. Paulssen propagierte darin die Schaffung eines Südstaates aus wirtschaftlichen Erwägungen heraus ${ }^{242}$.

Am 20. September 1946 glaubte Alfred Bund, der Leiter der Finanzverwaltung im Direktorium in Freiburg, mit Blick auf die im August durchgeführte Gründung von Rheinland-Pfalz, ähnlichen Verlautbarungen von Koenig für die Südzone zuvorkommen zu müssen ${ }^{243}$. Die Quintessenz des Vorstoßes ${ }^{244}$, den er beim Oberdelegierten Pène aus Furcht vor einer französischen Strukturreform führte, war einzig und allein der Nachweis, daß „die Militärregierung Südbaden mit der Staatsverwaltung eines in dieser Weise vereinten Gebietes [des Südstaates] beauftragen sollte“. Dazu führte Bund politische, wirtschaftliche und geographische Gründe an. Für Bund mußte Freiburg die Hauptstadt des Staates „Südbaden-Südwürttemberg“ sein, gegenüber Tübingen oder Rottweil verfüge die Stadt im Breisgau über die Nähe zu Frankreich und die Möglichkeit zur Ausdehnung.

Von vereinzelten Einwürfen abgesehen, fand die Neugliederungsdiskussion innerhalb der Militärregierung aber weiterhin ohne die Teilnahme deutscher Persönlichkeiten statt. Nur einmal - im Herbst 1946 - forderten die Besatzungsbehörden einige schriftliche Stellungnahmen ein. In den einschlägigen Akten des Zivilkabinetts von General Koenig sind zwei derartige Gutachten überliefert. Das eine entstammt der Feder von Professor Hubert Armbruster aus Mainz, das andere ist aus der Hand des Baden-Badener Gewerkschaftsvorsitzenden Matthias Schneider ${ }^{245}$. Diese Ausarbeitungen stellen wirkliche Auftragsarbeiten für die französische Besatzungsmacht dar.

Hubert Armbruster ${ }^{246}$, Professor an der neugegründeten Johannes-Gutenberg-Universität in Mainz, schlug im September 1946 in seinem sieben Seiten umfassenden Gutachten „die Zusammenfassung Südbadens, Südwürttembergs, Hohenzollerns und des

${ }^{240}$ [Hans Constantin Paulssen]: „Idées pour la fondation d'un ,pays de la zone““ vom 23. 11. 1945; AdO HCFA Con. Pol. 196-III-O.

${ }^{41}$ Verfasser war Hans Constantin Paulssen, Direktor der Aluminiumwerke in Singen. Im Herbst 1945 versuchte er mit dem Zeppelinkonstrukteur Hugo Eckener, eine Partei mit Namen „Süddeutsche Volkspartei für Aufbau und inneren Frieden “ ins Leben zu rufen, die aus Sicht der Besatzungsmacht mit der Alpenlandbewegung in Verbindung stand; vgl. Kapitel V/2.

242 Vgl. dazu Kapitel V/2.

${ }^{243}$ „Administration civile des territoires allemands situés au bord droit du Rhin de la Zone Française d'Occupation", Bund an Pène vom 20. 9. 1946; AdO HCFA AP c. 3304 p. 104 d. 1520.

${ }^{244}$ Zum Projekt von Alfred Bund im Rahmen der Auseinandersetzungen innerhalb der BCSV vgl. Kapitel V/1.

${ }^{245}$ Hubert Armbruster: „Die Neugliederung der französischen Südzone“ vom 20.9.1946 und Matthias Schneider: [ohne Titel] vom 30. 9. 1946; AdO HCFA Cab. Civil c. 31 Pol III A d. 8. Vgl. auch: Wolfrum, Neugliederungspläne, S. $446 \mathrm{f}$.

246 Hubert Armbruster war 1945/46 zeitweise in der Staatskanzlei in Tübingen als Oberregierungsrat beschäftigt. Carlo Schmid urteilte Jahre später über Armbruster: „Im übrigen glaube ich, daß er außerordentlich stark nach der französischen Seite hinüberhängt, nicht im bösen Sinn, aber aus einer gewissen Dankbarkeit dafür, daß man ihn, ohne daß die sachlichen und formellen Voraussetzungen vorgelegen hatten, so früh an die Universität Mainz ernannt hat. Diese Ernennung geschah damals ja durch die Franzosen“; Carlo Schmid an Fritz Heine vom 3. 9. 1952; AsD NL Schmid 1401. 
Kreises Lindau zu einem einzigen südwestdeutschen Land mit einer einheitlichen Landesregierung vor“. Vier leitende Prinzipien legte Armbruster seinen Gedanken zugrunde: das Prinzip der Elastizität, der Parität, des Föderalismus und der Einfachheit. Die Elastizität sei wegen der Ungewißheit der späteren politischen und wirtschaftlichen Gesamtlage unverzichtbar. Der zukünftige föderative Aufbau in Form eines Bundesstaates oder eines Staatenbundes sei jedoch möglich, weshalb man in der Südzone mit der Entwicklung Schritt halten müsse. Hier deckten sich die Ausführungen Armbrusters mit den Vorstellungen des Kabinetts Koenig von der „Zünderfunktion“ einer Konföderation „Südschwaben“. Laut Armbruster gelte das Prinzip der Elastizität im Hinblick auf die Offenhaltung der „Möglichkeit einer künftigen gebietsmässigen Wiedervereinigung Südbadens mit Nordbaden bezw. Südwürttemberg mit Nordwürttembergs “247. Die 150 Jahre alte Verwaltungstradition in Baden und Württemberg habe ein Staatsgefühl geschaffen, das sich über mancherlei Verschiedenheiten hinweggesetzt habe. Vor allem die Badener lebten in der ständigen Furcht, von den Württembergern vereinnahmt zu werden. Diese Einsicht erfordere die Anwendung des Prinzips der Parität. „Die Besetzung der leitenden Stellen und Ämter des zu schaffenden Landes muss deshalb nach Möglichkeit paritätisch erfolgen, um dieser Besorgnis den Boden zu entziehen.“ Das dritte Prinzip Armbrusters, der Föderalismus, stand im Zentrum des Gutachtens. Der Erörterung der Grundlagen dieses Prinzips folgte das Bekenntnis zum Stammesföderalismus: „Die ursprünglichen Länder Baden und Württemberg sind Ergebnisse einer Gliederung, die nach formalen dynastischen Grundsätzen erfolgte, d. h. unter Absehung von der Stammesgrundlage und dem Stammesbewußtsein. Der Föderalismus muß die stammesmässige Gliederung entschieden in den Mittelpunkt stellen." Dem Prinzip inhärent sei die Subsidiarität, die in der Stärkung der Kreise und Gemeinden ihren Ausdruck finden möge. Scharf wandte sich der Mainzer Professor gegen eine Anlehnung an das schweizerische Verfassungssystem. Die Kantone besässen Staatsqualität, die Kreise der Südzone seien aufgrund ihrer Kleinräumigkeit dafür nicht geeignet, derartige Zwergstaaten lägen nicht im Sinne des Föderalismus, der auf Staaten mittlerer Größe aufgebaut sein müsse. „Die Zusammenfassung der französischen Südzone [d. h. des Südstaates] ergibt ein Staatsgebilde mittlerer Grösse, das durchaus lebensfähig wäre und das sich die erforderliche Geltung verschaffen könnte." Das letzte Prinzip, die Einfachheit, betonte Armbruster beim Aufbau der Verwaltung. Als Spitze des Staates war das Amt des Staatspräsidenten vorgesehen, der den Ministerpräsidenten ernennen sollte. Zwei Kammern, der gewählte Landtag und der ständisch aufgebaute Senat ${ }^{248}$, sowie Kreisversammlungen und Gemeinderäte hätten das Verwaltungssystem nach unten vervollständigt. Zwei Verwaltungsprovinzen waren des weiteren vorgesehen, Südbaden mit Freiburg und Südwürttemberg samt Hohenzollern mit Tübingen als Mittelpunkt; einzig für den Kreis Lindau hätte eine Sonderregelung zu erfolgen. Als Sitz der Regierung komme die alte Reichsstadt Rottweil in Frage. Nicht nur in diesem Punkt kamen Armbrusters

247 Hubert Armbruster: „Die Neugliederung der französischen Südzone“; AdO HCFA Cab. Civil c. 31 POL III A d. 8.

248 Armbruster führte dazu aus: „Der Senat: er setzt sich zusammen aus Vertretern der Unternehmerverbände, Gewerkschaften, der Landwirtschaft, der Kirchen, Universitäten, der Rechtsanwaltskammer, des Handwerks, der Ärzteschaft und ist in teils beratender und teils auch beschliessender Form an der Gesetzgebung beteiligt. Die Mitglieder werden auf Vorschlag der beteiligten Körperschaften und Organisationen vom Staatspräsidenten ernannt"; ebenda. 
Vorschläge den Ideen Otto Fegers recht nahe ${ }^{249}$, wenngleich die kritisierte Nichtanwendbarkeit der Kantonsverfassung als Spitze gegen den Konstanzer Archivar gesehen werden kann.

Mit weit weniger Elan ging der Gewerkschaftsfunktionär Matthias Schneider im September 1946 in Baden-Baden an die Arbeit. Auf knapp zwei Seiten skizzierte er „auf Wunsch“ von Major Mercier, dem Leiter der Section Politique im Zivilkabinett Koenigs und selbst Verfasser von Neugliederungsplänen, die Umrisse eines „Schwäbisch-Alemannischen Bundes“. Es ist kaum vorstellbar, daß Schneider in der Namensgebung nicht von Fegers Schwäbisch-Alemannischer Demokratie beeinflußt worden ist. Überhaupt scheint das Exposé hastig dahingeschrieben zu sein. Einen Staatscharakter sollte der schwäbisch-alemannische Bund nicht beinhalten, vielmehr werde mit dem Zusammenschluß von Südbaden und Südwürttemberg eine „Zwischenlösung“ geschaffen. Die endgültige Lösung nannte Schneider nicht beim Namen, aber an seiner Präferenz für die Wiederherstellung der alten Länder besteht kein Zweifel. Der Dezentralisierung trug er im geplanten Verwaltungsaufbau genügend Rechnung. Die Gemeinden und die darauf aufgebauten Bezirksämter sollten die untersten beiden Verwaltungsgruppen bilden. Aus jeweils vier bis fünf Bezirksämtern sei sodann ein Kreis zu konstituieren. Allen Verwaltungsgruppen hätte nach Schneiders Gutdünken die volle Steuerhoheit zugestanden. Eine Identität von Kammerbezirken und Kreisen waren für den Gewerkschafter die Gewähr „für eine gute Mitarbeit aller Bürger an der Neugestaltung des politischen und wirtschaftlichen Lebens“250. Auf der Grundlage der Kreise könne sich dann die Schaffung zweier Regierungskommissariate vollziehen, eines für Südbaden und eines für Südwürttemberg, „damit die Eigenständigkeit erhalten bleibt“. Der Sitz des gemeinsamen Landtages und der Regierung des schwäbisch-alemannischen Bundes sollte nach Donaueschingen auf die Baar verlegt werden.

\section{Französische Meinungsumfragen}

Die französische Besatzungsmacht bediente sich auch des Instruments der Meinungsumfrage, um Erkenntnisse über die Stimmungslage in Südwestdeutschland zu gewinnen. Viele Deutsche hegten den Verdacht, daß Frankreich eine neue Rheinbundpolitik betreiben werde und man sich deshalb um die Süddeutschen bemühe ${ }^{251}$. Der Südstaat war unter den gegebenen Voraussetzungen eine sehr wahrscheinliche Neugliederungslösung.

Die Kreisdelegierten wurden mit der Aufgabe betraut, maßgebliche Politiker in der Südzone über deren Ansichten zu den Neugliederungsplänen zu befragen. Die Befragung fand in fast allen südbadischen Kreisen statt, wahrscheinlich 1947252. Die Frage lautete: „Befürworten Sie einen Zusammenschluß von Südbaden mit Südwürttemberg oder die Vereinigung von ganz Baden mit ganz Württemberg?“ Die Antworten fielen von

${ }^{249}$ Feger plädierte ebenfalls für die Stadt am Neckar: „Vielleicht wäre die alte Reichsstadt Rottweil am besten geeignet, einer $z$ wangsläufig bescheidenen schwäbischen Regierung Sitz und Unterkunft zu geben." Feger, Demokratie, S. 159 f. Zu Fegers Neugliederungsplan vgl. Kapitel IV/1.

250 Schneider vom 30. 9. 1946; AdO HCFA Cab. Civil c. 31 Pol III A d. 8.

251 Paradigmatisch sei auf die Tagebuchaufzeichnungen von Hedwig Maier, einer Mitarbeiterin Gustav von Schmollers am Institut für Besatzungsfragen in Tübingen, verwiesen: Dies., Eroberung, S. 70 .

252 „Résumé des réponses obtenues“; AdO Bade AP Sec. Pol. c. 2801. 
West nach Ost unterschiedlich aus. Während in den Kreisen Offenburg, Bühl, Emmendingen, Neustadt, Müllheim, Lörrach und Säckingen sich die Befragten tendenziell gegen den Südstaat und gegen ein mit Württemberg vereinigtes Baden aussprachen, gewann die Idee des Südstaates in den Kreisen Waldshut, Donaueschingen, Stockach und Überlingen deutlich an Zulauf. Damit einher ging in den östlichen badischen Landkreisen auch eine Akzeptanz für einen Südweststaat. In Freiburg vertrat Leo Wohleb, der Badische Staatspräsident, die Meinung, daß ein Südstaat lebensfähiger wäre als die „gegenwärtige Vereinigung" Württemberg-Baden in der ABZ. Entschieden sprachen sich Friedrich Leibbrandt, der Vorsitzende der SPB, und Prälat Föhr vom Erzbischöflichen Ordinariat für den Südstaat aus, letzterer für den Fall, daß die Besatzung sich hinzöge und Freiburg Hauptstadt würde. Von mehreren Befragten wurde eindringlich darauf hingewiesen, daß jede Reform von der Bevölkerung gebilligt werden müsse. So zeigt der französische Vorstoß anschaulich, wie gespalten die Lager in Südbaden waren. Die räumliche Nähe zu Württemberg erwies sich als positiver Faktor für die Akzeptanz einer staatlichen Neugliederung im Südwesten. 
